GLORYS VILLARROEL DE BUENO

\title{
FORMULAÇÃO E OTIMIZAÇÃO DE UMA MISTURA DE INIBIDORES DE CORROSÃO PARA AÇO CARBONO EM MEIO DE ÁGUA DE RESFRIAMENTO INDUSTRIAL USANDO PLANEJAMENTO ESTATÍSTICO
}

São Paulo

2008 
GLORYS VILLARROEL DE BUENO

\title{
FORMULAÇÃO E OTIMIZAÇÃO DE UMA MISTURA DE INIBIDORES DE CORROSÃO PARA AÇO CARBONO EM MEIO DE ÁGUA DE RESFRIAMENTO INDUSTRIAL USANDO PLANEJAMENTO ESTATÍSTICO.
}

\begin{abstract}
Dissertação apresentada a Escola Politécnica da Universidade de São Paulo para a obtenção do titulo de Mestre em Engenharia.
\end{abstract}

Área de Concentração: Engenharia Química

Orientadora: Prof ${ }^{a}$. Drª . Isabel C. Guedes.

São Paulo

2008 
Ao Gustavo, meu companheiro de todas as jornadas. Aos meus filhos: Guillermo e Gustavo R. 


\section{AGRADECIMIENTOS}

A Profa. Dra. Isabel orientadora deste trabalho pela oportunidade, a amizade e o apoio incondicional e permanente.

A Profa. Maria Elena pela ajuda na execução dos analises estatísticos sempre de uma forma generosa, atenta e enriquecedora.

Ao Prof. Hercílio pelas orientações acertadas nos momentos cruciais deste trabalho.

A Profa. Idalina, ao Prof. Neiva e ao Prof. Galo, pelo acompanhamento nos seminários semestrais, sempre com sugestões pertinentes.

Ao Eng. Davi Fontes que forneceu as amostras de água e ao Eng. Dr. Marcos Fernandez Oliveira que forneceu ao Laboratório as amostras de silano

A Tereza pela ajuda, amizade e apoio para mim e todos nos no laboratório. Ao Tato e ao pessoal administrativo do departamento pela ajuda oportuna sempre que foi possível.

Aos colegas do laboratório e da sala de computadores, Cristiane, Isabella, Jean, Jesús, Márcia, Patrícia, Paulo R., Rocío, Sérgio, Vera, e as Marinas: Menucci e Modesto, Juliana, Marcelo e Paulo. Com todos tive a oportunidade de estabelecer pontes de comunicação além das barreiras culturais ou lingüísticas; compartimos bolos de aniversário, almoços, cafés da manhã, especialmente calendários do potenciostato, e celinhas nas semanas mais árduas. Muito em especial a Rocío sempre disposta a compartilhar sua experiência e seu conhecimento com autêntica generosidade e inteligência. Ao Jean com quem vivencie que fazer o melhor café de garrafa, treinar natação ou corrida para uma maratona e fazer pesquisa cientifica não são incompatíveis A Marina Modesto e a Márcia sempre com seu espírito otimista fortaleceram meu animo. A Juliana minha companheira nas corridas de manhã pela USP.

A minha turma da natação pela amizade; em especial a Tatiana pelo seu interesse nos avanços do trabalho e a Fernanda quem gentilmente se ofereceu ler de parte dos originais e ajudar a evitar o "portunhol", minha grande preocupação. 
A Diana e ao Prof. Jose Luis Camacho quem me apresentaram no departamento de engenharia química da USP.

E não por último menos importante ao Victor do IP da USP quem me ajudou recuperar a confiança e a coragem para encerrar este trabalho. 


\section{RESUMO}

O objetivo deste trabalho foi formular e otimizar uma mistura de quatro substâncias atóxicas como inibidores de corrosão para o aço carbono ABNT 1005 em meio de água de resfriamento industrial. As substâncias estudadas foram o molibdato de sódio, o tungstato de sódio, a ftalocianina de cobre e um tensoativo polimérico a base de silano de peso molecular $17.000 \mathrm{~g} \cdot \mathrm{mol}^{-1}$. As técnicas usadas neste estudo foram medidas de potencial de corrosão, espectroscopia de impedância eletroquímica e curva de polarização anódicas e catódicas. O tratamento dos resultados de espectroscopia de impedância eletroquímica foi feito por meio da modelagem com circuitos elétricos equivalentes, que permitiu quantificar parâmetros como resistência a transferência e carga $\left(R_{t c}\right)$ e capacitância dupla camada elétrica, $\left(\mathrm{C}_{\mathrm{dl}}\right)$. Para caracterizar a superfície do metal foram obtidas imagens por microscopia eletrônica de varredura, onde foi comprovada a alteração da superfície pela presença das substâncias estudadas. Pelas curvas de polarização foi verificado que todas as substâncias estudadas se comportam como inibidores de corrosão anódicos no meio estudado, isto é, diminuem a velocidade de dissolução do metal na presença de maiores concentrações. $O$ uso de um projeto fatorial completo, do tipo $2^{4}$ foi decisivo para identificar os principais efeitos e interações entre as substâncias; sendo que os mais importantes foram devidos à presença de molibdato e tungstato de sódio, ou seja, a presença destas duas substâncias aumentou a resistência à transferência de carga do aço carbono no meio estudado. Em seguida, a análise estatística do projeto fatorial composto permitiu estimar a concentração ótima para a mistura de molibdato e tungstato de sódio; como o ponto de máximo da função superfície de resposta obtida. A concentração ótima estimada de molibdato e de tungstato de sódio foi de $3,6 \times 10^{-3} \mathrm{M}$ e

$3,5 \times 10^{-3} \mathrm{M}$ respectivamente. Finalmente, foi feita a avaliação ao longo de um período de tempo de 88 horas que permitiu identificar que o melhor comportamento da $R_{t c}$ e da $\mathrm{C}_{\mathrm{dl}}$ foi entre 48 e 72 horas de imersão.

Palavras-chaves: Aço carbono. Inibidores de corrosão. Eletroquímica (Técnicas). Planejamento e análise de experimentos. Experimentos com mistura (Formulação e otimização). 


\section{ABSTRAC}

The aim of this investigation is to obtain the optimum formulation of four nontoxics substances tested as corrosion inhibitors for ABNT 1005 carbon steel in watercooling systems. The studied substances were: sodium molybdate, sodium tungstate, copper phthalocyanine and a modified copolymer of polyoxialkylene and polidimethysiloxane. Electrochemical techniques as corrosion potential, impedance spectroscopy (EIS) and potenciodynamic anodic and cathodic polarization curves were used. Electrochemical impedance spectroscopy results were fitted through equivalent electric circuit modeling that allowed quantifying parameters like: the charge transfer resistance $\left(\mathrm{R}_{\mathrm{tc}}\right)$ and double layer capacitance $\left(\mathrm{C}_{\mathrm{dl}}\right)$ among others. In order to characterize the metal surface, scanning electronic microscopy images were obtained. These images allowed to evidence the surface alteration resulted from the addition of the studied inhibitors. Using polarization curves were verified that all substances studied behave as anodic corrosion inhibitors, this is, metal dissolution rate decrease when higher inhibitors concentrations were added. By applying a $2^{4}$ design of experiments (DOE) were possible to identify the main effects and interactions between the substances (entry variables) on the charge transfer resistance (response variable). The main effects and interactions were obtained due to the presence of sodium molybdate and sodium tungstate; the $R_{\text {tc }}$ got higher values as result of the presence of sodium molybdate and sodium tungstate. As a next step, using a design of experiments with central point was allowed to estimate the optimum concentration of sodium molybdate and sodium tungstate as result of the maximum of response surface obtained from statistic analysis in a wider range of concentrations. The optimum concentration estimated was $3,6 \times 10^{-3} \mathrm{M}$ and $3,5 \times 10^{-3} \mathrm{M}$ from sodium molybdate and sodium tungstate respectively. Finally it was done an immersion time evaluation until 88 hours using the optimum inhibitors concentration; the best performance of de $R_{t c}$ and $\mathrm{C}_{\mathrm{dl}}$ were between $\mathbf{4 8}$ and $\mathbf{7 2}$ hours of immersion.

Keywords: Carbon steel. Corrosion Inhibitors. Electrochemical techniques. Design of experiments. Optimization. 


\section{SUMÁRIO}

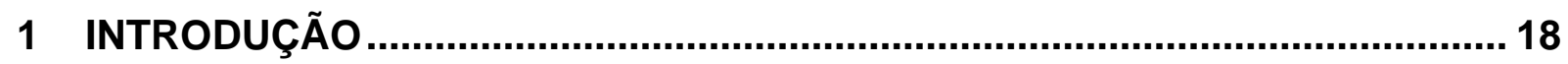

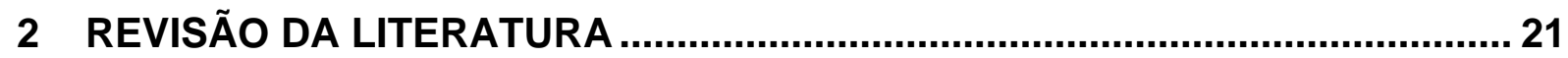

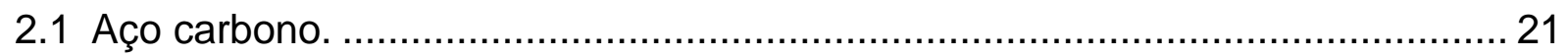

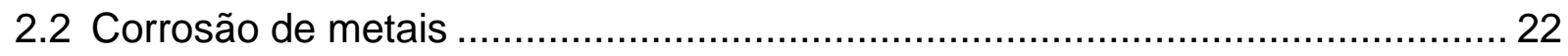

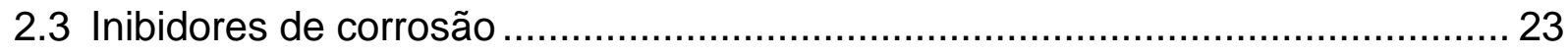

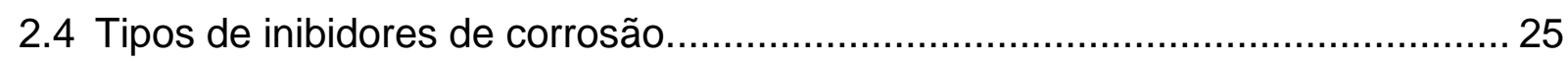

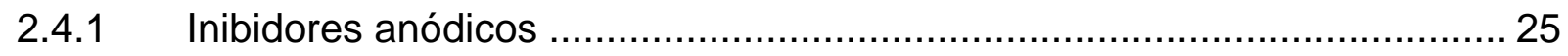

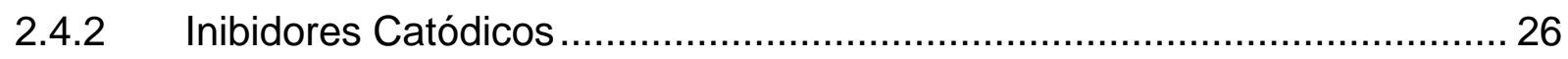

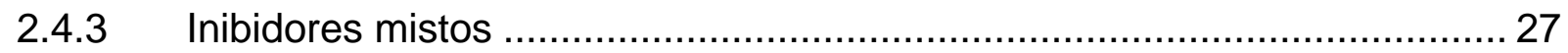

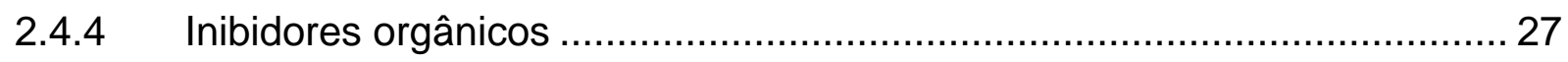

2.4.5 Inibidores multicomponentes ......................................................... 28

2.5 Técnicas eletroquímicas usadas neste trabalho ........................................... 29

2.5.1 Potencial de Corrosão ………………............................................. 29

2.5.2 Espectroscopia de impedância eletroquímica (EIE) ................................ 30

2.5.3 Curvas de polarização potenciodinâmicas anódicas e catódicas................ 34

2.6 Microscopia Eletrônica de Varredura (MEV) ..................................................... 36

2.7 Planejamento fatorial e análise de experimentos. .......................................... 36

2.8 Substâncias estudadas como inibidores de corrosão....................................... 38

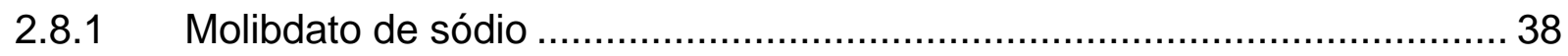

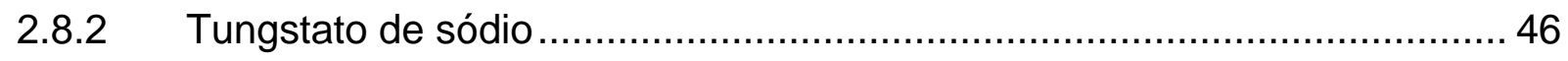

2.8.3 Copolímero de polioxiaquileno e polidimetilsiloxano, (CPPM)................... 49

2.8.4 Ftalocianina de cobre, Ft-Cu ....................................................... 51 


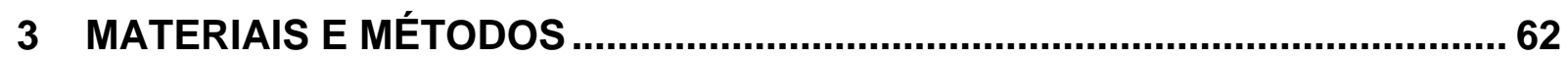

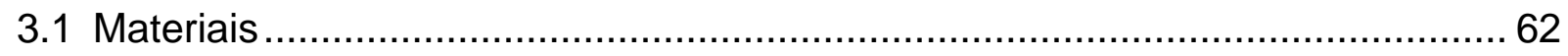

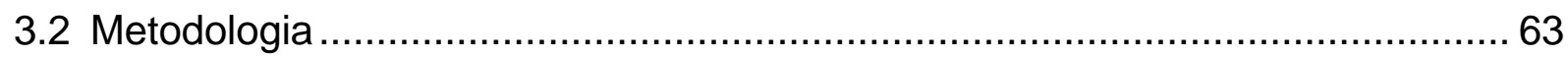

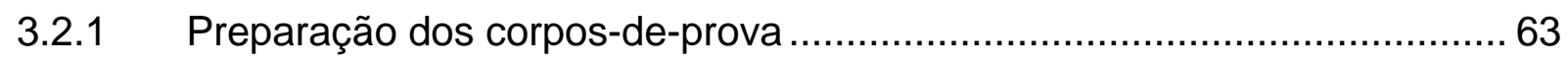

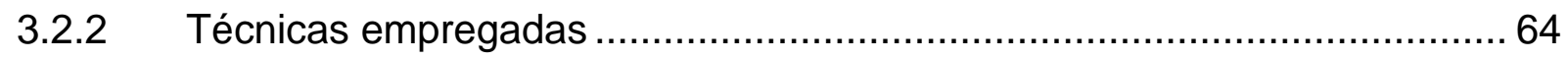

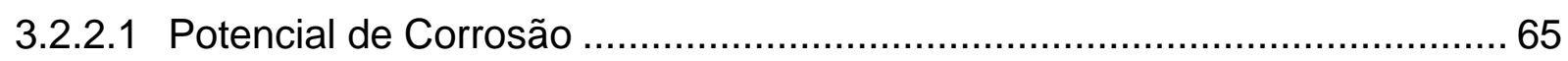

3.2.2.2 Ensaios por espectroscopia de impedância eletroquímica (EIE) ................. 65

3.2.2.3 Curvas de polarização potenciodinâmicas anódicas e catódicas. ……........ 66

3.2.2.4 Microscopia eletrônica de varredura, (MEV) ........................................... 66

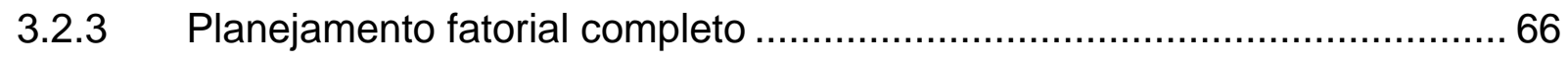

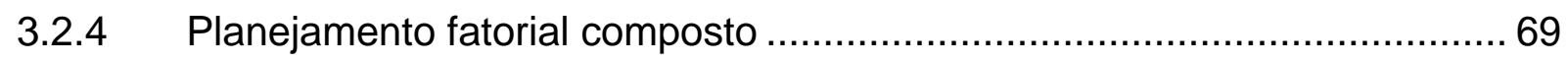

3.2.4.1 Avaliação da evolução com o tempo. ................................................ 71

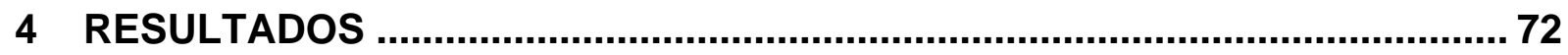

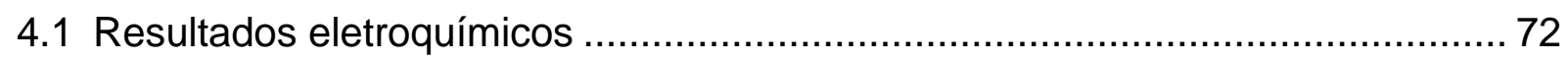

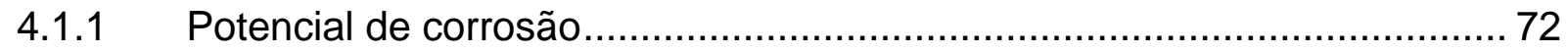

4.1.2 Espectros de impedância eletroquímica ................................................ 73

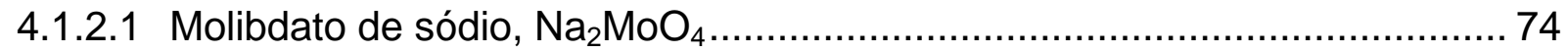

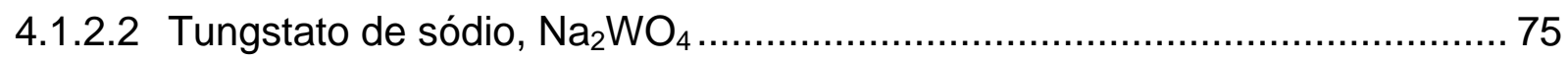

4.1.2.3 Copolímero de polioxiaquileno e polidimetilsiloxano, CPPM …….............. 76

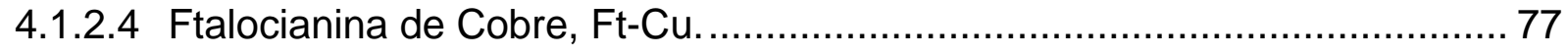

4.1.3 Parâmetros de Impedância eletroquímica.............................................. 78

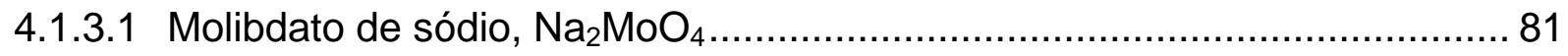




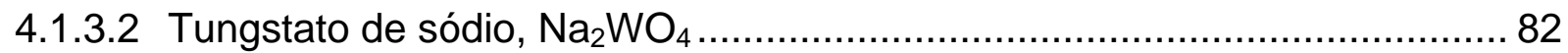

4.1.3.3 Copolímero de polioxialquileno e polidimetilsiloxano, CPPM...................... 84

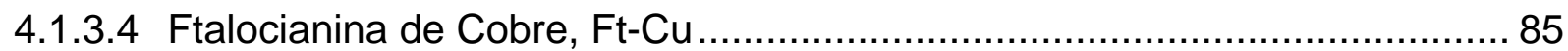

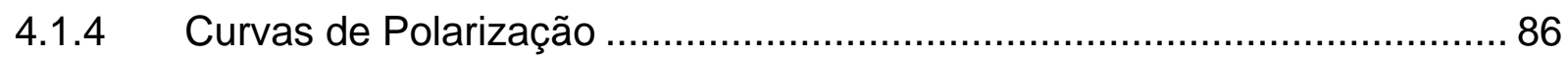

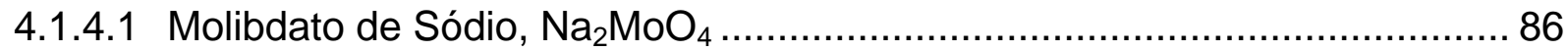

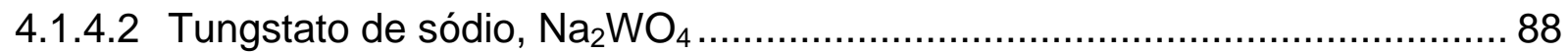

4.1.4.3 Copolímero de polioxialquileno e polidimetilsiloxano, CPPM...................... 90

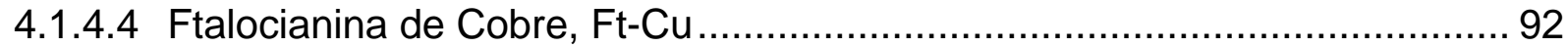

4.2 Comparação dos resultados obtidos com as substâncias estudadas

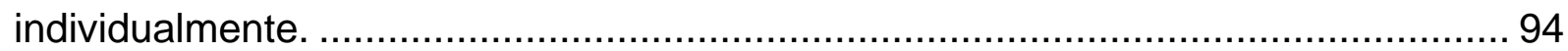

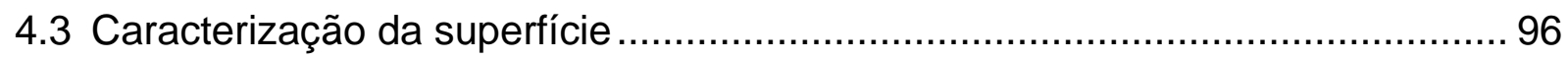

4.3.1 Molibdato de sódio e Tungstato de sódio............................................... 96

4.3.2 Copolímero de polioxialquileno e polidimetilsiloxano, CPPM ..................... 97

4.3.3 Ftalocianina de cobre, Ft-Cu .......................................................... 98

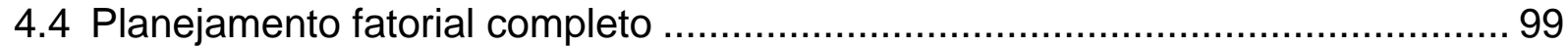

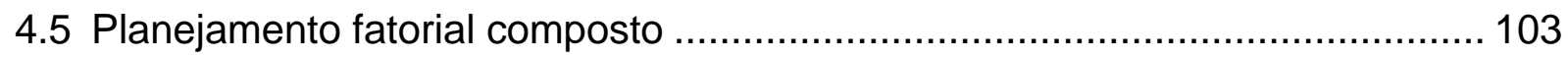

4.6 Avaliação da mistura no ponto de ótimo ao longo do tempo ........................... 109

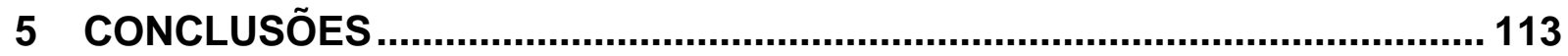

5.1 Estudo individual das substâncias como inibidores de corrosão...................... 113

5.2 Caracterização da superfície ..................................................................... 114

5.3 Planejamento fatorial completo ….......................................................... 114

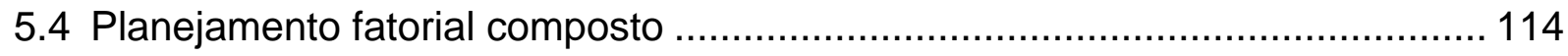

5.5 Avaliação da mistura no ponto de ótimo ao longo do tempo. ...........................115 
REFERÊNCIAS BIBLIOGRÁFICAS............................................................... 116 


\section{LISTA DE FIGURAS}

Figura 1- Representação genérica de um sistema metal/meio. (a) Diagrama de Nyquist e (b) Diagrama de Bode. Fonte: Oliveira, (2006). 32

Figura 2 - Estrutura química do molibdato de sódio. 39

Figura 3 - Modelo do mecanismo de inibição da corrosão do ferro em presença do molibdato de sódio em meio de água de resfriamento industrial proposto por Saremi, Dehghanian e Sabet, (2006) 44

Figura 4 - Estrutura química do tungstato de sódio. 46

Figura 5 - Estrutura química da ftalocianina de cobre. 52

Figura 6- Esquema básico de funcionamento de uma torre de resfriamento industrial.56

Figura 7- Torres de resfriamento de uma planta química. 57

Figura 8 - Construção dos ensaios do planejamento fatorial composto. 70

Figura 9 - Diagrama de impedância que foram obtidos para o aço carbono ABNT 1005 em meio de água de resfriamento industrial na ausência e na presença de $\mathrm{Na}_{2} \mathrm{MoO}_{4}$ 74

Figura 10 - Diagrama de impedância que foram obtidos para o aço carbono ABNT 1005 em meio de água de resfriamento industrial na ausência e na presença de $\mathrm{Na}_{2} \mathrm{WO}_{4}$. 75 
Figura 11- Diagrama de impedância que foram obtidos para o aço carbono ABNT 1005 em meio de água de resfriamento industrial na ausência e na presença de CPPM.

Figura 12 - Diagramas de impedância que foram obtidos para o aço carbono ABNT 1005 em meio de água de resfriamento industrial na ausência e na presença de $\mathrm{Ft}-\mathrm{Cu}$ 78

Figura 13 - Circuito elétrico equivalente proposto para ajuste dos resultados de impedância, obtidos para o aço carbono ABNT 1005 em água de resfriamento industrial, cujos diagramas apresentam uma constante de tempo. 79

Figura 14 - Circuito elétrico equivalente proposto para ajuste dos resultados de impedância, obtidos para o aço carbono ABNT 1005 em água de resfriamento industrial, cujos diagramas apresentam duas constantes de tempo. 79

Figura 15 - Curvas de Polarização potenciodinâmicas do aço carbono ABNT 1005 em água de resfriamento industrial com e sem $\mathrm{Na}_{2} \mathrm{MoO}_{4}$

Figura 16 - Curvas de Polarização potenciodinâmicas do aço carbono ABNT 1005 em água de resfriamento industrial com e sem $\mathrm{Na}_{2} \mathrm{WO}_{4}$ 89

Figura 17 - Curvas de Polarização potenciodinâmicas do aço carbono ABNT 1005 em água de resfriamento industrial com e sem CPPM.

Figura 18 - Curvas de Polarização potenciodinâmicas do aço carbono ABNT 1005 em água de resfriamento industrial com e sem Ft-Cu. 93 
Figura 19 - Imagens obtidas em MEV por elétrons secundários com aumento de 1000X. (a) sem inibidor. (b) com $1,0 \times 10^{-3} \mathrm{M}$ de molibdato de sódio. (c) com 1,0×10${ }^{3} \mathrm{M}$ de tungstato de sódio. 97

Figura 20 - Imagens obtidas em MEV por elétrons secundários do aço ABNT 1005 após 3 horas de imersão em água de resfriamento industrial com aumento de 1000X. (a) sem inibidor. (b) $1,0 \times 10^{-3} \mathrm{M}$ CPPM. 98

Figura 21 - Imagens obtidas em MEV por elétrons secundários do aço ABNT 1005 após 3 horas de imersão em água de resfriamento industrial com aumento de 1000X. (a) sem inibidor. (b) $1,0 \times 10^{-3} \mathrm{M} \mathrm{Ft}$-Cu. (c) detalhe com aumento de $3000 X$. 99

Figura 22 - Gráfico de probabilidade normal para os efeitos das variáveis de entrada para cada substância estudada como inibidor de corrosão, destacando as variáveis de entrada com maior efeito na variável de resposta, $\left(R_{\mathrm{tc}}\right)$. 102

Figura 23 - Gráfico de probabilidade normal dos resíduos. 103

Figura 24 - Superfície de resposta obtida tendo como variáveis de entrada concentração de $\mathrm{Na}_{2} \mathrm{MoO}_{4}$ e $\mathrm{Ma}_{2} \mathrm{WO}_{4}$, e variável de saída $\mathrm{R}_{\mathrm{tc}}$ 106

Figura 25 - Superfície de resposta obtida tendo como variáveis de entrada concentração de $\mathrm{Na}_{2} \mathrm{MoO}_{4}$ eNa $\mathrm{WO}_{4}$, e variável de saída $\quad \mathrm{IZI}$ a 100 mHz. ....106

Figura 26 - Diagramas de impedância eletroquímica obtidos para sistema metal/meio estudado, com a concentração ótima da mistura: $3,6 \times 10^{-3} \mathrm{M}$ de $\mathrm{Na}_{2} \mathrm{MoO}_{4}+$ $3,5 \times 10^{-3} \mathrm{M}$ de $\mathrm{Na}_{2} \mathrm{WO}_{4}$ para diferentes tempos de imersão 109

Figura 27 - Variação com o tempo da resistência a transferência de carga $\left(R_{\mathrm{tc}}\right)$, e da capacitância da dupla camada elétrica $\left(\mathrm{C}_{\mathrm{dl}}\right)$ para o sistema metal/meio na presença da concentração ótima de molibdato e tungstato de sódio. 


\section{LISTA DE TABELAS}

Tabela 1 - Composição do aço carbono ABNT 1005.

Tabela 2 - Composição química em ppm da água do sistema de resfriamento usado neste trabalho.

Tabela 3 - Equivalência entre o valor codificado e o valor real das variáveis de entrada do planejamento fatorial completo.

Tabela 5 - Equivalência entre os valores codificados e reais da variável de entrada do planejamento fatorial composto. 70

Tabela 6 - Matriz de ensaios de projeto fatorial composto na ordem padrão. 71

Tabela 7 - Potencial de corrosão, ( $E_{\text {corr }}$ ) do aço carbono ABNT 1005 com e sem a presença das substâncias estudadas. 73

Tabela 8 - Parâmetros obtidos a partir do ajuste dos resultados de impedância do sistema aço carbono ABNT 1005/água de resfriamento industrial com e sem a presença de $\mathrm{Na}_{2} \mathrm{MoO}_{4}$ 81

Tabela 9 - Parâmetros obtidos do ajuste dos resultados de impedância do sistema aço carbono ABNT 1005/água de resfriamento industrial com e sem a presença de $\mathrm{Na}_{2} \mathrm{WO}_{4}$. 83

Tabela 10 - Parâmetros obtidos a partir do ajuste dos resultados de impedância do sistema aço carbono ABNT 1005 / água de resfriamento industrial na ausência e presença de CPPM. 
Tabela 11- Parâmetros obtidos a partir do ajuste dos resultados de impedância do sistema aço carbono ABNT 1005 / água de resfriamento industrial na ausência e na presença de Ft-Cu. 85

Tabela 12 - Valores de densidades de correntes de corrosão, (i $\left.\mathrm{i}_{\text {corr }}\right)$ para aço carbono ABNT 1005 em meio de água de resfriamento industrial na ausência presença de $\mathrm{Na}_{2} \mathrm{MoO}_{4}$. 88

Tabela 13 - Densidades de correntes de corrosão e valores de eficiência para aço carbono ABNT 1005 em meio de água de resfriamento industrial na ausência e na presença de $\mathrm{Na}_{2} \mathrm{WO}_{4}$ 90

Tabela 14 - Densidades de correntes de corrosão e valores de eficiência para aço carbono ABNT 1005 em meio e água de resfriamento industrial na presença e na ausência de CPPM. 92

Tabela 15 - Densidades de correntes de corrosão e valores de eficiência para aço carbono ABNT 1005 em meio de água de resfriamento industrial na presença e na ausência de Ft-Cu 94

Tabela 16 - Valores de eficiência das substâncias estudadas como inibidores de corrosão estimada pela $R_{\text {tc }}$ e pela $i_{\text {corr }}$ 95

Tabela 16 - Matriz de ensaios experimentais para as variáveis de entrada codificadas, tendo como resposta os valores de resistência à transferência de carga $\left(R_{t c}\right)$ 100

Tabela 17- Resultados da análise estatística usando o software Minitab, mostrando os valores dos efeitos individuais e as interações na variável de resposta resistência à transferência de carga. 
Tabela 18- Matriz de ensaios experimentais para as variáveis de entrada codificadas, tendo como variáveis de resposta os valores de resistência à transferência

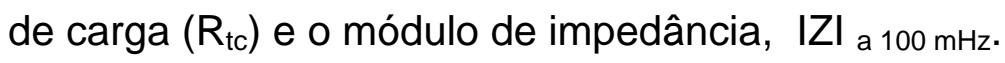
104

Tabela 19 - Análise estatística do planejamento fatorial composto usando como variável de reposta a resistência à transferência de carga $\left(R_{t c}\right)$. 105

Tabela 20 - Análise estatística do planejamento fatorial composto usando como variável de resposta o módulo de impedância $\mid \mathrm{ZI}$ a $100 \mathrm{mHz}$. 105

Tabela 21 - Valores ótimos da mistura de molibdato e tungstato de sódio em valores codificados. 108

Tabela 22 - Concentração ótima da mistura de molibdato e tungstato de sódio obtidas para as variáveis de resposta $R_{\mathrm{tc}}$ e IZI a $100 \mathrm{mHz}$ 108

Tabela 23 - Parâmetros de impedância eletroquímica para diferentes tempos de imersão do aço carbono ABNT 1005 em meio de água de resfriamento industrial na presença da concentração ótima da mistura de molibdato e tungstato e de sódio. 110 


\section{INTRODUÇÃO}

Nos sistemas de água de resfriamento industrial é comum o uso de substâncias específicas que ajam como inibidores de corrosão, para evitar o desgaste do material e alguns efeitos prejudiciais indesejáveis nas condições de operação.

Entretanto, segundo Hjeresen (2001) dentro das preocupações ambientais crescentes que enfrenta o mundo atual, a diminuição de fontes de água doce dá uma clara ilustração da influência e importância das ações e iniciativas em prol da prevenção da poluição dos reservatórios de água. Nos países desenvolvidos, o consumo de água na indústria química é significativo, por este motivo, há a necessidade de que a corrosão nos processos industriais seja controlada com o uso de substâncias de baixos índices de toxidez, pois é esta uma das principais causas da poluição dos mananciais.

Como exemplo desta situação, pode-se mencionar que, até a década de 1980, as substâncias usadas para a inibição da corrosão foram àquelas formadas por sais de cromatos (cromo hexavalente). O uso destas substâncias esteve atrelado a sua excelente relação custo / benefício para diferentes substratos metálicos e em diferentes meios aquosos. No entanto, em virtude da sua alta toxidez, o uso destes compostos vem sendo cada vez mais restrito pelas legislações ambientais (VUKASOVICH; ROBITAILLE, 1977; FARR; SAREMI, 1983; OCHOA et al., 2002; SHAFTINGHEN et al., 2004; SHIBLI; SAJI, 2005).

Nesta linha de pensamento é preciso observar que as substâncias escolhidas para este estudo e que foram testadas como inibidores de corrosão; tais como, o molibdato de sódio, o tungstato de sódio, a ftalocianina de cobre e um copolímero de polioxialquileno e polidimetilsiloxano modificado (CPPM), com peso molecular de $17.000 \mathrm{~g} \cdot \mathrm{mol}^{-1}$ apresentam baixos índices de toxidez, e de bio-acumulação. Na indústria é comum o uso de mistura de substâncias que ajam como inibidores de corrosão, cujo objetivo é aumentar a proteção dos materiais. Segundo Sastri (2001), é possível desenhar misturas de substâncias inibidoras de corrosão para um material metálico particular em um meio agressivo; que permitam aumentar a proteção do material, 
diminuir os custos operacionais e principalmente que a mistura dessas substâncias sejam "amigáveis" com o meio ambiente, e assim, minimizar os impactos ambientais principalmente quando estas são descartadas nos mananciais.

O molibdato de sódio e o tungstato de sódio têm sido estudados como inibidores de corrosão, como demonstra a literatura científica existente; sendo que o molibdato de sódio já é usado comercialmente como inibidor de corrosão especialmente em sistemas de resfriamento (SASTRI, 1991).

As ftalocianinas de cobre e o copolímero surfactante a base de silano são substâncias que vem sendo investigadas e, portanto estão em fase de pesquisa experimental como inibidores de corrosão. As ftalocianinas e seus derivados estão sendo estudados, tendo em vista que nos processos de sínteses a variedade de complexos que pode formar com grupos orgânicos e/ou metálicos é bastante versátil, mas, sobretudo pelas suas propriedades de adsorção (BELTRÁN et. al., 2005).

Não menos importante, os silanos, vem sendo utilizados como promotores de aderência e como aditivos para melhorar a resistência à corrosão em diversos tipos de pinturas; atualmente são muito estudados, principalmente porque é uma alternativa amigável para o ambiente e promissora para a proteção das superfícies metálicas. Os derivados de silano, que são moléculas surfactantes têm sido testados como inibidores de corrosão para aço carbono principalmente em meio acido.

Neste contexto, o laboratório de eletroquímica e corrosão do Departamento de Engenharia Química, e o laboratório de corrosão do Departamento de Metalurgia, ambos da Escola Politécnica da Universidade de São Paulo; vêm desenvolvendo projetos com o uso de silanos e seus derivados, visando estudar o comportamento como inibidores de corrosão e como pré-tratamentos superficiais para diferentes substratos metálicos tais como, aço carbono e alumínio; sendo possível destacar os trabalhos de Souza 2005, Aquino 2006, Oliveira, 2006, Palomino 2007, Suegama 2008.

Neste sentido, é importante mencionar que as substâncias capazes de agir como inibidores de corrosão, participam das reações de interface metal /meio, de modo que podem reduzir ou até cessar o processo corrosivo. Estas substâncias podem, portanto, 
inibir as reações de dissolução do metal, ou ainda reações de redução das espécies oxidantes presentes no meio (GUEDES, 1996; SASTRI, 2001).

Perante o exposto, e sendo as reações que acontecem nos processos corrosivos de caráter principalmente eletroquímico; o objetivo deste trabalho é formular e otimizar uma mistura de inibidores de corrosão para aço carbono ABNT 1005 em meio de águas de resfriamento industrial.

Inicialmente as quatro substâncias atóxicas foram avaliadas individualmente por meio de técnicas eletroquímicas de medidas do potencial de corrosão, espectroscopia de impedância eletroquímica levantamento de curvas de polarização anódicas e catódicas; além de técnicas de caracterização da superfície como de microscopia eletrônica de varredura e energia dispersiva de raios-X.

Por fim, para atingir os objetivos propostos, o trabalho foi dividido em três etapas: na primeira etapa, foram identificados os efeitos sinérgicos entre as substâncias mediante um planejamento estatístico fatorial completo; na segunda etapa, através de um planejamento estatístico fatorial composto foi obtido um modelo matemático/estatístico que possibilitou identificar o "ponto de ótimo" da mistura das substâncias. Na etapa final, foram realizados ensaios eletroquímicos com a mistura na concentração do ponto de ótimo, para avaliar a evolução com o tempo das características inibidoras da corrosão. 


\section{REVISÃO DA LITERATURA}

\subsection{Aço carbono.}

O aço carbono é uma liga constituída de $\mathrm{Fe}-\mathrm{C}$, e é a mais amplamente empregada em qualquer âmbito da vida moderna seja industrial, comercial ou urbana, tendo em vista que apresenta uma combinação de propriedades úteis para as mais diversas aplicações da engenharia, além de um custo relativamente baixo.

Segundo Chiaverini (1959) no aço-carbono os dois principais elementos de liga são o ferro e o carbono. Outros elementos residuais podem estar presentes como impurezas, tais como fósforo, enxofre, silício e manganês. Logo o aço carbono pode ser definido como sendo uma liga de ferro-carbono ( $\mathrm{Fe}-\mathrm{C})$ contendo geralmente de $0,008 \%$ até $2,0 \%$ de carbono. O limite inferior de $0,008 \%$ corresponde à máxima solubilidade do carbono no ferro à temperatura ambiente e o limite superior de 2,0\% é à máxima quantidade de carbono que se dissolve no ferro a $1130^{\circ} \mathrm{C}$.

Entretanto, é sabido que o aço carbono, sem adição de elementos de liga possui baixa resistência à corrosão, levando à formação de filmes de óxidos/hidróxidos ou sais pouco aderentes e com mínima capacidade de proteger a superfície contra o ataque dos meios corrosivos. Isto implica a necessidade de um processo ou de vários processos adicionais, como por exemplo, a aplicação de um revestimento ou pintura capaz de garantir uma proteção contra a corrosão no meio de emprego do material ou ainda pela adição de inibidores de corrosão.

Tendo em vista a ampla aplicação industrial do aço carbono, os estudos da corrosão têm uma importância relevante. Embora o aço e suas ligas possuam boas propriedades físicas e químicas tais como ductilidade, maleabilidade, condutividade térmica, condutividade elétrica e resistência aos diversos tipos de esforços mecânicos; quase todos os materiais metálicos são deteriorados ao reagir com o meio ambiente, devido ao fato de apresentarem uma condição termodinamicamente instável. Por esse 
motivo tendem espontaneamente a passar para uma condição de maior estabilidade, através da formação de óxidos, hidróxidos e sais. Assim, o aço carbono, quando exposto ao meio ambiente transforma-se em óxidos de ferro, que são mais estáveis que o próprio aço (GENTI, 2007).

\subsection{Corrosão de metais}

A corrosão metálica pode ser definida como sendo o processo em que estes passam do estado metálico para a forma combinada (produto de corrosão), por uma interação com o meio. A interação entre o metal e o meio pode ser de natureza química ou eletroquímica e estar associada ou não a esforços mecânicos. O processo é natural, espontâneo, irreversível, e na maioria das vezes, ocorre em condições não controláveis. (GENTIL; 2007; RAMANTHAN)

Dessa forma, a corrosão é um processo espontâneo indesejável; por este motivo o estudo e controle da corrosão dos materiais são fundamentais para minimizar efeitos prejudiciais tais como, desgaste ou falhas do material metálico, os quais podem ocasionar uma deterioração no funcionamento do componente afetado ou no sistema total. (MARÍN-CRUZ et. al., 2006; SASTRI, 2001; GUEDES, 1996).

No caso do ferro, que é o principal componente do aço carbono, as alterações que acontecem na superfície devido à corrosão podem ser mostradas por meio das reações químicas seguintes:

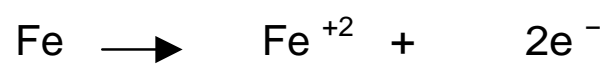

$\mathrm{Na}$ reação (1), o ferro perde elétrons para passar a ser um íon carregado positivamente, e assim ter condições para fazer ligações com outro grupo de átomos carregados negativamente, o qual é conhecido como reação anódica. 
Em meio aquoso e neutro, como o investigado neste trabalho, a reação (2) é a reação catódica ou de redução.

$$
\mathrm{O}_{2}+2 \mathrm{H}_{2} \mathrm{O}+4 \mathrm{e}^{-} \longrightarrow 4 \mathrm{OH}^{-}
$$

Nos processos corrosivos as reações (1) e (2) acontecem simultaneamente e em diferentes regiões da superfície metálica. Portanto, o processo corrosivo pode ser basicamente descrito quando se escrevem em forma combinada as reações (1) e (2):

$$
2 \mathrm{Fe}+\mathrm{O}_{2}+2 \mathrm{H}_{2} \mathrm{O} \longrightarrow 2 \mathrm{Fe}(\mathrm{OH})_{2}
$$

Ou seja, o ferro em presença de água com oxigênio dissolvido forma hidróxido de ferro. Na etapa seguinte, o oxigênio dissolvido em excesso reage rapidamente com o hidróxido de ferro de acordo com a seguinte reação:

$$
4 \mathrm{Fe}(\mathrm{OH})_{2}+\mathrm{O}_{2} \longrightarrow \mathrm{H}_{2} \mathrm{O}+2 \mathrm{Fe}_{2} \mathrm{O}_{3} \cdot \mathrm{H}_{2} \mathrm{O}
$$

para produzir óxidos hidratados de ferro, que é conhecido com a ferrugem.

Portanto, para que aconteça o processo corrosivo os íons metálicos necessitam da presença de um meio oxidante, usualmente a água, além da presença de oxigênio. Logo, o metal tem que estar pronto para liberar os elétrons e começar o processo corrosivo e o produto de corrosão formado pode novamente reagir ou formar uma camada protetora na superfície do metal original, que é conhecida como camada de passivação (GENTIL, 2007; MARÍN et al., 2006).

\subsection{Inibidores de corrosão}


Dentre os métodos de controle e prevenção da corrosão estão o uso dos inibidores de corrosão. Rozenfeld (1981), Guedes (1996), Kunznetsov (1996), Sastri (2001), e Gentil (2007) coincidem em definir os inibidores de corrosão como substâncias químicas ou misturas delas que adicionadas ao meio onde está exposto o metal conseguem diminuir ou até deter a velocidade de corrosão ou de dissolução do metal.

Os meios onde os inibidores de corrosão podem agir são aquosos, parcialmente aquosos a gasosos. Os meios aquosos e parcialmente aquosos geralmente são encontrados em águas naturais, águas de resfriamento de $\mathrm{pH}$ neutro ou próximo da neutralidade. Geralmente os meios corrosivos em uma faixa de $\mathrm{pH}$ menor ou ácido são encontrados em águas usadas em plantas de produção e refino de gás e óleo, águas usadas na remoção de carbonatos em sistemas de produção industrial.

Os inibidores de corrosão têm a vantagens de ser de fácil aplicação "in situ" e de não precisar da interrupção do processo. Alguns fatores tais como: o custo do inibidor, o qual não pode ser alto em relação ao metal que deve ser protegido; a quantidade e a toxidez do inibidor em relação a seres vivos e ao meio ambiente; devem ser levados em consideração na hora de escolher o inibidor de corrosão (FUCHS-GODEC, 2007; WANG et AL., 2005; EMREGÜL; AKSÜT, 2003).

A ação dos inibidores de corrosão é sempre associada a mudanças na superfície metálica a ser protegida devido à adsorção e /ou formação de compostos pouco solúveis ou insolúveis que contem cátions do metal. Tais compostos agem diminuindo as áreas eletricamente ativas na superfície do metal, dificultando assim, que aconteçam as reações de oxido-redução, ou seja, as reações eletroquímicas atribuídas aos processos corrosivos dos metais.

Os fenômenos clássicos de proteção estão associados à adsorção, mas no mecanismo de inibição, os processos de adsorção podem estar combinados com oxidação ou complexação na superfície metálica. Portanto, o estudo da interface metal/eletrólito é de vital importância nestes sistemas, isto porque a presença do meio aquoso é o principal responsável pela corrosão nas diferentes formas que ela apresenta-se (LORENZ; MANSFELD, 1985; KUZNETSOV, 2004; WANG et al., 2005; ZHANG; SOMADUNDARAN, 2006). 


\subsection{Tipos de inibidores de corrosão.}

Existe uma variedade de inibidores de corrosão disponíveis para uso industrial, mas os inibidores de corrosão têm sido classificados usando muitos critérios. Não obstante, são duas as classificações mais aceitas, a primeira pela natureza química, na qual os inibidores de corrosão são identificados como orgânicos e inorgânicos; a segunda, pela forma que agem na interface metal-eletrólito, sendo assim diferenciados entre inibidores anódicos, catódicos e mistos. Nesta classificação coincidem muitos autores entre eles: Rozenfeld (1981), Kuznetsov (1996), Sastri (2001) e Gentil (2007).

A caracterização dos inibidores como anódicos, catódicos e mistos, está diretamente relacionada com as propriedades do metal e também do meio. Para conhecer o comportamento dos metais com respeito ao meio corrosivo, o metal a ser caracterizado é polarizado ou afastado do potencial de corrosão com conseqüente passagem de corrente líquida. A extensão do desvio do potencial em relação ao potencial de corrosão é denominada sobretensão (GUEDES, 1996; TRABANELLI, 1987).

\subsubsection{Inibidores anódicos}

Este tipo de inibidor é caracterizado por ter a propriedade de deslocar a curva de polarização anódica para valores menores de densidade de corrente de corrosão em relação ao eletrodo polarizado na ausência do inibidor. Geralmente, este tipo de polarização ocorre devido à presença de substâncias ou ânions inorgânicos presentes na molécula, logo são chamados de inibidores inorgânicos. Os ânions presentes podem ser oxidantes e não oxidantes. Os ânions oxidantes têm a propriedade de passivar o metal na presença de oxigênio, sendo chamados de inibidores passivantes. Os inibidores passivantes mais conhecidos são os cromatos, nitritos e nitratos. 
Até os anos 80, estas substâncias foram muito usadas devido a sua alta eficiência. Entretanto, atualmente seu uso vem sendo muito limitado ou banido em virtude de seu caráter tóxico. Para substituí-los, têm sido propostos outros ânions como sais de fosfatos, de molibdato, de tungstato, e silicatos. (VUKASOVICH; ROBITAILLE, 1977; SAJI; SHIBLI, 2002; WANG et al., 2005).

Os inibidores anódicos são os mais amplamente usados devido a sua alta eficiência em relação aos outros tipos. Sua principal desvantagem é a necessidade de manter no meio uma concentração que permita proteger. Quando a concentração é menor do que a mínima necessária, e no meio existe a presença de outros íons como cloreto, pode então acontecer uma adsorção competitiva na superfície, podendo favorecer a corrosão localizada a qual é altamente indesejável (EL SHAMS; WANG, 1996; SAJI; SHIBI, 2002; SHIBLI; KUMARY, 2004).

\subsubsection{Inibidores Catódicos}

Os inibidores catódicos são caracterizados pela redução da velocidade das reações catódicas, sendo as mais típicas a redução de oxigênio em pH básico e perto da neutralidade e a reação de redução de hidrogênio em meio ácido. Estas substâncias precipitam nas regiões catódicas da superfície do metal, ou seja, deixando a superfície mais negativa, aumentando a resistência à corrosão e diminuindo a velocidade de difusão do oxigênio; sendo assim, com menor teor de oxigênio disponível no meio, a velocidade das reações de redução é diminuída. (GUEDES, 1996; TRABANELLI, 1987).

A ação dos inibidores catódicos pode ser explicada por dois mecanismos diferentes: um desses mecanismos é a formação de precipitados nas áreas catódicas, como no caso dos inibidores que formam compostos com cálcio ou magnésio, que permitem a formação de óxidos na superfície do metal, que agem como barreira. Outro mecanismo é o empregado pelas substâncias que agem como seqüestrantes de oxigênio. Estes compostos têm a capacidade de reagir com o oxigênio presente no 
meio. Este mecanismo funciona através da remoção do oxigênio do sistema para minimizar a corrosão (SASTRI, 2001; TRABANELLI, 1987).

\subsubsection{Inibidores mistos}

Os inibidores mistos têm como função minimizar e até impedir tanto as reações de dissolução do metal ou reações anódicas, como as reações catódicas ou de redução de uma ou mais espécies oxidantes presentes no meio corrosivo.

Este tipo de inibidor atua formando uma película protetora tanto nas regiões catódicos como nas regiões anódicas e, portanto, capaz de revestir toda a superfície do metal. Este comportamento pode ser identificado nas curvas de polarização, pois, tanto as curvas anódicas quanto as curvas catódicas são polarizadas em relação àquela obtida na ausência do inibidor (GUEDES, 1996; TRABANELLI, 1987).

\subsubsection{Inibidores orgânicos}

Este tipo de inibidor é caracterizado porque a maioria das substâncias orgânicas usadas como inibidores de corrosão podem adsorver-se na superfície do metal formando um filme protetor, através do grupo funcional. Ele forma uma camada hidrofóbica na superfície que evita a dissolução do metal. A eficiência deste tipo de inibidor depende da estrutura e da sua composição química, assim como de sua afinidade com o substrato metálico (GUEDES, 1996; KUZNETOV, 2002).

Alguns dos inibidores orgânicos são freqüentemente usados e estudados como alternativas mais amigáveis com o ambiente. Estão classificados como ânions e cátions orgânicos. As substâncias sulfonadas e fosfonadas são exemplos de ânions orgânicos que agem como inibidores de corrosão, entre elas o ácido 
1,1,hidroxietilideno difosfônico, (HEDP). Compostos Químicos com grupos ativos como os alifáticos, os aromáticos ou as aminas carregadas positivamente são exemplos de cátions que agem como inibidores orgânicos.

Dentre da avaliação de novos compostos como inibidores de corrosão, têm sido estudados e usados compostos orgânicos como triazoles, diazoles e derivados de imidazol que resultam em excelentes inibidores para substratos metálicos como cobre, embora não sejam compostos orgânicos amigáveis com o ambiente (SASTRI, 2001).

\subsubsection{Inibidores multicomponentes}

Em poucas ocasiões são usados inibidores de um só componente. Em geral são usados dois, três, ou mais componentes com diferentes características, mas que apresentem efeitos sinérgicos entre si, permitindo que a eficiência da mistura seja maior do que a contribuição da soma dos efeitos individuais. Portanto, as vantagens do uso de inibidores anódicas e/ou catódicos que podem ser combinados e otimizados são significativos (SASTRI, 2001; KUZNETSOV, 2002; ZHANG; SOMASUNDRAN, 2006; BLIN et al., 2007; FUCHS-GODEC, 2007).

Em vista disso, Aoki, Guedes e Taqueda (1998) estudaram a possível existência de sinergismo entre três inibidores de corrosão: benzotriazole (BTAH), N-fenil-tiourea (N-PTU) e cloreto de hexadeci-trimetil-amonio-quaternário (HTAQ) para um aço de alta resistência e baixa liga em meio de acido clorídrico.

Para este estudo foram realizados ensaios de perda de massa e curvas de polarização anódicas e catódicas. O estudo foi desenvolvido com um projeto estatístico fatorial que permitiu propor um modelo cúbico que foi obtido pela análise de regressão para prever o grau de proteção da superfície do metal como função das concentrações de inibidor. Os valores de grau de cobertura obtidos pelo modelo proposto foram concordantes com aqueles resultados obtidos experimentalmente, permitindo identificar efeitos sinérgicos entre BTAH e N-PTU e também entre N-PTU e HTAC. 
Um tipo de mistura de inibidores usando substâncias atóxicas foi estudada pelo Lahodny-Sarc e Kapor (2002). Eles estudaram como inibidores de corrosão a mistura de taninos e gluconato de sódio em meio de água destilada e água corrente para o aço carbono. O estudo foi desenvolvido por meio do levantamento de curvas de polarização. Os resultados mostraram que houve um efeito sinérgico entre as substâncias estudadas quando comparados com os resultados individuais de cada substância, tanto em água destilada como em água corrente, sendo o efeito sinérgico mais pronunciado em água destilada.

\subsection{Técnicas eletroquímicas usadas neste trabalho}

\subsubsection{Potencial de Corrosão}

O potencial de corrosão é um dos parâmetros eletroquímicos de mais fácil determinação experimental. O monitoramento do potencial de corrosão com o tempo é necessário, principalmente nos estágios iniciais do ensaio eletroquímico, tendo em vista que a superfície metálica modifica-se com o tempo de imersão na solução eletrolítica. Assim, o acompanhamento da variação do potencial pode fornecer informações importantes para a investigação, principalmente quando se deseja estudar alguns métodos de proteção, tais como: revestimentos; inibidores; proteção catódica etc. e também quando se deseja conhecer o comportamento de um metal em um determinado meio.

As medidas de potencial de corrosão em função do tempo também são fundamentais quando se deseja estudar o comportamento do metal através da técnica de espectroscopia de impedância eletroquímica, pois a perturbação é aplicada em torno do potencial de corrosão. Assim, é muito importante que o potencial esteja estável ( $E_{\text {corr }}$ constante), isto e, que tenha atingido o estado estacionário, e assim torne 
possível minimizar as flutuações dos resultados de impedância principalmente em baixas freqüências.

\subsubsection{Espectroscopia de impedância eletroquímica (EIE)}

Segundo Bonora (1996), a espectroscopia de impedância eletroquímica vem sendo utilizada nos últimos anos para investigar os mecanismos de resistência à corrosão dos revestimentos orgânicos em metais. No entanto, atualmente o uso desta técnica permite que sejam tiradas importantes informações, tais como: identificação dos processos que acontecem na interface metal/eletrólito como adsorção; resistência à transferência de carga; difusão, etc., e a partir deles estimar a eficiência do inibidor. Já que, a partir dos diagramas de impedância é possível quantificar os parâmetros envolvidos o que normalmente é feito através da modelagem dos circuitos elétricos equivalentes.

O estudo dos espectros de impedância eletroquímica consiste na avaliação da resposta de um sistema a uma perturbação contínua de pequena amplitude, seja ela em potencial ou em corrente, sendo mais comum à perturbação em potencial $(E)$ e medindo a variação em corrente (I). A relação temporal entre o potencial e corrente corresponde à impedância do sistema, pois a impedância $Z$ pode ser definida como a relação $E / I$.

Segundo Wolynec (2003), num circuito de corrente alternada, o potencial elétrico $E(t)$ varia com o tempo $t$ de acordo com a equação (5):

$$
E(t)=A \cos \omega t
$$

onde $\omega=2 p f$, sendo $f$ a freqüência com que a corrente alternada oscila, normalmente medida em Hertz $(\mathrm{Hz}) . \mathrm{O} \omega$ é expresso em radianos.

A resposta da corrente elétrica $\mathrm{I}(\mathrm{t})$ a oscilação do potencial se dá conforme a equação (6): 


$$
I(t)=B \operatorname{sen}(\omega t+f)
$$

onde f é a defasagem de corrente com relação ao potencial e é conhecido como ângulo de fase.

A relação entre o potencial e a corrente pode ser representada por uma expressão semelhante à lei de Ohm, de acordo com a equação (7):

$$
E(t)=Z I(t)
$$

onde, $Z$ é definido com sendo a impedância do sistema.

Quando a resposta em corrente está defasada em relação ao potencial, o sistema tem características capacitivas ou indutivas e a impedância tem um componente imaginário. Quando não há defasagem, a impedância tem apenas um componente real, e o comportamento é resistivo. Estes diferentes comportamentos e a sua variação ao longo de uma varredura de freqüências devem estar associados às características do processo eletroquímico. Logo, a impedância pode ser descrita por um componente real e um imaginário.

Os diagramas mais utilizados para interpretação das informações obtidas no ensaio de impedância eletroquímica são os de Nyquist (a) e os de Bode (b) como os apresentados na Figura 1. No diagrama de Nyquist observa-se a impedância imaginária (Z') versus a impedância real ( $\left.Z^{\prime}\right)$, medidas em diferentes freqüências. No diagrama de Bode encontra-se o logaritmo do módulo da impedância (|Z|) e o ângulo de fase $(T)$ em função do logaritmo da freqüência. Os diagramas de Nyquist são úteis para reconhecer o tipo de processo envolvido. Os diagramas de Bode, por sua vez, usualmente utilizam uma escala logarítmica para a freqüência, o que pode ser particularmente interessante quando estão presentes processos que ocorrem em escalas de tempo muito diferentes. 


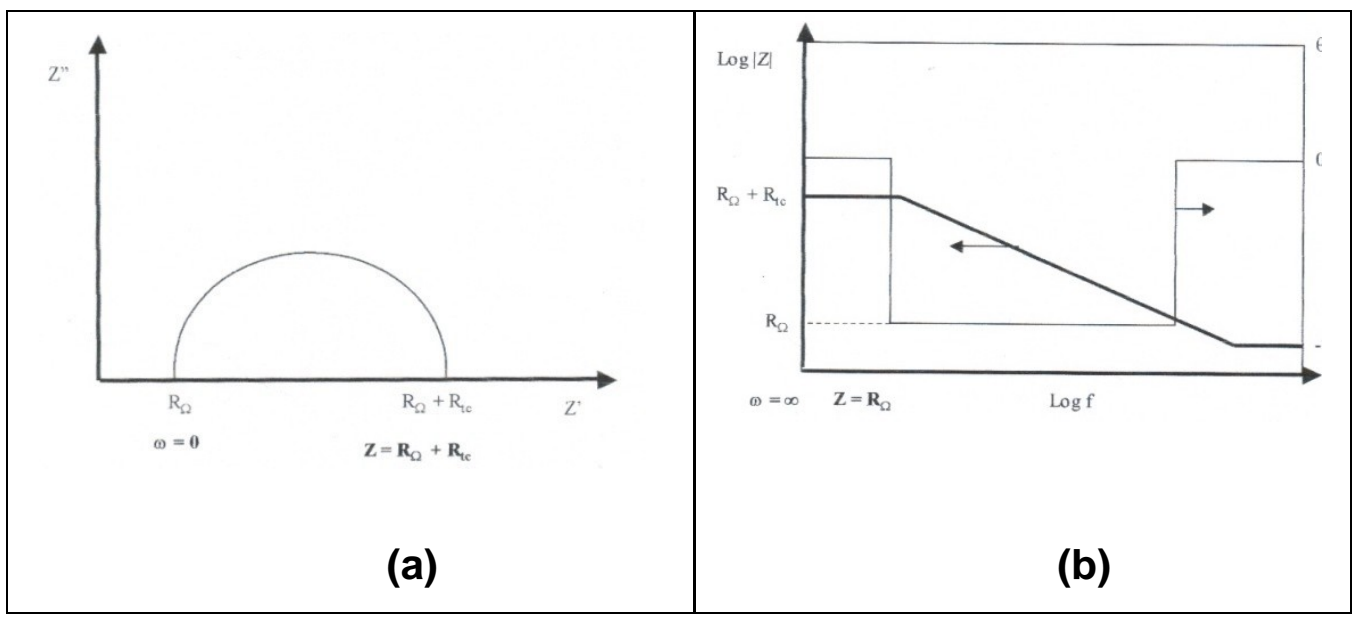

Figura 1- Representação genérica de um sistema metal/meio. (a) Diagrama de Nyquist e (b) Diagrama de Bode. Fonte: Oliveira, (2006).

A análise do diagrama de Nyquist revela que a freqüência tem seu máximo à esquerda, no inicio do semicírculo, onde o intercepto com o eixo real Z' fornece a resistência do eletrólito $R_{s}$; enquanto que o intercepto no valor de baixas freqüências fornece à resistência a transferência de carga $R_{\mathrm{tc}}$, que representa as características da interface metal/solução, logo, quanto maior a $\mathrm{R}_{\mathrm{tc}}$ maior será resistência a corrosão do metal. Portanto, quanto maior o diâmetro do arco capacitivo, maior a resistência do filme na interface e melhor o efeito protetor da película formada na superfície.

Com o objetivo de analisar o comportamento dos filmes formados pelas diferentes substâncias estudadas como inibidor de corrosão; e visando determinar parâmetros importantes como a resistência a transferência de carga $R_{\mathrm{tc}}$, módulo de impedância $|Z|$, ângulo de fase, $\theta$, capacitância da dupla camada elétrica, $C_{d l}$, após o monitoramento do potencial de corrosão, seguem os ensaios de espectroscopia de impedância eletroquímica, EIE.

Uma das aplicações mais poderosas do uso dos espectros de impedância eletroquímica; como no caso da corrosão de um metal, é a associação desses fenômenos a circuitos elétricos equivalentes que através de programas de simulação permitem quantificar os elementos. Esta associação é muito útil quando se deseja estudar o comportamento de revestimentos, filmes formados por inibidores de corrosão etc. Esses circuitos equivalentes contêm elementos como resistências, capacitores e indutores que podem ser arranjados em serie ou em paralelo para representar os 
processos de formação de filme na superfície de metal, reações químicas com transferência de carga na dupla camada elétrica, processos de difusão, etc. (BONORA, 1996).

Diversos estudos de avaliação e caracterização do comportamento de substâncias como inibidores de corrosão para águas de resfriamento industrial usaram a modelagem por circuitos equivalentes, como no caso desta investigação, sendo possível mencionar os trabalhos de Marin et al., (2004), Saremi, Dehghanian e Sabet (2006).

Saremi; Dehghanian e Sabet (2005) estudaram o efeito da concentração de molibdato e da hidrodinâmica na inibição da corrosão de aço carbono imerso em água de resfriamento industrial; valendo-se entre outras técnicas, da modelagem dos circuitos equivalentes associados aos diagramas de impedância eletroquímicos obtidos nas situações estudadas.

No ano 2004, Marin et al. estudaram a interface entre o aço carbono e água de resfriamento industrial na presença de dois inibidores; o ácido hidroxi-fosfôno-acético (HPA) e o ácido 1,1 hidroxietilideno difosfônico (HEDP), por meio de espectros de impedância eletroquímica e modelagem de circuitos equivalentes para avaliar ao longo do tempo de imersão o comportamento dos parâmetros como resistência à transferência de carga, $R_{t c}$, capacitância da dupla camada elétrica, $C_{d l}$ e do filme, $C_{f}$.

Ambos os trabalhos demonstram a utilidade da obtenção dos espectros de impedância eletroquímica e a quantificação dos elementos associados aos processos que acontecem na interfase metal/meio com o auxilio da modelagem por meio dos circuitos elétricos equivalentes.

Finalmente, precisa ser destacado que Mansfelfd, Kending e Tsai (1982) comparam os resultados obtidos na estimação da resistência à transferência de carga, e da densidade de corrente de corrosão para aço carbono e aço inox na presença de hexanol, propano glicol 2 buteno 1,4 diol como inibidores de corrosão em meio acido. Eles concluem que nem sempre existe correlação entre os métodos devido à natureza dos processos corrosivos metal meio na presença de inibidores.

Os autores enfatizam que as principais suposições quando se interpretam os diagramas de impedância são que: 
- Cada um dos processos que acontecem na superfície metal eletrólito está associado a uma só constante de tempo.

- Os processos e suas cinéticas estão bem estabelecidos e conhecidos.

- A resistência à transferência de carga só é determinada pelos processos faradaícos que controlam as reações de corrosão.

Na pratica é sabido que dependendo das características do sistema podem estar acontecendo outros processos como dessorção do inibidor, ou reações redóxes que envolvem o inibidor e que podem alterar a forma e quantidade dos arcos capacitivos e, portanto o valor de resistência à transferência de carga.

No caso das curvas de polarização é varrida uma faixa potencial que pode alterar irreversivelmente a superfície do metal, especialmente em sistema neutros ou alcalinos, como é o caso desta investigação; onde nas condições estudadas podem ser produzidas voluminosas camadas porosas de produtos de corrosão. Esta situação indicaria que não estaria acontecendo uma corrosão uniforme da superfície; pelo contrario a velocidade de corrosão nesta situação é altamente dependente do tempo e de possíveis condições hidrodinâmicas, os quais podem alterar sensivelmente os cálculos analíticos de densidade de corrente pela extrapolação das retas de Tafel.

\subsubsection{Curvas de polarização potenciodinâmicas anódicas e catódicas.}

Nos estudos teóricos, mas principalmente na prática é importante conhecer o comportamento eletroquímico de um metal num potencial de eletrodo diferente do potencial de corrosão (ou de equilíbrio).

Um controle adequado do potencial de eletrodo é conseguido com um potenciostato, através do qual é possível, além de impor ao eletrodo o potencial desejado com relação ao eletrodo de referência, também se pode medir a corrente de polarização e registrá-la em função do potencial. 
Lembrando que a equação de Tafel é de natureza logarítmica, uma das maneiras mais convenientes de apresentar as curvas de polarização é num diagrama $E$ vs.log I i I, (WOLYNEC, 2003). Os valores de densidade de corrente de corrosão, $\mathrm{i}_{\text {corr }}$ são determinados a partir da extrapolação da reta catódica de Tafel até o potencial de corrosão, $\mathrm{E}_{\text {corr. }}$ A extrapolação da reta de Tafel é obtida considerando-se o trecho linear em torno de 50 a $80 \mathrm{mV}$ abaixo do potencial de corrosão. Para melhorar a precisão é necessário que a região de Tafel se estenda por pelo menos uma década logarítmica.

Matematicamente as equações de Tafel podem ser expressas como:

$$
\eta_{a}=b_{a} \log \frac{i_{\text {corr }}}{i_{o}}
$$

Onde $\eta_{a}$ é a sobretensão anódica, $b_{\mathrm{a}}$ e a inclinação anódica de Tafel, $i_{c o r r}$ é a densidade de corrente de corrosão e $i_{o}$ é a densidade de corrente de troca.

Similarmente e de forma análoga na região catódica, a equação de Tafel é dada por:

$$
\eta_{c}=b_{c} \log \frac{i_{\text {corr }}}{i_{o}}
$$

Onde $\eta_{c}$ é a sobretensão catódica aplicada e $b_{c}$ é a inclinação de reta catódica de Tafel.

Uma das vantagens do método da extrapolação da reta de Tafel é que, além da densidade corrente de corrosão (i corr), também é possível obter informações importantes do mecanismo do eletrodo, tais como os parâmetros de inclinações anódicas $\left(b_{a}\right)$ e catódicas $\left(b_{c}\right)$, além de possíveis alterações no mecanismo de dissolução do metal e do mecanismo de redução da espécie oxidante. (WOLYNEC, 2003).

A sobreposição de várias curvas de polarização permite fazer uma avaliação qualitativa do processo, principalmente conhecer o mecanismo de inibição e 
principalmente o tipo de inibidor, isto é, se anódico, catódico ou misto. Assim, tendo uma curva de polarização sem inibidor e outras curvas para diferentes concentrações, é possível tirar importantes informações tais como eficiência do inibidor, mecanismo de ação dos inibidores, tipo de inibidor, etc.

\subsection{Microscopia Eletrônica de Varredura (MEV)}

A microscopia eletrônica de varredura baseia-se na varredura de uma região da superfície da amostra por um feixe de elétrons, e a posterior detecção dos elétrons que podem ser uns re-emitidos pela amostra conhecidas como elétrons secundários, de energia muito menor que a do feixe incidente; e outros retro-espalhados com energia igual à do feixe. O sinal obtido pelos detectores é lido em varredura sincronizada com a do feixe, gerando-se uma imagem. Devido ao pequeno ângulo de incidência e ao pequeno comprimento de onda utilizado, esta técnica permite grandes profundidades de campo e excelentes definições.

A imagem por elétrons secundários é extremamente sensível a relevo e tem alta resolução, permitindo aumentos até cerca de $30.000 \mathrm{X}$. A imagem por elétrons retroespalhados tem menor definição, mas é especialmente sensível a diferença de composição química ou estrutura cristalina, sendo muito útil para diferenciar fases (ALVES; BRETT; MONTEMOR, 2005).

\subsection{Planejamento fatorial e análise de experimentos.}

A seguir são descritas as técnicas de planejamento e analise de experimentos usados neste para atingir os objetivos deste trabalho. 
O Planejamento de Experimentos (Design of Experiments, DOE) é uma ferramenta poderosa para definir que variáveis de entrada ou fatores têm maior influência nas variáveis de resposta de um sistema ou processo de interesse. É uma técnica de extrema importância para a indústria e grande aliada na área de pesquisa, pois seu emprego permite resultados confiáveis economizando dinheiro e tempo.

O tratamento dos resultados é realizado usando os diferentes softwares de estatística disponíveis, que garantem resultados rápidos e confiáveis e que facilitam a sua interpretação, mas é importante lembrar que nunca substitui o conhecimento do experimentador do sistema em estudo (BRASIL et al., 2006).

O planejamento de experimentos permite determinar os fatores que têm efeitos relevantes na resposta e também como o efeito de um fator varia com os níveis dos outros fatores. O planejamento de experimentos também permite medir as interações entre diferentes fatores. $\mathrm{Na}$ ausência de um planejamento de experimento, é possível que importantes interações de fatores deixem de ser detectadas; e que a obtenção dos valores no ponto de ótimo do sistema possa precisar da realização de um número maior de ensaios e, portanto levar mais tempo e tornar o processo mais oneroso para conseguir resultados confiáveis (FIGUEIREDO; ABREU, 2002).

Para definir um planejamento de experimentos é necessário identificar:

- As variáveis de entrada, também chamadas de variáveis independentes ou fatores, $\mathrm{k}$;

- Os níveis correspondentes às faixas dos valores das variáveis de entrada a serem estudados;

- A variável de resposta ou variável de saída.

Uma das técnicas mais conhecidas de planejamento de experimentos é o planejamento fatorial, no qual podem estar envolvidos $k$ fatores ou variáveis de entrada, onde cada um deles está presente em diferentes níveis. O caso mais simples é aquele em que cada fator está presente em apenas dois níveis, visando obter uma combinação de ensaios, resultante em $2^{\mathrm{K}}$. Por conveniência na hora de interpretar os resultados da análise de um projeto fatorial em dois níveis, o valor mínimo de cada variável de entrada corresponde -1 e o valor máximo a +1. (BOX; HUNTER, 1978). 
O planejamento fatorial $2^{k}$, com pontos centrais, ou planejamento fatorial composto, como será identificado nesta investigação, consiste em adicionar um ponto de experimentação no nível intermediário aos níveis investigados das variáveis de entrada (GALDAMEZ; CARPINETTI, 2004).

A metodologia de superfície de reposta é um conjunto de técnicas de planejamento e análise de experimentos usados na modelagem matemática de respostas. Ou seja, procura-se identificar o relacionamento que existe entre as variáveis de entradas e as variáveis de respostas do sistema analisado (GALDAMEZ; CARPINETTI, 2004).

\subsection{Substâncias estudadas como inibidores de corrosão.}

A seguir é apresentada uma revisão das características das sustâncias estudadas como inibidores de corrosão neste trabalho. Serão considerados aspectos como suas características químicas gerais, toxidez, e comportamento eletroquímico, possíveis mecanismos da atuação na superfície do metal segundo a literatura estudada.

\subsubsection{Molibdato de sódio}

Geralmente os sais de molibdato apresentam-se na forma hidratada de $\mathrm{Na}_{2} \mathrm{MoO}_{4} 2 \mathrm{H}_{2} \mathrm{O}$. A estrutura química do ânion do molibdato $\left(\mathrm{MoO}_{4}{ }^{-2}\right)$ apresenta-se na forma tetraédrica, tanto na forma sólida como na aquosa; na forma do sal os cátions metálicos que são de sódio se encontram enlaçados ao oxigênio como mostrado na Figura 2. A literatura é rica em estudos desenvolvidos com o sal de molibdato de sódio para proteção contra a corrosão e mais especificamente como inibidor de corrosão, tendo em vista que os ânions de molibdato pertencem ao mesmo grupo químico do 
cromato, ou seja, o grupo químico VI. Embora esteja bem estabelecido que o molibdato possua propriedades oxidantes inferiores as do cromato, em compensação os sais de molibdato não são tóxicos.

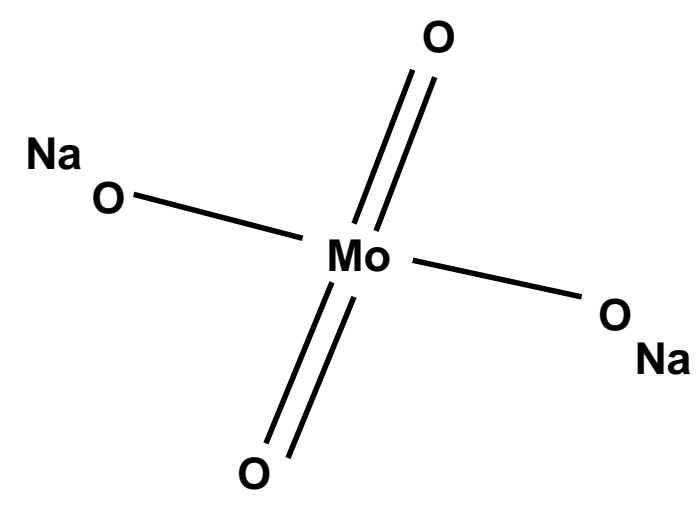

Figura 2 - Estrutura química do molibdato de sódio.

A preocupação com o elevado índice de toxidez do cromato e por tanto a necessidade de encontrar substitutos para seu uso como inibidores de corrosão, é basicamente a razão pela qual o estudo com molibdato têm sido constante nos últimos cinqüenta anos como demonstra a ampla literatura disponível. (ROBERTSON, 1951; VUKASOVICH; ROBITAILLE, 1977; FARR; SAREMI, 1982 e 1983; VUKASOVICH; FARR, 1985; ZHAO; ZUO, 2001; SHIBLI; KUMARY, 2004; ALENTAJANO; AOKI, 2004; AMEER et al., 2004; SAREMI; DEHGHANIAN; SABET, 2006).

Embora ambas as substâncias, cromato e molibdato façam parte da lista II das substâncias não permitidas na Europa, existem referências com evidencias experimentais da baixa toxidez dos compostos de molibdato, e sua pouca sensibilidade para animais aquáticos. (VUKASOVICH; ROBAITAILLLE,1977; VUKASOVICH; FARR, 1985; DIAMANTINO et al., 2000).

A baixa toxidez do molibdato para o meio ambiente e os seres vivos foi comprovada por Diamantino et al. (2000). Em seu estudo, eles encontraram uma grande diferença de toxicidade entre o dicromato de sódio e o molibdato de sódio. Nesse estudo de toxidez foram realizadas testes de inibição da acetilcholinesterase (enzima vital para o funcionamento dos organismos vivos e que pode ser inibida pelos metais) e avaliação de testes de toxicidade crônicos e severos em organismos 
aquáticos através de Daphnia Magna. Os resultados de ambos os testes mostraram que o molibdato apresenta índice de toxidez desprezível quando comparado com o índice de toxidez do dicromato.

O molibdato de sódio tem sido estudado como inibidor não só de aço carbono, mas também em outros substratos metálicos como aço inox, alumínio o zinco. Podemos citar os trabalhos de Alentejano e Aoki (2004) para aço inox 304 em água pura, Emeregül e Aksüt (2003) que estudaram a corrosão por pite do alumínio em presença dos ânions do molibdato e Wang et al. (2005) que estudaram o processo de formação do filme enriquecido com molibdato na superfície do zinco.

Alentejano e Aoki (2004) estudaram o comportamento dos ânions do molibdato e do tungstato como inibidores de corrosão para aço inox 304 em água pura. Os autores estudaram o efeito da temperatura e a presença de íons cloreto; tanto a adição dos ânions de molibdato quanto de tungstato melhoram a camada de passivação do aço inox 304, ou seja, na presença dos íons cloreto, o molibdato e o tungstato deslocam o potencial de pite para valores mais positivos, embora em altas temperaturas o efeito seja inferior. Os resultados obtidos indicam uma melhor eficiência do molibdato que do tungstato.

Emeregül e Aksül (2003) verificaram que os ânions molibdato na presença de íons cloreto retardam a iniciação de pites e melhoram o processo de passivação do alumínio, sendo que a resistência do filme aumenta com o aumento do $\mathrm{pH}$ do meio . Foram estudados em $\mathrm{pH} 10,7$, e 3.

Wang et. al (2005) estudaram o processo de formação e crescimento do filme na superfície do zinco na presença de molibdato usando a técnica de micro-balance por meio de cristal de quartzo. Por meio desta técnica, os autores estabeleceram uma equação que descreve o tempo de formação e crescimento do filme na superfície como função da variação da massa interfacial.

Segundo os autores a compreensão do processo e a velocidade de formação do filme são muito úteis para e controle e prevenção da corrosão localizada (pite) que é a quebra do filme passivo, além de permitir uma melhor compreensão do mecanismo de proteção. Os autores também ressaltam que os métodos eletroquímicos tradicionais, assim como as técnicas de análise de superfície como microscopia eletrônica de 
varredura ou espectroscopia de raios-X fornecem apenas informação qualitativa ou semi-quantitativa sobre a formação do filme.

A técnica de micro-balance de cristal de quartzo é baseada no efeito piezelétrico do cristal de quartzo e permite estudar a mudança da quantidade de massa na interface. Esta técnica é extremamente sensível pois trabalha medidas de massa na ordem de nano-gramas e tempos na ordem de mili-segundos. Alem de permitir estudar a formação do filme "in situ", também permite avaliar a dissolução espontânea do mesmo.

Outro aspecto observado na literatura é que os sais de molibdato são estudados e usados comercialmente em mistura de inibidores de corrosão, embora suas propriedades oxidantes sejam inferiores as do cromato. Termodinamicamente os cálculos mostram que o molibdato forma sais pouco solúveis em potenciais de dissolução do ferro em meio ácido $(\mathrm{pH}<6)$. As propriedades oxidantes de molibdato de sódio em relação ao ferro, não se manifestam em meios neutros, logo, para uma eficiente proteção da superfície do metal é requerida à presença de mais outro oxidante, e/ ou meios naturalmente aerados (CHEN ET AL.1991; KUZNETSOV, 2004).

Assim sendo, tem sido investigada uma variedade de misturas de sais de molibdato com outros compostos orgânicos ou não, com o objetivo de avaliar efeitos sinérgicos que melhorem sua eficiência como inibidor de corrosão para diferentes metais e meios (FARR E SAREMI, 1982; CHEN ET AL, 1991, SHIBLI E KUMARY, 2004).

Farr e Saremi (1982) verificaram que existe uma cooperação entre o molibdato e o ácido 1,1, hidroxietilideno difosfônico (HEDP) para alumínio em meio de águas de resfriamento industrial. Os estudos mostraram que as interações desses compostos promovem a proteção contra a corrosão em uma ampla faixa de potencial. Esta afirmação foi tirada dos resultados da curva de polarização anódica. O mesmo efeito foi identificado usando como substrato metálico o cobre imerso na mistura de molibdato e benzotriazol (BTAH).

Chen et al. (1991) estudaram os efeitos da misturas de molibdato com silicatos como inibidores de corrosão para aço carbono em meio de água destilada aerada e desaerada. Para este trabalho foram usadas as técnicas de medidas de curvas de 
polarização potenciodinâmicas, espectroscopia Auger e pelos raios-X. Os autores concluíram que os silicatos reagem preferencialmente com substrato de ferro limitando a incorporação composta de molibdato na superfície do metal.

Shibli e Kumary (2004) estudaram o sinergismo entre molibdato de sódio e o gluconato de sódio para aço carbono em meio de água destilada. Foi considerado o fato de que ambas as substâncias não são tóxicas, e que devido ao caráter relativamente pouco oxidante do molibdato, seria necessária a presença de outra substância para melhorar a eficiência como inibidor de corrosão, especialmente em meio neutro. Segundo Rajendran et al. (1998) apud Shibli e Kumary (2004), o gluconato de sódio têm mostrado efeitos sinérgicos quando combinado com outros inibidores que agem favorecendo a passivação.

As técnicas adotadas neste estudo foram: ensaios de perda de massa; curvas de polarização e espectroscopia de impedância eletroquímica. Misturando as substâncias em uma faixa de até 200 ppm para cada uma delas, os autores verificaram que a adição do gluconato de sódio permite diminuir a quantidade de molibdato necessária para obter uma mesma eficiência como inibidor de corrosão, e que quando a concentração de uma delas aumenta, a outra necessariamente precisa ser diminuída para obter o mesmo nível de eficiência.

Outro aspecto levantado pelos autores é que a literatura mostra que em estudos com altas concentrações de gluconato para tempo de imersão de até sete dias; os complexos gluconato-ferro formados na superfície são dissolvidos, diminuindo assim a eficiência da inibição da corrosão drasticamente, portanto eles sugerem que a formulação mais apropriada é 1:1. Foi concluído que a mistura comporta-se como inibidor anódico. Os diagramas de Nyquist revelaram que a resistência à transferência de carga aumenta quando comparada com cada substância estudada em separado.

Quanto ao mecanismo de inibição da corrosão pelo molibdato, Robertson (1950), no primeiro estudo comparativo entre os inibidores de corrosão: molibdatos; tungstatos; cromatos e nitritos, em meio de água destilada; estabeleceu que a inibição da corrosão em meio neutro esta mais associada à adsorção dos ânions na superfície do que apenas ao caráter oxidante dos ânions ou ainda a sua capacidade de formar 
precipitados insolúveis na superfície. Isto pode explicar a inibição da corrosão por ânions como molibdato e tungstato de sódio.

Em 1977, Vukasovich e Robaitaille propuseram que quando o ferro corroi, os ânions de molibdato competem com outros ânions presentes no meio para serem adsorvidos formando complexos não protetores de $\mathrm{Fe}^{+2}$. Numa segunda etapa, esses íons de $\mathrm{Fe}^{+2}$ podem ser oxidados a $\mathrm{Fe}^{+3}$ pelo oxigênio dissolvido no meio, transformando esses complexos de molibdato de $\mathrm{Fe}^{+2}$ em complexos de molibdato de $\mathrm{Fe}^{+3}$, os quais são insolúveis e, portanto protetores para a superfície do ferro em meio neutro. Além do complexo de molibdato de $\mathrm{Fe}^{+3}$, esse filme protetor pode conter outros complexos de $\mathrm{Fe}^{+3}$, provavelmente alguns óxidos de $\mathrm{Fe}^{+3}$, que incrementam as camadas protetoras.

Como o molibdato age adsorvendo-se na superfície, outros íons como os sulfatos e em maior intensidade os cloretos podem competir e interferir na formação do filme passivo; por isso, são requeridas maiores quantidades de molibdato para proteger o aço carbono em águas de resfriamento industrial do que em água destilada, fato que foi verificado por vários autores entre eles, El Sham (1996), e Vukasovich e Robitaille (1977).

Outro fator a ser levado em consideração é a necessidade de oxigênio ou outro oxidante presente no meio para que o molibdato possa agir como maior eficácia. Nos sistemas de resfriamento a aeração está garantida, mas deve ser limitada a presença de oxidantes fortes para evitar a corrosão localizada, sendo mais comum a corrosão por pite, como acontece na presença dos íons cloreto.

Já no ano de 2006, Saremi, Dehghanian e Sabet fizeram um estudo do molibdato de sódio em meio de águas de resfriamento industrial com e sem efeito hidrodinâmico, Foi usada a técnica de impedância eletroquímica e o tratamento dos dados foi feito com o auxilio da modelagem de circuitos elétricos equivalentes.

Sem efeito hidrodinâmico, identificaram e quantificaram os processos de adsorção, de transferência de carga e difusão de oxigênio para diferentes concentrações de molibdato de sódio. Quando o sistema foi submetido ao efeito hidrodinâmico, os valores de resistência à corrosão, medida como sendo a resistência à transferência de carga, resultaram maiores que sem efeito hidrodinâmico. 
Os autores associaram os melhores valores de resistência à transferência de carga, a formação de uma camada mais espessa e menos permeável; devida possivelmente aos processos de adsorção do molibdato e oxigênio na superfície do aço que foram favorecidos.

Em virtude dos resultados obtidos, Saremi, Dehghanian e Sabet (2006) propõem um modelo para o mecanismo da inibição da corrosão do ferro na presença de molibdato em meio de água de resfriamento industrial. O modelo do mecanismo é o apresentado na Figura 3. Este modelo considera a pouca homogeneidade do filme formado pelo molibdato, assim como o processo de formação das camadas protetoras na superfície. O molibdato pode em primeiro lugar, adsorver-se fisicamente na superfície do metal ou na camada irregular de hidróxido de ferro disponível na superfície, agindo como um mecanismo de fechamento dos poros dessa camada. $O$ molibdato também pode adsorver-se quimicamente e/ou cooperar na produção de compostos de molibdato de ferro que são protetores da superfície de ferro. Segundo eles, este modelo não explica ainda na sua totalidade o mecanismo da inibição da corrosão em meio neutro ou próximo da neutralidade.

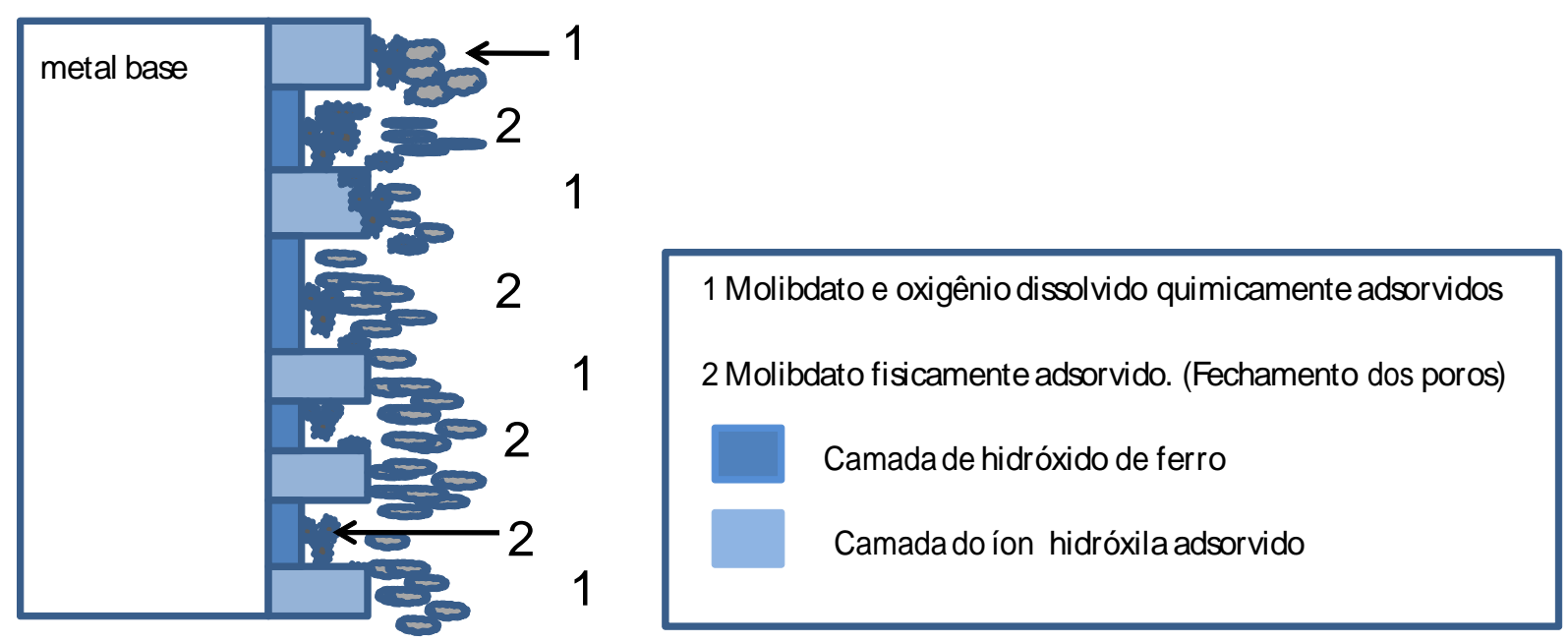

Figura 3 - Modelo do mecanismo de inibição da corrosão do ferro em presença do molibdato de sódio em meio de água de resfriamento industrial proposto por Saremi, Dehghanian e Sabet, (2006). 
Zhao e Zuo (2002) comparam o efeito da formação de pites e da propagação da corrosão por pite no aço carbono em solução de bicarbonato, que contém íons cloreto na presença de ânions de molibdato e de dicromato. Os autores empregaram medidas de potencial cíclico para medir o potencial de formação de pites e testes galvanostáticos para conhecer o mecanismo de propagação e a influencia do $\mathrm{pH}$ em soluções com a presença de $\mathrm{Fe}^{+2}$ para estimular a propagação de pites.

Segundo os resultados obtidos, tanto os ânions de molibdato como os de dicromato, nas condições estudadas, retardam a nucleação dos pites, resultado que foi observado através das medidas de potencial cíclico, onde foi verificado um aumento do potencial de formação de pites para concentração crescente da cada um dos ânions estudados.

No entanto, ao estudar propagação dos pites, o comportamento de ambos os ânions foi diferente; a presença dos ânions de molibdato na solução retarda a propagação dos pites, mas os de dicromato não conseguem inibir a propagação destes.

Os autores verificaram que a presença de ânions de molibdato e de íons de Fé ${ }^{+2}$ na solução preparada para estudar a propagação dos pites o pH aumenta. $\mathrm{O}$ aumento do $\mathrm{pH}$ pode ser explicado sabendo-se que os ânions de molibdato são estáveis em soluções alcalinas, $(\mathrm{pH}>6)$, mas não em soluções ácidas. Quando o valor do $\mathrm{pH}$ é menor do que 6 são favorecidas reações de hidrólise e de polimerização que conduzem a formação de composto de paramolibdatos. Estas reações precisam consumir o hidrogênio presente no meio, o qual, por sua vez aumenta o pH dentro dos pites propiciando assim a repassivação do filme na superfície do metal.

Na presença dos ânions de dicromato que é um oxidante forte, o pH da solução diminui como resultado das reações de oxido-redução entre o dicromato e os íons de ferro. Posteriormente reações de hidrólise do $\mathrm{Cr}^{+3}$ e do $\mathrm{Fe}^{+3}$ podem acontecer simultaneamente, as quais tem um papel importante na diminuição adicional do $\mathrm{pH}$ dentro dos pites, o qual resulta na geração de íons hidrogênio, presentes na solução que aceleram o seu crescimento. 


\subsubsection{Tungstato de sódio}

O tungstato de sódio é um sal solúvel em água e um oxidante moderado de estrutura química em forma de tetraedro como apresentada na Figura 4.

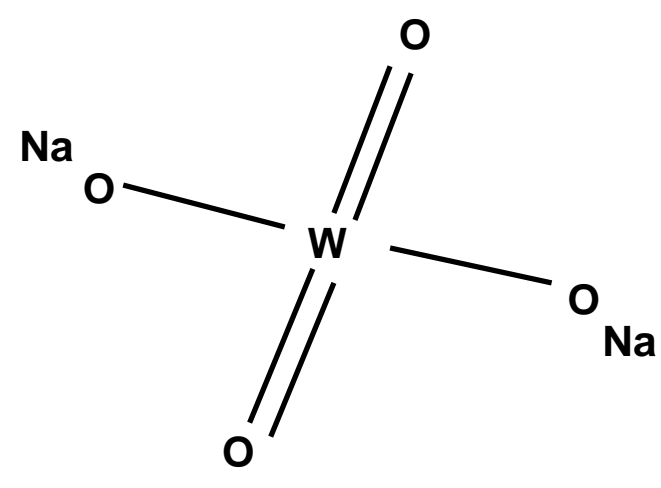

Figura 4 - Estrutura química do tungstato de sódio.

Freqüentemente encontra-se na forma hidratada de $\mathrm{Na}_{2} \mathrm{WO}_{4} 2 \mathrm{H}_{2} \mathrm{O}$. O tungstato de sódio age como inibidor anódico, e tem sido estudado com o objetivo de proteger substratos de ferro, zinco e alumínio em meios neutros, básicos e ácidos. É importante ressaltar que os estudos vêm sendo desenvolvidos com o objetivo de substituir o cromo. No entanto, devido ao custo ser relativamente alto, além do baixo poder oxidante não e recomendado ser usado isoladamente (SAJI E SHIBLI, 2002).

Em relação à toxidez do tungstato, é importante mencionar que originalmente foi considerado seguro tanto para os seres humanos como para os animais aquáticos ou terrestres. No entanto, em recente evento documentado pelo Koitsispyrus et al. 2006, o tungstênio e seus compostos estão entrando numa etapa de revisão quanto a seu verdadeiro impacto ambiental, pois existem lacunas no real conhecimento dos mecanismos de degradação envolvidos após o seu descarte no meio ambiente, aquático ou terrestre. 
Segundo os autores, um dos aspectos críticos desta situação é que não existe acordo quanto à quantidade segura a ser descartada nos mananciais, ou quanto deve ser admitido em águas para consumo humano, levando em consideração que o uso de tungstênio e seus compostos vêm aumentando aceleradamente nas últimas década. Assim, torna-se necessário um estudo mais profundo no que diz respeito aos impactos ambientais.

El Kader, El Warraki, El Aziz (1998a), estudaram exaustivamente o comportamento dos ânions de tungstato em meio neutro aereado, desaerado e saturado de oxigênio para aço carbono. As técnicas usadas neste estudo foram ensaios de perda de massa e medidas do potencial de corrosão. Os autores verificaram que é necessário à presença tanto de tungstato como de oxigênio para obter as camadas protetoras na superfície do metal.

Neste contexto, foi desenvolvido um estudo do tungstato com outras substâncias como inibidores de corrosão para avaliar os efeitos sinérgicos. Para tanto, El Kader, El Warraky, El Aziz (1998b) estudaram o efeito da adição de três substâncias orgânicas ao tungstato de sódio, isto é, o benzoato de sódio ( $\mathrm{NaBz})$, o gluconato de cálcio (CaG) e glicerofosfato de sódio ( $\mathrm{NaGp}$ ) em meio de água destilada contaminada com cloreto

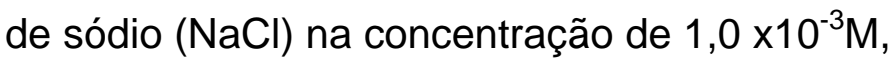

Os autores encontraram que em água destilada, as três substâncias são coinibidores de corrosão com o tungstato de sódio, mostrando sinergismo. No entanto, é necessária uma quantidade menor de tungstato de sódio na presença dos co-inibidores, para conseguir o mesmo efeito que aquele obtido com a mínima quantidade de tungstato quando estudado individualmente. Os resultados mais promissórios correspondem à mistura de tungstato de sódio e $\mathrm{CaG}$ em uma

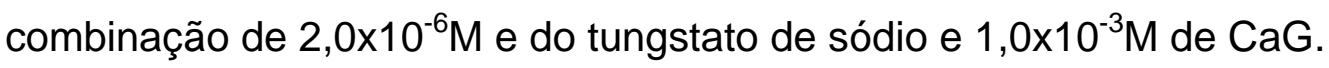

Entretanto, na presença da água destilada, contaminada com o íon cloreto $\left(\mathrm{Cl}^{-}\right)$ e na concentração de $1,0 \times 10^{-3} \mathrm{M}(58,5 \mathrm{ppm})$, com e sem a presença dos três coinibidores e do tungstato de sódio, visando atingir a mesma eficiência que em água destilada pura, os resultados indicaram que é necessária uma concentração maior tanto do tungstato quanto dos co-inibidores, em virtude do íon cloreto competir com os ânions dos inibidores através da adsorção nas regiões ativas da superfície do metal. 
Outros autores têm estudado misturas de tungstato e outros compostos na procura de efeitos sinérgicos para melhorar a eficiência na inibição da corrosão, especialmente em meio neutro e com possibilidades de aplicação em águas de resfriamento industrial. Dentre eles, Saji e Shibli (2002) estudaram a mistura de tungstato e silicato em água destilada, no ano 2005 a mistura de tungstato e iodato de potássio; e Jabeera, Shibli e Anirudhan (2005) investigaram o efeito do tartarato como co-inibidor da corrosão junto ao tungstato para aço carbono.

Shibli e Saji (2005) estudaram as propriedades da proteção contra a corrosão do tungstato de sódio e o iodato de potássio. Neste trabalho foi selecionado o iodato de potássio pela sua baixa toxidez e o caráter oxidante da molécula como co-inibidor do tungstato de sódio para a proteção do aço carbono em meio de água destilada.

$O$ estudo foi desenvolvido em condições naturalmente aeradas e desaeradas visando estudar a influência da presença do oxigênio e planejado para investigar o efeito oxidante do iodato de potássio no comportamento passivante do tungstato de sódio para o aço carbono.

As técnicas empregadas foram ensaios de perda de massa, medidas do potencial de corrosão e curvas de polarização. Por meio das curvas de polarização foi estimada a densidade de corrente de corrosão.

Inicialmente, foram realizados ensaios individuais de cada inibidor entre $100 \mathrm{e}$ 1000 ppm, concentrações que são equivalentes a $3,4 \times 10^{-4} \mathrm{M}$ e $3,4 \times 10^{-3} \mathrm{M}$ para o tungstato de sódio, e para o iodato de sódio são equivalentes a $4,7 \times 10^{-4} \mathrm{M}$ e $4,7 \times 10^{-3} \mathrm{M}$; também foram feitas combinações dessas substâncias na mesma faixa de concentração.

Os resultados obtidos neste estudo permitiram verificar que a presença do oxigênio favorece a formação do filme protetor com os produtos de corrosão, uma vez que, os valores de densidade de corrosão foram menores em meio aereado do que em meio desaerado.

Outro fato importante neste estudo está relacionado com a escolha da concentração ótima da mistura. Com o objetivo de escolher a concentração ótima dos inibidores, foi feita uma avaliação durante 100 dias. Os autores obtiveram os menores 
valores de densidade de corrente de corrosão para uma relação de concentração de tungstato e iodato de 2:1.

Em vista disto, foram feitas duas avaliações com o tempo de imersão por um período de 90 dias; na primeira foram usados $200 \mathrm{mg} / \mathrm{l} \mathrm{e} 100 \mathrm{mg} / /$ de tungstato e iodato respectivamente e na segunda avaliação foi usado de $600 \mathrm{mg} / \mathrm{l}$ e $300 \mathrm{mg} / \mathrm{l}$. Os autores concluíram que os melhores resultados foram obtidos com a relação de 200 $\mathrm{mg} / \mathrm{l}$ de tungstato e $100 \mathrm{mg} / \mathrm{l}$ de iodato de potássio. Devido a que o potencial de corrosão foi deslocado para valores mais positivos durante o período estudado.

Entretanto, Castinheiro (2008), em seu trabalho de mestrado investigou a eficiência dos oxiânions molibdato e tungstato na inibição da corrosão localizada em aços inox austeníticos (347 e 304L) em sistemas de água com alto grau de pureza na presença de íons cloreto. Os resultados mostraram que a adição dos inibidores molibdato e tungstato de sódio melhorou a qualidade da camada passiva, aumentando os valores de potencial de pite e do módulo de impedância. O melhores resultados para ambos os aços foram obtidos na presença de $1,0 \times 10^{-2} \mathrm{M}$ de inibidor tanto para o tungstato quanto para o molibdato, sendo este com eficiência levemente melhor.

\subsubsection{Copolímero de polioxiaquileno e polidimetilsiloxano, (CPPM).}

Os tensoativos ou surfatantes são moléculas que tem a capacidade de reduzir a tensão superficial. Estas moléculas contêm uma parte hidrofílica ou solúvel em água e outra lipofílica ou solúvel em óleo. Podem ser classificadas como aniônicas e não aniônicas dependendo da carga do grupo hidrofílico.

Os tensoativos a base de silano consistem basicamente em uma estrutura formada por polidimetilsiloxano, onde alguns dos grupos metil são substituídos por grupamentos orgânicos de caráter hidrofílico. A estrutura de silano pode ser considerada como uma pequena parte do composto, devido à alta concentração dos grupos metil presente. (KNAG, 2006; SOUZA, 2005) 
De forma geral, os silanos podem ser descritos por uma estrutura química do tipo $\mathrm{R}^{-}-\mathrm{Si}-(\mathrm{R})_{3}$, onde $\mathrm{R}^{\prime}$ é normalmente uma cadeia curta de carbono contendo a adição de alguma funcionalidade química, capaz de reagir com uma resina da película de pintura e $\mathrm{R}$ é o grupo final hidrolisável que pode ser um etóxi, metóxi ou cloro. $\mathrm{O}$ grupo $\mathrm{R}$ pode reagir com a água presente ou ser adsorvida na superfície do substrato.

Os compostos organo-silanos têm sido propostos como formadores de filmes para diferentes substratos tais como: alumínio e suas ligas; cobre; ferro e suas ligas e o zinco (SUBRAMANIAN; VAN OOIJ, 1998; SCHAFTINGHEN et al., 2004).

Mais recentemente, no laboratório de Corrosão e Eletroquímica do departamento de engenharia química da EPUSP, vêm sendo estudadas as propriedades de alguns derivados dos silanos como promotores de aderência e com o objetivo de promover maior resistência à corrosão em pinturas; por meio da formação de filmes ou revestimentos na supeirfie do metal. Estes compostos, derivados dos silanos, são investigados como alternativas de baixos índices de toxidez e, portanto, menos prejudiciais ao meio ambiente. Podem-se mencionar os trabalhos de Suegema e Aoki (2008), Palomino et al (2007) e o trabalho de doutorado de Oliveira (2006).,

Suegama e Aoki (2008) estudaram as propriedades do filme de bis-[ trimetoxisililpropil]amina (BTSPA) adicionado de ftalocianina de cobre (Ft-Cu) e depositado sobre aço carbono. Os autores verificaram que a incorporação de $\mathrm{Ft}$-Cu no filme de BTPSA mostrou um efeito positivo na proteção contra a corrosão principalmente para um filme formado com duas camadas.

Palomino et al (2008), investigaram o comportamento anti-corrosivo de camadas de silano bis-1,2-[trietoxisilil]etano (BTSE) modificadas com íons de Cerio e napno particulas de sílica aplicadas na liga de alumínio 2024-T3, em meio de $\mathrm{NaCl}$ 0,1 M. Os resultados mostraram que os aditivos introduzidos melhoraram as propriedades anticorrosivas das camadas do silano BTSE.

Oliveira (2005) estudou as propriedades resistivas dos filmes e a redução da velocidade de corrosão de chapas de aço carbono, similar as utilizadas na fabricação de veículos. Os filmes foram formados por compostos organo silanos funcionais e não funcionais em diferentes condiciones experimentais. 
O objetivo foi determinar o melhor desempenho de duplas camadas de organo silanos. O melhor resultado foi apresentado pela combinação de camadas de BTSE com bis-( $y$-trimetoxisililiporpilamina)amina (BTSPA). Esta combinação determinou uma redução da ordem de $95 \%$ na velocidade de corrosão em relação a uma chapa sem tratamento e uma perda de espessura da ordem de $70 \%$ menor que um corpo-de-prova revestido apenas com uma camada convencional de fosfatizaçao.

Entretanto, também no Laboratório de Corrosão e Eletroquímica do departamento de engenharia química da EPUSP, Souza (2005) testou três copolímeros surfactantes como inibidores de corrosão para aço carbono em meio de ácido clorídrico 2M. Neste estudo foram empregadas técnicas de ensaios gravimétricos, medidas de potencial de corrosão, curvas de polarização anódicas e catódicas e espectroscopia de impedância eletroquímica. Dentre os resultados mais importantes desse trabalho, o autor observou que os compostos estudados comportam-se como inibidores mistos para aço carbono nas condições estudadas.

\subsubsection{Ftalocianina de cobre, Ft-Cu}

As Ftalocianinas são compostos macro-cíclicos que alternam átomos de nitrogênio e carbono numa estrutura de anel aromático. Embora as ftalocianinas sejam substâncias obtidas através de síntese química, juntamente com as porfirinas e as polianilinas estão classificadas no grupo dos polímeros condutores pela semelhança na estrutura química. Os polímeros condutores são macromoléculas a partir dos quais se geram relativamente novos tipos de materiais orgânicos. Esses materiais possuem características que combinam a solubilidade e flexibilidade dos plásticos com as propriedades elétricas e ópticas dos metais e materiais semicondutores, além de possuir excelentes propriedades anticorrosivas (DOWDY et al. 1990).

Este tipo de material pode ser utilizado como componentes de aparelhos eletroquímicos e eletrônicos tais como fotocélulas e sensores químicos, aproveitando assim a forte interação com superfícies metálicas devido principalmente a interação 
dos orbitais $p$ da macromolécula com os orbitais "d" do metal (HIETTIARACHI ET AL; 1989).

Outra característica das ftalocianinas é que facilmente complexa com outros elementos como os metais e/ou grupos orgânicos coordenados no centro da molécula. (KUZNETSOV; 2004). As ftalocianinas metálicas, neste caso a Ft-Cu apresentam boas propriedades anticorrosivas que são atribuídas a sua estrutura química plana com sistema de elétrons $p$ livres, que se traduzem em boa condutividade eletrônica o qual permite alto nível de adsorção na superfície. (HETTIARACHCHI ET AL; 1989). Na Figura 5 é apresentada a estrutura química da Ftalocianina de cobre.

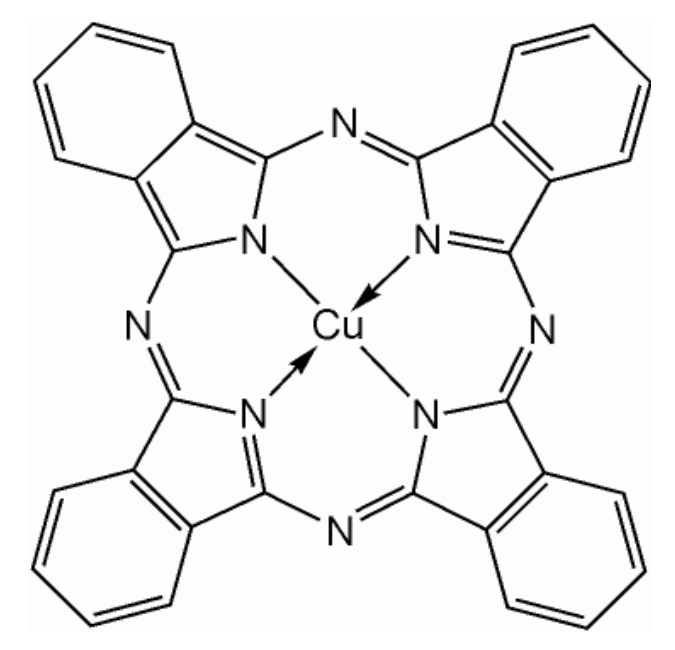

Figura 5 - Estrutura química da ftalocianina de cobre.

$\mathrm{Na}$ indústria, sua aplicação mais importante é como pigmentos para tintas, devido a sua cor azul característica, e sua pouca solubilidade em água, (máximo 1\%) o que faz com que seja ideal para pigmentos na área têxtil, papel etc. (ULLMANN'S ENCICLOPEDIA, 1992).

Embora a ftalocianina de cobre apresente baixos índices de toxidez e esteja liberada para diversos usos como corantes de suturas de polipropileno, lentes de contato e embalagem de alimentos, pela Federal Drug Administration (FDA) dos Estados Unidos de América; os possíveis riscos ao ambiente e para os seres vivos 
ainda não foram identificados e estudados em profundidade (ULLMANN'S ENCICLOPEDIA, 1992).

Devido a sua capacidade de adsorção e, portanto capacidade para a formação de filmes na superfície metálica, a sua potencialidade como inibidor de corrosão vem sendo estudada. No entanto, a literatura mostra que, as ftalocianinas solúveis em água são menos eficientes como inibidor de corrosão que as não solúveis, principalmente para aço em meio acido. Este fato foi verificado pelo Hettiarachi et al. (1989), que estudou um monômero de ftalocianina e poli-ftalocianinas de ferro e cobalto como inibidores de corrosão de aço em meio de $\mathrm{NaCl}$ (1\%), através da obtenção revestimentos para o aço.

Os autores estudaram ftalocianinas solúveis e insolúveis na água. Segundo eles, os resultados obtidos das curvas de polarização mostraram que a inibição da corrosão é maior com o uso da tetreamino-ftalocianina que é insolúvel em água, do que na tetrasulfo-ftalocianina solúvel em água. No entanto, os autores sugerem que a solubilidade não é o principal fator na habilidade das ftalocianinas para formar filmes estáveis nas superfícies dos metais.

Dos resultados obtidos com os monômeros da ftalocianina e as poli ftalocianinas, os autores encontraram os valores mais altos de eficiência para as poliftalocianinas de ferro no meio estudado, que foi $\mathrm{NaCl} 1 \%$. Os valores de eficiência foram calculados a partir das densidades de corrente de corrosão, e dos valores de resistência à transferência de carga obtidos dos diagramas de Nyquist. Os resultados foram consistentes por ambos os três métodos. As ftalocianinas apresentaram comportamento como inibidor misto, ou seja, tanto a curva catódica como a curva anódica se mostraram polarizadas em relação a curva obtida sem inibidor.

Nesta mesma linha de pesquisa, embora existam poucas referências no uso das ftalocianinas como inibidores de corrosão principalmente em meio neutro; é possível ressaltar o trabalho de Aoki, Guedes e Maranhão (2002), onde foram estudadas as propriedades da ftalocianina de cobre, numa faixa de concentração $5,0 \times 10^{-5} \mathrm{M}$ até $5,0 \times 10^{-4} \mathrm{M}$, como inibidor de corrosão para aço ASTM A606-4 em meio de ácido clorídrico (16\%). Os autores usaram as técnicas de medidas de perda de massa, 
medição do potencial de corrosão, curvas de polarização, e espectroscopia de impedância eletroquímica.

Os resultados obtidos neste estudo permitiram verificar que a ftalocianina de cobre age como inibidor misto no meio estudado, devido às poucas variações do potencial de corrosão com a presença da $\mathrm{Ft}$-Cu além das curvas de polarização anódicas e catódicas se mostrarem polarizadas. Os diagramas de Nyquist apresentaram arcos capacitivos crescentes com a concentração de Ft-Cu. Com os dados de perda de massa foi observado que a eficiência da ftalocianina de cobre aumenta com a concentração de inibidor, assim como, ter havido obediência dos resultados à isoterma de adsorção de Langmuir.

Mais recentemente, Zhao et. al. (2005) estudaram ftalocianinas metálicas e não metálicas; numa faixa de concentrações de $1,0 \times 10^{-5} \mathrm{M}$ até $1,0 \times 10^{-3} \mathrm{M}$ em meio de ácido clorídrico 1M. Neste trabalho foram estudadas: a ftalocianina de cobre (Ft-Cu); um derivado da ftalocianina de cobre que é o tretra-sulfo-ftalocianina de cobre (FtCu. $\left.\mathrm{S}_{4} \cdot \mathrm{Na}_{4}\right)$ e a ftalocianina não metálica $\left(\mathrm{H}_{2}-\mathrm{Ft}\right)$. Foram empregadas técnicas eletroquímicas de curvas de polarização potenciodinâmicas, e espectroscopia de impedância eletroquímica, e caracterização de superfície mediante microscopia eletrônica de varredura e difração de raios-X.

Baseados nas medidas eletroquímicas e de caracterização da superfície, os autores observaram que a eficiência da inibição diminui na seguinte ordem FtCu. $\mathrm{S}_{4} \cdot \mathrm{Na}_{4}>\mathrm{Ft}-\mathrm{Cu}>\mathrm{H}_{2} \mathrm{Ft}$. Por meio das curvas de polarização identificaram que os compostos estudados agem como inibidores mistos no meio de $\mathrm{HCl} 1 \mathrm{M}$. Nos diagramas de Nyquist foram observados arcos capacitivos crescentes com a concentração do inibidor para todos os casos estudados, condizente com a formação de um filme de adsorção na superfície do metal.

Outras ftalocianinas metálicas têm sido estudadas como inibidores de corrosão para o aço carbono. Hiram et al. (2005) estudaram a inibição da corrosão da vários compostos de ftalocianina de estanho em meio de $\mathrm{NaCl}$. Essas ftalocianinas foram obtidas usando diferentes métodos de sínteses no laboratório, (térmica e microonda), procurando aperfeiçoar mediante a síntese das macromoléculas, o isomerismo das posições cis-trans e o comprimento da cadeia de carbono. Todos esses fatores 
influenciam nas propriedades de adsorção, além do que a posição cis da macromolécula de ftalocianina confere a posição dos elétrons $p$ melhor propriedades de adsorção, pois os elétrons estão numa posição côncava e, portanto mais facilmente expostos para adsorver-se.

\subsection{Torres de resfriamento industrial}

As torres de resfriamento são equipamentos utilizados para o resfriamento de água industrial, como aquela proveniente de condensadores de usinas de geração de energia, instalações de refrigeração, trocadores de calor, etc.

Basicamente as torres de resfriamento visam transferir ao ar o calor residual dos processos industriais, cujo objetivo é evitar em primeiro lugar, a poluição térmica dos cursos de água e em segundo lugar possibilitar a reutilização da água em processo fechado, a qual pode ser tratada a um custo relativamente menor, tornando o processo economicamente mais atrativo.

Para tanto, a água passa pela torre de resfriamento e retorna ao circuito de resfriamento do processo. Este sistema de torres que é o mais comumente usado é chamado de torre de resfriamento evaporativo.

Portanto, em uma torre de resfriamento, a principal contribuição é a evaporação de parte dessa água que re-circula na torre. A evaporação da água, que se considera como transferência da massa da fase liquida - água - para a fase gasosa - ar causa o abaixamento da temperatura da água que escoa ao longo da torre de resfriamento.

Logo, uma torre de resfriamento de água é um equipamento de operação contínua que tem como função transferir massa e calor para resfriar a água. Como essas transferências se processam através da superfície, conclui-se que em uma torre de resfriamento é necessário maximizar a superfície de água exposta ao ar.

A água aquecida proveniente do processo é gotejada na parte superior da torre e desce lentamente através dos leitos de "enchimentos" que podem ser de diferentes tipos, em contracorrente com $\mathrm{o}$ ar frio (normalmente à temperatura ambiente). No 
contato direto das correntes de água e ar ocorre a evaporação da água, principal fenômeno que produz seu resfriamento. (REIS; SILVERIA; DOMENI, 2007).

Uma torre de resfriamento é essencialmente uma coluna de transferência de massa e calor, projetada de forma a permitir uma grande área de contato entre as duas correntes. Isto é obtido mediante a aspersão da água líquida na parte superior e do "enchimento" da torre, isto é, bandejas perfuradas, colméias de material plástico ou metálico, etc, que aumenta o tempo de permanência da água no seu interior e a superfície de contato água - ar. O esquema básico de funcionamento é apresentado na Figura 6 (KREITH; 1977).

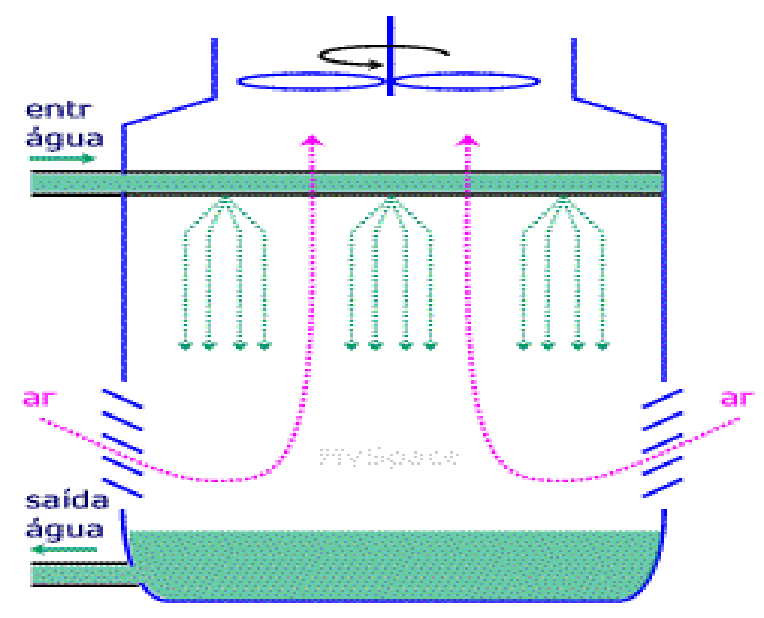

Figura 6- Esquema básico de funcionamento de uma torre de resfriamento industrial.

Para entender claramente como funciona uma torre de resfriamento industrial, é fundamental entender o conceito das temperaturas de bulbo seco e bulbo úmido do ar.

A temperatura de bulbo seco do ar é a própria temperatura do gás (o bulbo do termômetro usado na medição está seco). A temperatura de bulbo úmido é medida com o bulbo do termômetro envolto com uma gaze com água com cuidados específicos.

Por definição, a temperatura de bulbo úmido é aquela atingida em regime permanente, (não de equilíbrio termodinâmico), por uma pequena porção de água, em contacto com uma corrente continua de ar, em condições adiabáticas (só há troca térmica entre o ar e a massa de água), desprezando-se os efeitos da radiação térmica nessa troca. 
A temperatura de bulbo úmido é menor ou no máximo igual em relação à temperatura de bulbo seco. Isso ocorre porque, exposta a uma corrente de ar não saturado (umidade relativa menor do que 100\%), parte da água presente na gaze evapora e com isso, a temperatura abaixa. Assim se explica o fenômeno de resfriamento devido à evaporação que acontece nas torres de resfriamento industrial.

O projeto de uma torre de resfriamento tem como ponto de partida os valores da vazão e da temperatura da água a ser resfriada. Logo, uma vez especificada a geometria da torre em termos de suas dimensões e tipo de enchimento, o funcionamento adequado dependerá do controle da vazão de ar. Em termos de insumo energético, a torre demandará potência para fazer escoar o ar, sendo que o enchimento da torre é um elemento que gera a perda de carga; assim, a água deverá ser bombeada até o ponto de aspersão.

A eficiência de um sistema de água de resfriamento é em muitos casos, um dos fatores chave para garantir a desempenho operacional de uma unidade industrial, daí a importância dos tratamentos das águas dos sistemas de resfriamento industrial.

Em geral, para esses sistemas procura-se reduzir os custos de manutenção, aumentar a segurança operacional, otimizar a troca térmica nos diversos equipamentos, maximizar os ciclos de concentração (para torres de resfriamento), o tempo de operação contínua do sistema, a vida útil dos equipamentos e a tubulação; assim como, minimizar o consumo de água, a geração de efluente, e a utilização de produtos químicos, de modo a não agredir o meio ambiente. (ROSE CORROSION INHIBITION SERVICES LIMITED, 2003).

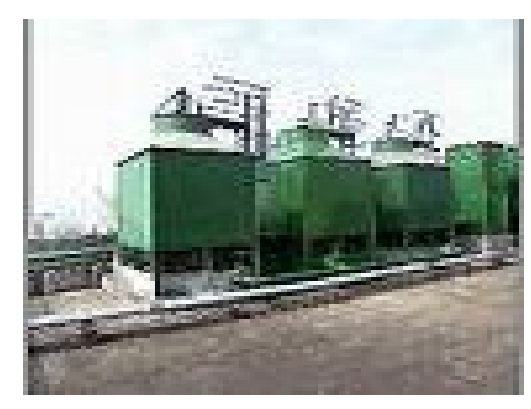

Figura 7- Torres de resfriamento de uma planta química. 
Basicamente, os problemas possíveis de ocorrer em um sistema de resfriamento podem ser classificados em três tipos:

(1) A corrosão que está relacionada com o desgaste ou deterioração dos materiais metálicos e suas ligas presentes no sistema de resfriamento.

(2) As incrustações que tem a ver com a formação de depósitos nas superfícies de troca térmica do sistema.

(3) A falta de turbidez que é devida à ação de microorganismos presentes na água de resfriamento. Por isso, a água dos sistemas de resfriamentos industrial geralmente é tratada para evitar esses efeitos indesejáveis.

Diferentes estudos têm sido realizados com misturas de substâncias polifuncionais para diminuir ou ate cessar esses efeitos mencionados anteriormente. Neste contexto, podemos citar Ochoa et al. (2001), que estudaram a inibição da corrosão do aço carbono contendo $200 \mathrm{mg}^{-1}{ }^{-1}$ de cloreto de sódio, $(\mathrm{NaCl})$, por um inibidor de multicomponente, formado por uma amina graxa $(A G)$ e um sal de ácido fosfino-carboxílico (AFC). Esta mistura de substâncias orgânicas tem como finalidade tanto a prevenção da corrosão quanto a formação de depósitos em sistemas de resfriamento industrial.

Os autores usaram as técnicas: potencial de corrosão; impedância eletroquímica e curva de polarização, além de técnicas de caracterização de superfície por espectroscopia de fotoelétron de raios-X. A principal vantagem desta mistura é que não é tóxica e é biodegradável. Dos resultados do estudo os autores concluíram que o AFC age como inibidor anódico, e o AG age como inibidor misto. Na região anódica da curva de polarização para o AFC, foi observada corrosão localizada devido à presença de íons cloreto. Esta corrosão foi identificada como um aumento abrupto da densidade de corrente de corrosão, embora a curva de polarização também apresentasse uma região de passivação identificada com um "plateou", para todas as concentrações de AFC estudadas. 
Posteriormente os autores concluíram que a composição da mistura das substâncias que resultou com maior eficiência foi $200 \mathrm{mg} / \mathrm{l}$ de AFC e $50 \mathrm{mg} / \mathrm{l}$ da AG, quando comparada com as eficiências obtidas com as substâncias estudadas individualmente. A eficiência na proteção contra a corrosão foi estimada a partir dos valores da resistência a transferência de carga obtida dos diagramas de impedância eletroquímica.

Para avaliar a composição do filme formado na superfície do metal pela mistura dos inibidores, os autores usaram a técnica de espectroscopia de fotoelétrons de raios-X. O filme estava composto por óxidos e hidróxidos de ferro que incorporam a mistura dos AFC e AG na sua estrutura, devido à adsorção cooperativa dos compostos na camada de óxidos e hidróxidos de ferro.

Conhecido que dois dos problemas mais comuns nas torres de resfriamento industrial são a formação de depósitos de carbonato de cálcio e a corrosão; MarínCruz et.al. (2004) usando técnicas de impedância eletroquímica e caracterização da superfície por microscopia eletrônica de varredura, estudaram a evolução com o tempo da camada de produtos de corrosão formada no aço carbono, em meio de águas de resfriamento industrial que foram preparadas em laboratório.

Os inibidores usados foram ácido 1,1 hidroxietilideno difosfônico (HEDP), que age principalmente para evitar a formação de depósitos de carbonato de cálcio e o ácido hidroxi-fosfôno-acético (HPA), o qual é usado como inibidor de corrosão do aço carbono. Os espectros de impedância foram obtidos a cada duas horas por 24 horas em presença e ausência dos inibidores. Os autores verificaram que após de 5 horas de imersão os espetros de impedância eletroquímica permaneciam praticamente estáveis.

Os resultados mostraram efeitos sinérgicos na mistura estudada quando comparada com os resultados individuais de cada substância. Os valores de resistência à corrosão (medidos através de resistência à transferência de carga) resultaram em uma ordem de magnitude superior aquela obtida sem inibidor, e duas vezes maior que o obtido com HEDP.

Com a análise de caracterização da superfície, foi identificado às modificações que acontecem na camada de produtos de corrosão e depósitos na superfície do metal pela presença do HEDP e HPA. O mecanismo proposto pelos autores indica que o 
inibidor de corrosão HPA promove a formação de uma camada de produtos, principalmente formada pela complexação da molécula do inibidor com o cálcio; o HEDP regula a quantidade de depósitos do complexo HPA-cálcio na superfície. Dessa forma é confirmado que ambos inibidores têm um comportamento sinérgico de acordo com o observado nos espectros de impedância eletroquímica.

Com a finalidade de minimizar os problemas de corrosão, a formação de depósitos e a presença de microorganismos, Dong-Jin, Seung-Jae e Jun-Gu (2001) desenvolveram um mistura ambientalmente correta para águas sintéticas de sistemas de resfriamento industrial. A formulação foi de uma mistura de quatro substâncias: o ácido cítrico, o ácido 1,1 hidroxietilideno difosfônico (HEDP); um copolímero de acrilato peso molecular aproximado de $3980 \mathrm{~g} / \mathrm{mol}$ e o isothiazolone numa relação 2:4:4:1. O ácido cítrico funciona como inibidor da corrosão e estabilizante para formulação, o HEDP funciona como inibidor da formação de depósitos e da corrosão, o copolímero de acrilato também age para evitar a formação de depósitos, e finalmente o isothiazolone é usado como biocida para vários microrganismos. Foram conduzidos ensaios de perda de massa de cinco dias de imersão, ensaios eletroquímicos, ensaios específicos para determinar tanto a formação de depósitos como a presença de microrganismos. Além disso, foram realizadas análises de superfície usando microscopia ótica, e microscopia eletrônica de varredura e energia dispersiva de raios$\mathrm{X}$.

Das diferenças observadas nas imagens da superfície, obtidas das micrografias das amostras com e sem inibidor, os autores sugeriram que a inibição acontece devido à presença de um filme fino e estável, que é formado através da adsorção das substâncias orgânicas na superfície do metal. Análises detalhadas de energia dispersiva de raios $X$ determinaram a presença de ferro, cálcio e fósforo, os quais são responsáveis pela formação de compostos de fosfato de cálcio e oxido de ferro. $\mathrm{O}$ fosfato de cálcio funciona como uma barreira para prevenir a redução de oxigênio. $O$ ácido cítrico e os fosfonatos contribuíram com o bicarbonato, de modo a agir como inibidor de corrosão, permitindo a formação de magnetita-hematita $\left(\mathrm{Fe}_{3} \mathrm{O}_{4}-\right.$ y $\left.\mathrm{Fe}_{2} \mathrm{O}_{3}\right)$.

Dos ensaios eletroquímicos, os autores observaram que as curvas de polarização anódicas tornaram-se mais polarizadas com a presença da mistura. $\mathrm{Na}$ 
região catódica, foi observada uma diminuição da corrente limite para a redução de oxigênio, mostrando assim a inibição da reação catódica; mas como o potencial de corrosão resultou mais positivo, em aproximadamente $300 \mathrm{mV}$ no sentido anódico, comparado com o potencial de corrosão na ausência do inibidor, logo esta mistura tende mais a um comportamento como inibidor anódico do que misto.

Os resultados de eficiência obtidos pelos ensaios de perda de massa e a partir das densidades de corrente de corrosão resultantes da extrapolação da reta catódica de Tafel até o potencial de corrosão resultaram em eficiências em torno de 95,6\%. 


\section{MATERIAIS E MÉTODOS}

Neste capítulo são apresentados os materiais utilizados, as técnicas e os procedimentos experimentais adotados neste trabalho.

\subsection{Materiais}

Neste estudo foi empregado aço carbono ABNT 1005. A Tabela 1 apresenta a composição química do aço.

Tabela 1 - Composição do aço carbono ABNT 1005.

\begin{tabular}{llllllll}
\hline $\mathbf{C ~ ( \% )}$ & Mn (\%) & Al (\%) & $\mathbf{P ~ ( \% ) ~}$ & $\mathbf{S ~ ( \% )}$ & $\mathbf{C r}(\%)$ & $\mathbf{N i}(\%)$ & $\mathbf{F e}(\%)$ \\
\hline 0,05 & 0,3 & 0,05 & 0,016 & 0,011 & 0,010 & 0,002 & 99,42 \\
\hline
\end{tabular}

O meio corrosivo utilizado para este estudo foi uma água que alimenta o sistema de resfriamento da empresa Oxiteno. $\mathrm{O} \mathrm{pH}$ e a condutividade da água usada foram em torno de 6,9 e $1100 \mu \mathrm{S} . \mathrm{cm}^{-1}$ respectivamente. A composição química da água foi fornecida pela empresa Oxiteno e é apresentada na Tabela 2.

As substâncias testadas como inibidores de corrosão foram:

- Molibdato de sódio, $\mathrm{Na}_{2} \mathrm{MoO}_{4} 2 \mathrm{H}_{2} \mathrm{O}, \mathrm{PA}$

- Tungstato de sódio, $\mathrm{Na}_{2} \mathrm{WO}_{4} 2 \mathrm{H}_{2} \mathrm{O}, \mathrm{PA}$

- Ftalocianina de Cobre, (Ft-Cu), PA

- Copolímero de polioxialquileno e polidimetilsiloxano modificados (CPPM), com peso molecular de $17.000 \mathrm{~g} \cdot \mathrm{mol}^{-1}$, de nome comercial surfactante Silwet L-7220, fornecido pela empresa Momentive Performance Materials. 
Tabela 2 - Composição química em ppm da água do sistema de resfriamento usado neste trabalho.

\begin{tabular}{lc}
\hline Íon & Concentração / ppm \\
\hline $\mathrm{Ca}^{+2}$ & 125 \\
$\mathrm{Fe}^{+2}$ & 1 \\
$\mathrm{Si}$ & 11 \\
Cloro total & 3 \\
Cloro livre & 1 \\
$\mathrm{Cl}^{-}$ & 326 \\
Dureza total $\left(\mathrm{Ca}^{+2}, \mathrm{Mg}^{+2}\right)$ & 175 \\
Sólidos suspensos & 52 \\
Alcalinidade $(\mathrm{KOH})$ & 90 \\
\hline
\end{tabular}

A avaliação individual das substâncias testadas como inibidores de corrosão foi realizada nas concentrações de: $1,0 \times 10^{-5} \mathrm{M}, 1,0 \times 10^{-4} \mathrm{M}$ e $1,0 \times 10^{-3} \mathrm{M}$, e comparadas com meio sem a presença das mesmas.

As formulações para as misturas das substâncias utilizadas nas etapas seguintes do trabalho são apresentadas nas seções 3.2.7 e 3.2.8 deste capitulo, que correspondem ao planejamento fatorial completo e ao planejamento fatorial composto respectivamente.

\subsection{Metodologia}

\subsubsection{Preparação dos corpos-de-prova}

Para realizar as medidas eletroquímicas as amostras de aço ABNT 1005 foram cortadas em forma de disco e tratadas superficialmente com lixas d'água de grana 
320, 400, e 600, lavadas com água destilada, álcool e acetona e posteriormente secas com corrente ar quente. Os corpos-de-prova assim tratados foram usados como eletrodo de trabalho, cuja área exposta foi de $1 \mathrm{~cm}^{2}$.

\subsubsection{Técnicas empregadas}

As técnicas empregadas para este estudo foram:

- Medidas de potencial de corrosão

- Espectroscopia de impedância eletroquímica

- Curvas de polarização potenciodinâmicas anódicas e catódicas

- Microscopia eletrônica de varredura

Todos os ensaios eletroquímicos foram realizados em célula de três eletrodos de capacidade para $500 \mathrm{ml}$; como eletrodo de referência foi usado prata/cloreto de prata saturado $\left(\mathrm{Ag} / \mathrm{AgCl}_{\text {sat }}\right)$ e como contra-eletrodo uma folha de platina com área plana exposta à solução de $15 \mathrm{~cm}^{2}$. O eletrodo de trabalho, aço carbono ABNT 1005, foi montado em um porta-eletrodo constituído de polivinilidenodifluorado com contato interno de aço inoxidável.

Todos os experimentos foram realizados com 0 uso de um Potenciostato/Galvanostato EG\&G Princenton Applied Reserach (PAR modelo 273) acoplado ao analisador de freqüências SOLARTON 1255, ambos controlados por um micro-computador.

Os ensaios foram realizados em meio da água de resfriamento industrial na ausência e na presença das diferentes substâncias estudadas como inibidores de corrosão e conduzidos na temperatura ambiente, meio não agitado e naturalmente aerado. 


\subsubsection{Potencial de Corrosão}

Para medir o potencial de corrosão, os corpos-de-prova foram imersos no meio corrosivo, onde o sistema evoluiu espontaneamente durante três horas, tempo este que foi previamente avaliado como sendo o tempo suficiente para estabilização do potencial de corrosão do aço carbono em meio da água usada neste trabalho.

\subsubsection{Ensaios por espectroscopia de impedância eletroquímica (EIE)}

Após o monitoramento do potencial de corrosão, seguiram os ensaios de espectroscopia de impedância eletroquímica, EIE.

Os diagramas de impedância foram obtidos na faixa de freqüência entre $50 \mathrm{kHz}$ a $0,005 \mathrm{~Hz}$ com varredura logarítmica, sendo realizadas 10 leituras por década de freqüência com perturbação em potencial de $10 \mathrm{mV}$ em relação ao potencial de corrosão.

Para controle dos equipamentos e aquisição dos dados utilizou-se o software "Zplot", e a análise quantitativa dos ensaios de EIE for realizada usando circuitos equivalentes ajustados pelo software Zview. Este software possui um compilador (Fitting) que simula circuitos equivalentes, fornecendo um diagrama para ser comparado com aquele obtido experimentalmente. O programa fornece também os valores de cada um dos componentes do circuito, o desvio em relação ao digrama obtido experimentalmente, assim como o erro associado à estimativa de cada elemento do circuito. 


\subsubsection{Curvas de polarização potenciodinâmicas anódicas e catódicas.}

Ao caracterizar as diferentes substâncias estudadas como inibidor de corrosão, foram levantadas, imediatamente após os ensaios de impedância eletroquímica, as curvas de polarização. A faixa de potencial utilizada foi de $-0,1 \mathrm{~V} a+0,1 \mathrm{~V}$, em relação ao potencial de corrosão e a velocidade de varredura de $1,0 \mathrm{mV} / \mathrm{s}$.

\subsubsection{Microscopia eletrônica de varredura, (MEV)}

As análises morfológicas das amostras de aço com e sem a presença de inibidores de corrosão foram realizadas por MEV. As caracterizações por MEV foram realizadas no Laboratório de Microscopia Eletrônica de Varredura e Micro-análise do Departamento de Engenharia Metalúrgica e de Materiais da Escola Politécnica da USP. O microscópio eletrônico de varredura utilizado foi um Philips equipado com analisador de energia dispersiva, cujas imagens foram obtidas por elétrons retro-espalhados e por elétrons secundários, com energia do feixe de $20 \mathrm{keV}$.

\subsubsection{Planejamento fatorial completo}

Com o objetivo de identificar os possíveis efeitos sinérgicos entre as substâncias avaliadas como inibidores de corrosão, foi usado um planejamento fatorial completo.

As características do planejamento fatorial completo utilizado neste trabalho foram: 
- Quatro fatores ou variáveis de entrada, onde cada fator corresponde a cada uma das substâncias estudadas como inibidores de corrosão.

- Dois níveis, que correspondem à concentração mínima e máxima para cada fator: 0 e $1,0 \times 10^{-3} \mathrm{M}$. A concentração de $1,0 \times 10^{-3} \mathrm{M}$ corresponde aquela em que se obteve a máxima eficiência das substâncias estudadas individualmente.

- $A$ variável de resposta foi à resistência à transferência de carga $\left(R_{t c}\right)$

Esta combinação, de quatro fatores e dois níveis, $2^{4}$, resultou em um conjunto de 16 ensaios, que representa a formulação da mistura das substâncias a serem estudadas.

A análise estatística dos resultados experimentais foi feita com o auxílio do software Minitab. Esta análise estatística permite identificar os principais efeitos e interações das variáveis de entrada, sobre a variável de resposta.

A Tabela 3 mostra as equivalências entre as concentrações das variáveis de entrada em forma codificada e em forma real. $O$ uso dos valores codificados das variáveis de entrada facilita a entrada de dados ao software Minitab, e a posterior interpretação dos resultados.

Tabela 3 - Equivalência entre o valor codificado e o valor real das variáveis de entrada do planejamento fatorial completo.

\begin{tabular}{c|c}
\hline Variável codificada & Variável real / M \\
\hline 1 & 0 \\
+1 & $1,0 \times 10^{-3}$ \\
\hline
\end{tabular}

A formulação da mistura das substâncias a serem estudadas é mostrada na Tabela 4; onde a matriz de ensaios obtida é apresentada em ordem padrão e de execução, e as variáveis de entrada codificadas com seus correspondentes valores reais. Os ensaios foram realizados em ordem de execução aleatórios para garantir a independência estatística, ou seja, a ordem da realização não influencie nos resultados. 
Tabela 4 - Matriz de ensaios do projeto fatorial completo em ordem padrão.

\begin{tabular}{|c|c|c|c|c|c|c|c|c|c|}
\hline \multicolumn{2}{|c|}{ Ordem } & \multicolumn{4}{|c|}{$\begin{array}{c}\text { Variáveis de entrada } \\
\text { codificadas }\end{array}$} & \multicolumn{4}{|c|}{ Variáveis de entrada com valor real / $\mathrm{N}$} \\
\hline Padrãc & Exec. & $\mathrm{Na}_{2} \mathrm{MoO}_{4}$ & CPPM & $\mathrm{Na}_{2} \mathrm{WO}_{4}$ & Ft-Cu & $\mathrm{Na}_{2} \mathrm{MoO}_{4}$ & CPPM & $\mathrm{Na}_{2} \mathrm{WO}_{4}$ & $\mathrm{Ft}-\mathrm{Cu}$ \\
\hline 1 & 12 & -1 & -1 & -1 & -1 & 0 & 0 & 0 & 0 \\
\hline 2 & 9 & 1 & -1 & -1 & -1 & $1,0 \times 10^{-3}$ & 0 & 0 & 0 \\
\hline 3 & 3 & -1 & 1 & -1 & -1 & 0 & $1,0 \times 10^{-3}$ & 0 & 0 \\
\hline 4 & 16 & 1 & 1 & -1 & -1 & $1,0 \times 10^{-3}$ & $1,0 \times 10^{-3}$ & 0 & 0 \\
\hline 5 & 13 & -1 & -1 & 1 & -1 & 0 & 0 & $1.0 \times 10^{-3}$ & 0 \\
\hline 6 & 2 & 1 & -1 & 1 & -1 & $1,0 \times 10^{-3}$ & 0 & $1.0 \times 10^{-3}$ & 0 \\
\hline 7 & 4 & -1 & 1 & 1 & -1 & 0 & $1,0 \times 10^{-3}$ & $1.0 \times 10^{-3}$ & 0 \\
\hline 8 & 8 & 1 & 1 & 1 & -1 & $1,0 \times 10^{-3}$ & $1,0 \times 10^{-3}$ & $1,0 \times 10^{-3}$ & 0 \\
\hline 9 & 6 & -1 & -1 & -1 & 1 & 0 & 0 & 0 & $1,0 \times 10^{-3}$ \\
\hline 10 & 7 & 1 & -1 & -1 & 1 & $1,0 \times 10^{-3}$ & 0 & 0 & $1,0 \times 10^{-3}$ \\
\hline 11 & 1 & -1 & 1 & -1 & 1 & 0 & $1,0 \times 10^{-3}$ & 0 & $1,0 \times 10^{-3}$ \\
\hline 12 & 11 & 1 & 1 & -1 & 1 & $1,0 \times 10^{-3}$ & $1,0 \times 10^{-3}$ & 0 & $1,0 \times 10^{-3}$ \\
\hline 13 & 5 & -1 & -1 & 1 & 1 & 0 & 0 & $1,0 \times 10^{-3}$ & $1,0 \times 10^{-3}$ \\
\hline 14 & 10 & 1 & -1 & 1 & 1 & $1,0 \times 10^{-3}$ & 0 & $1,0 \times 10^{-3}$ & $1,0 \times 10^{-3}$ \\
\hline 15 & 14 & -1 & 1 & 1 & 1 & 0 & $1,0 \times 10^{-3}$ & $1,0 \times 10^{-3}$ & $1,0 \times 10^{-3}$ \\
\hline 16 & 15 & 1 & 1 & 1 & 1 & $1,0 \times 10^{-3}$ & $1,0 \times 10^{-3}$ & $1,0 \times 10^{-3}$ & $1,0 \times 10^{-3}$ \\
\hline
\end{tabular}

Foram realizadas medidas experimentais de potenciais de corrosão antes e depois das medidas de impedância eletroquímica, visando verificar o estado estacionário do sistema.

É importante salientar que no caso deste estudo foram considerados efeitos sinérgicos, os efeitos individuais e as interações positivas entre as variáveis de entrada; pois eles produzem aumentos na variável de resposta selecionada, que foi a resistência à transferência de carga, $R_{\mathrm{tc}}$, os quais são indicativos de maior proteção contra a corrosão. 


\subsubsection{Planejamento fatorial composto}

Uma vez identificadas as substâncias com efeitos sinérgicos, elas foram estudadas mais detalhadamente através de um planejamento fatorial composto. As características deste projeto permitiram ampliar a faixa de concentração dos inibidores a serem estudadas.

Para este planejamento as variáveis de entrada foram as concentrações do molibdato e do tungstato de sódio, e a variável de saída foi à resistência a transferência de carga, $R_{\mathrm{tc}}$ e o módulo de impedância a $100 \mathrm{mHz}$

E assim, usando o software Statistica foi possível conhecer a superfície de resposta que relaciona as variáveis de entrada com a variável de saída. Posteriormente foi identificado o "ponto de ótimo", aquele onde a variável de saída da superfície de resposta tem seu maior valor, isto é, onde a resistência á transferência de carga e / ou módulo de impedância a $100 \mathrm{mHz}$ atingem os valores máximos para uma combinação das substâncias identificadas com efeitos sinérgicos.

$\mathrm{Na}$ Figura 8 é ilustrada a geração do planejamento fatorial composto de 14 ensaios; onde se observa claramente que estes 14 ensaios correspondem às pontas da estrela formada pelo quadrado de lado dois assinalado arbitrariamente para facilitar a codificação posterior, e logo rotacionado em $45^{\circ}$ graus, mais o ponto central, que se deve repetir seis vezes para garantir o cálculo do erro experimental.

$\mathrm{Na}$ Tabela 5 é apresentada a equivalência entre os valores da variável de entrada em forma codificada, e seus correspondentes valores reais. Estas equivalências foram obtidas assumindo que o ponto central do planejamento fatorial composto corresponde à concentração $3,0 \times 10^{-3} \mathrm{M}$ e fazendo interpolação linear por meio da seguinte relação:

$$
\mathrm{C}_{\mathrm{c}}=0,5 \times 10^{3} \mathrm{C}_{\mathrm{r}}-1,5
$$

Onde $\mathrm{C}_{c}$ é o valor codificado da concentração real, $C_{r}$, expressada em concentração molar. 


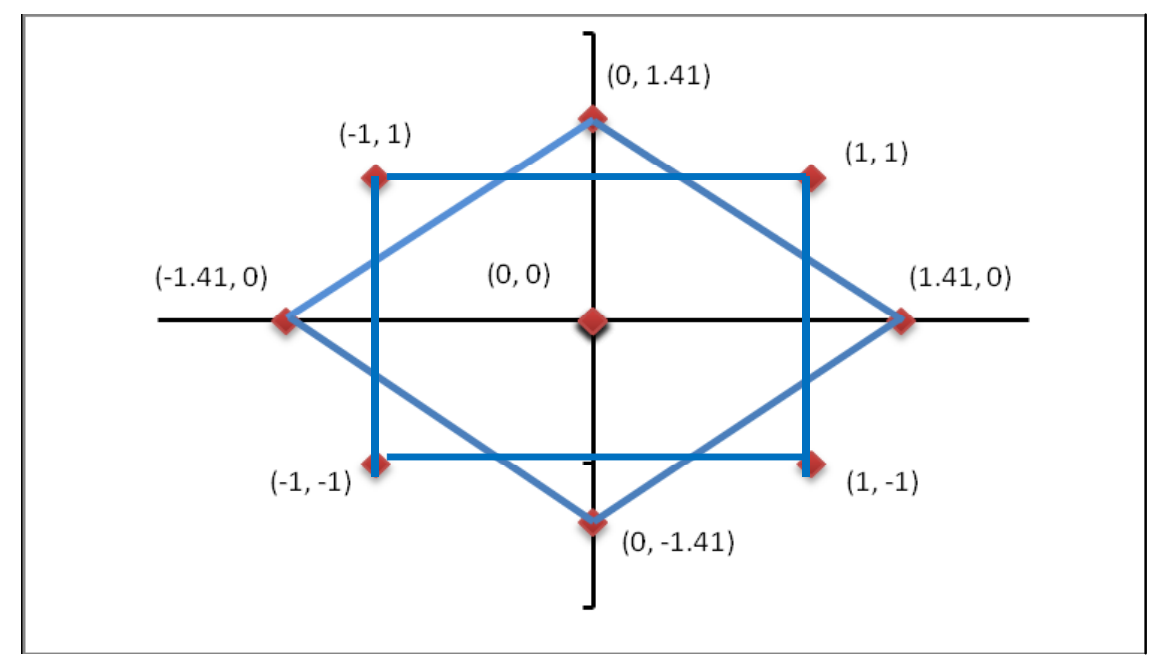

Figura 8 - Construção dos ensaios do planejamento fatorial composto.

Tabela 5 - Equivalência entre os valores codificados e reais da variável de entrada do planejamento fatorial composto.

\begin{tabular}{c|c}
\hline \multicolumn{2}{c}{ Variáveis de entrada } \\
\hline Codificada & Real / M \\
\hline$-1,41$ & $1,8 \times 10^{-4}$ \\
-1 & $1,0 \times 10^{-3}$ \\
0 & $3,0 \times 10^{-3}$ \\
1 & $5,0 \times 10^{-3}$ \\
1,41 & $5,8 \times 10^{-3}$ \\
\hline
\end{tabular}

$\mathrm{Na}$ Tabela 6 é apresentada a matriz de ensaios do projeto fatorial composto na ordem padrão e de execução, e os valores das variáveis de entrada em forma codificada e em valores reais, as quais representam a formulação da mistura das substâncias.

Como já mencionado no caso de planejamento fatorial completo, os ensaios foram realizados na ordem aleatória de execução, para garantir a independência estatística, e os valores das variáveis de entrada codificados para facilitar a entrada de 
dados ao software Statistica; também nesta etapa, foram realizadas medidas de potencial de corrosão antes e depois das medidas de impedância eletroquímica.

Tabela 6 - Matriz de ensaios de projeto fatorial composto na ordem padrão.

\begin{tabular}{cc|cc|cc}
\hline \multicolumn{2}{c|}{ Ordem } & \multicolumn{2}{|c|}{$\begin{array}{c}\text { Variáveis de entrada } \\
\text { codificadas }\end{array}$} & \multicolumn{2}{c}{$\begin{array}{c}\text { Variáveis de entrada em valor } \\
\text { real / M }\end{array}$} \\
\hline Padrão Exec. & $\mathrm{Na}_{2} \mathrm{MoO}_{4}$ & $\mathrm{Na}_{2} \mathrm{WO}_{4}$ & $\mathrm{Na}_{2} \mathrm{MoO}_{4}$ & $\mathrm{Na}_{2} \mathrm{WO}_{4}$ \\
\hline 1 & 10 & -1 & -1 & $1,0 \times 10^{-3}$ & $1,0 \times 10^{-3}$ \\
2 & 13 & 1 & -1 & $5,0 \times 10^{-3}$ & $1,0 \times 10^{-3}$ \\
3 & 12 & -1 & 1 & $1,0 \times 10^{-3}$ & $5,0 \times 10^{-3}$ \\
4 & 14 & 1 & 1 & $5,0 \times 10^{-3}$ & $5,0 \times 10^{-3}$ \\
5 & 9 & $-1,41$ & 0 & $1,8 \times 10^{-4}$ & $3,0 \times 10^{-3}$ \\
6 & 8 & $+1,41$ & 0 & $5,8 \times 10^{-3}$ & $3,0 \times 10^{-3}$ \\
7 & 11 & 0 & $-1,41$ & $3,0 \times 10^{-3}$ & $1,8 \times 10^{-4}$ \\
8 & 5 & 0 & $+1,41$ & $3,0 \times 10^{-3}$ & $5,8 \times 10^{-3}$ \\
9 & 3 & 0 & 0 & $3,0 \times 10^{-3}$ & $3,0 \times 10^{-3}$ \\
10 & 7 & 0 & 0 & $3,0 \times 10^{-3}$ & $3,0 \times 10^{-3}$ \\
11 & 2 & 0 & 0 & $3,0 \times 10^{-3}$ & $3,0 \times 10^{-3}$ \\
12 & 4 & 0 & 0 & $3,0 \times 10^{-3}$ & $3,0 \times 10^{-3}$ \\
13 & 6 & 0 & 0 & $3,0 \times 10^{-3}$ & $3,0 \times 10^{-3}$ \\
14 & 1 & 0 & 0 & $3,0 \times 10^{-3}$ & $3,0 \times 10^{-3}$ \\
\hline
\end{tabular}

\subsubsection{Avaliação da evolução com o tempo.}

Com a finalidade de avaliar a evolução com o tempo foram realizadas medidas de impedância eletroquímica com a mistura de inibidores na concentração de ponto de ótimo, para tempos de imersão de 3h, 6h, 12h, 24h, 48h, 72h e $88 \mathrm{~h}$. 


\section{RESULTADOS}

Os resultados obtidos neste trabalho serão apresentados por etapas, conforme a metodologia. Os resultados da primeira etapa permitiram conhecer o comportamento de cada uma das substâncias estudadas como inibidor de corrosão. Com os ensaios de microscopia eletrônica de varredura foi verificada a existência do filme protetor na superfície do aço.

Nas etapas seguintes, os resultados do planejamento fatorial completo levaram a identificação de efeitos sinérgicos entre as substâncias, assim como, com os resultados correspondentes ao planejamento fatorial composto foi possível determinar o ponto de ótimo da mistura de inibidores para uma posterior avaliação com o tempo de imersão.

\subsection{Resultados eletroquímicos}

\subsubsection{Potencial de corrosão}

Os valores das medidas de potencial de corrosão, $\mathrm{E}_{\text {corr }}$ obtidos para $\mathrm{o}$ aço carbono ABNT 1005 em meio da água de resfriamento industrial, na ausência e na presença das diferentes concentrações para cada uma das substâncias estudadas são apresentados na Tabela 7.

Para o molibdato de sódio, a ftalocianina de cobre e o CPPM, os resultados apresentados na Tabela 7 mostram que os valores de $E_{\text {corr }}$ foram apenas levemente alterados para valores mais positivos em relação ao valor obtido na ausência de inibidor. No caso do tungstato de sódio, os resultados mostram comportamento similar àquele encontrado com as outras substâncias, embora a presença de $1,0 \times 10^{-3} \mathrm{M}$ do 
tungstato tenha deslocado o potencial de corrosão em $470 \mathrm{mV}$, no sentido anódico. Esses resultados indicam que as substâncias estudadas devem agir como inibidores anódicos de corrosão.

Tabela 7 - Potencial de corrosão, $\left(E_{\text {corr }}\right)$ do aço carbono ABNT 1005 com e sem a presença das substâncias estudadas.

\begin{tabular}{|c|c|c|c|c|}
\hline \multirow[b]{2}{*}{ Conc. / M } & \multicolumn{4}{|c|}{$E_{\text {corr }}(m \mathrm{mV}$ vs $\mathrm{Ag} / \mathrm{AgCl})$} \\
\hline & $\mathrm{Na}_{2} \mathrm{MoO}_{4}$ & $\mathrm{Na}_{2} \mathrm{WO}_{4}$ & Ft-Cu & CPPM \\
\hline 0,0 & -750 & -750 & -750 & -750 \\
\hline $1,0 \times 10^{-5}$ & -700 & -624 & -675 & - \\
\hline $1,0 \times 10^{-4}$ & -692 & -532 & -664 & -668 \\
\hline $1,0 \times 10^{-3}$ & -698 & -280 & -669 & -664 \\
\hline
\end{tabular}

\subsubsection{Espectros de impedância eletroquímica}

Nesta seção são apresentados os diagramas de impedância eletroquímica que foram obtidos para o aço carbono em meio de água de resfriamento industrial na presença e ausência de cada uma das substâncias estudadas. Inicialmente será feita uma análise qualitativa dos espectros de impedância eletroquímica. A seguir, os espectros serão ajustados ao circuito elétrico equivalente com o fim de discutir os resultados quantitativamente.

Todos os diagramas de impedância obtidos para as diferentes substâncias estudadas apresentam arcos capacitivos com diâmetros crescentes e valores do módulo de impedância, IZI também crescentes com a concentração de inibidor, condizente com a formação de um filme protetor na superfície do metal. 


\subsubsection{Molibdato de sódio, $\mathrm{Na}_{2} \mathrm{MoO}_{4}$}

Nos diagramas de Nyquist, Figura 9a, observa-se arcos capacitivos com diâmetros crescentes para concentrações também crescentes de $\mathrm{Na}_{2} \mathrm{MoO}_{4}$. Pelos diagramas de Bode, Figuras 9b, observam-se valores crescentes de módulo de impedância, IZI e ângulo de fase, ( $\theta$ ) para concentrações crescentes de $\mathrm{Na}_{2} \mathrm{MoO}_{4}$. Estes resultados concordam com os encontrados por Saremi (2006) e devem estar associados à formação de um filme adsorvido na superfície do metal com características protetoras contra a corrosão. Também nos diagramas de Bode e na concentração de $1,0 \times 10^{-3} \mathrm{M}$ podem identificar-se duas constantes de tempo, a primeira em freqüência intermediaria associada com a formação do filme na superfície de aço e a segunda em baixas freqüências relativa aos processos de transferência de carga entre o eletrólito e o metal.

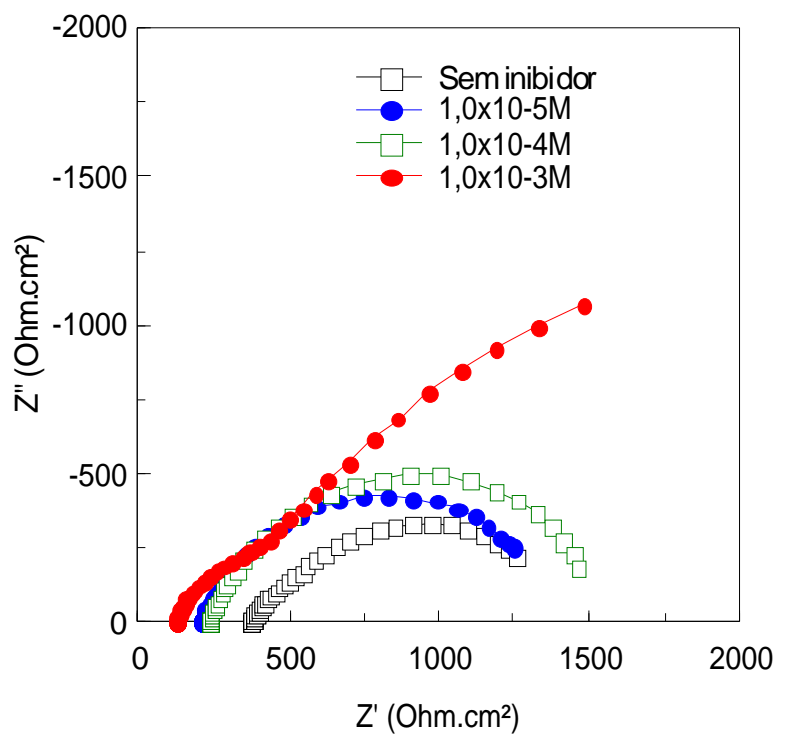

a) Nyquist

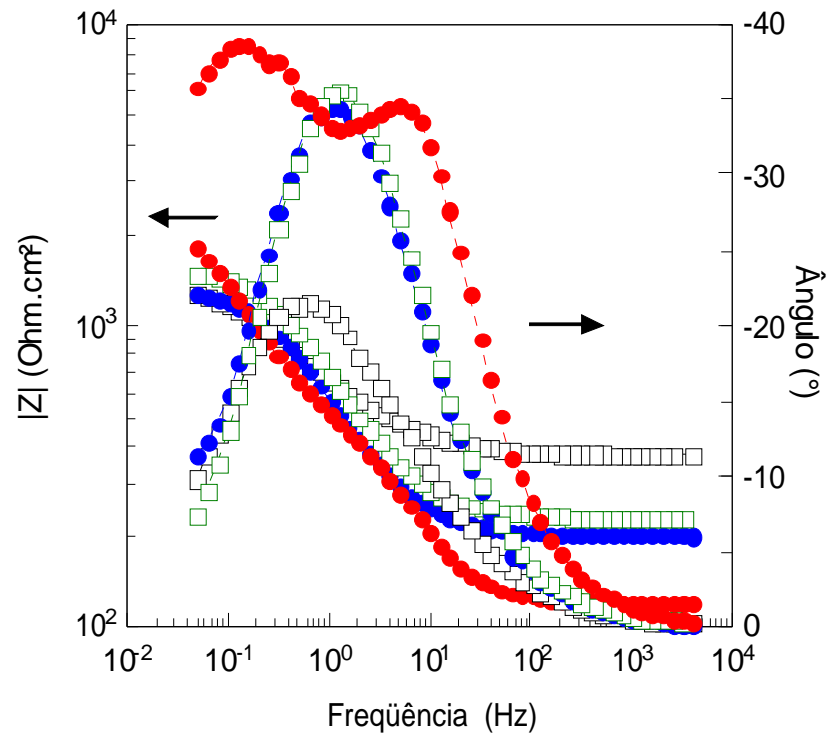

b) Bode

Figura 9 - Diagrama de impedância que foram obtidos para o aço carbono ABNT 1005 em meio de água de resfriamento industrial na ausência e na presença de $\mathrm{Na}_{2} \mathrm{MoO}_{4}$. 


\subsubsection{Tungstato de sódio, $\mathrm{Na}_{2} \mathrm{WO}_{4}$}

Na Figura 10 podem ser vistos os espectros de impedância eletroquímica, na presença e ausência do tungstato de sódio.

Os diagramas de Nyquist, Figura 10a, revelam que a resistência à transferência de carga impedância do sistema aumenta para valores crescentes da concentração de $\mathrm{Na}_{2} \mathrm{WO}_{4}$, constatando a presença de um filme protetor na superfície do metal.

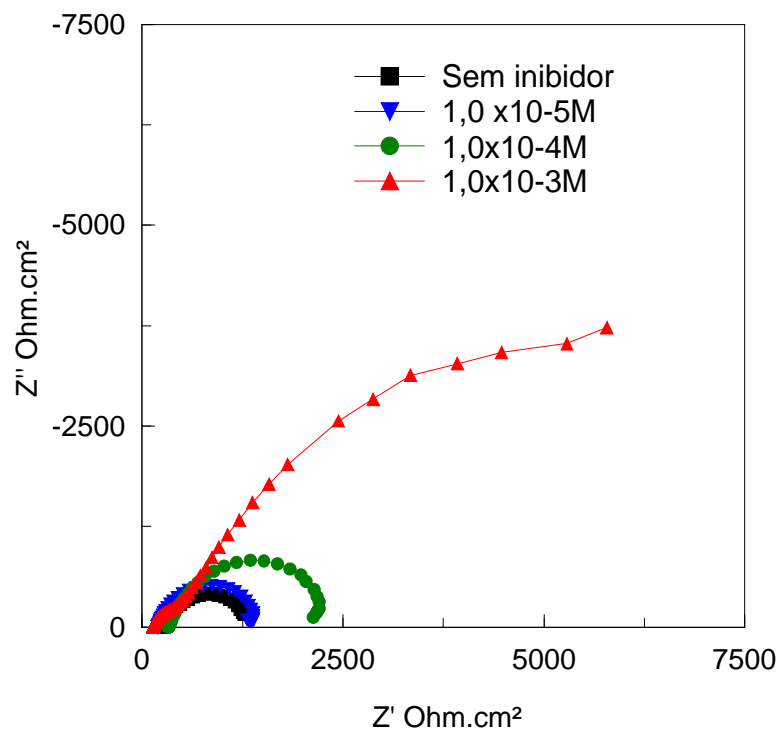

a) Nyquist

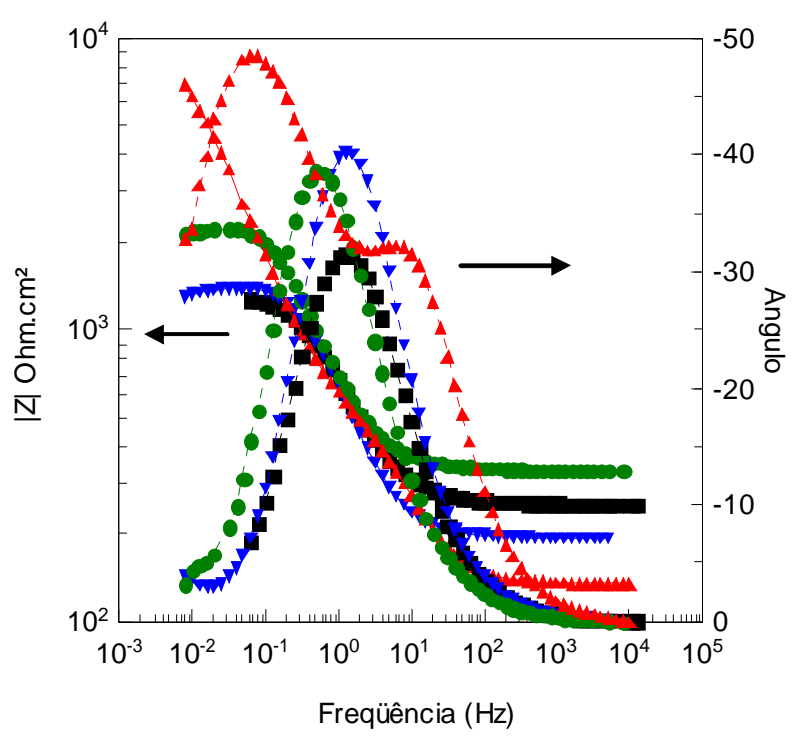

b) Bode

Figura 10 - Diagrama de impedância que foram obtidos para o aço carbono ABNT 1005 em meio de água de resfriamento industrial na ausência e na presença de $\mathrm{Na}_{2} \mathrm{WO}_{4}$.

Os diagramas de Bode, Figura $10 \mathrm{~b}$, para a concentração de $1,0 \times 10^{-3} \mathrm{M}$ de $\mathrm{Na}_{2} \mathrm{WO}_{4}$, revelam nitidamente duas constantes de tempo, caso que é semelhante ao 
observado com o molibdato; o que deve estar associado à formação de um filme na superfície do aço, representado pela primeira constante de tempo em freqüências intermediarias; e aos processos de transferência de carga na interfase metal/eletrólito, representado por sua vez pela segunda constante de tempo em baixas freqüências. $O$ módulo de impedância, IZI e o ângulo de fase, $(\theta)$ aumentam com a concentração de tungstato de sódio.

\subsubsection{Copolímero de polioxiaquileno e polidimetilsiloxano, CPPM}

Os espectros de impedância eletroquímica do aço carbono ABNT 1005 em presença e ausência do CPPM em meio das águas de resfriamento industrial usada neste estudo, são apresentados na Figura 11. No caso da CPPM, só serão apresentados resultados para as concentrações de $1,0 \times 10^{-4}$ e $1,0 \times 10^{-3} \mathrm{M}$.

Os diagramas de Nyquist, Figura 11a apresentam arcos capacitivos com diâmetros crescentes com a concentração de CPPM. Este comportamento é semelhante ao observado com as demais substâncias estudadas, isto é, a presença do CPPM também deve formar um filme inibidor que age como barreira entre o meio e o metal. Os diagramas de Bode, Figura 11b apresentam valores crescentes do módulo de impedância, IZI e do ângulo de fase, $(\theta)$ com o aumento da concentração do CPPM. 


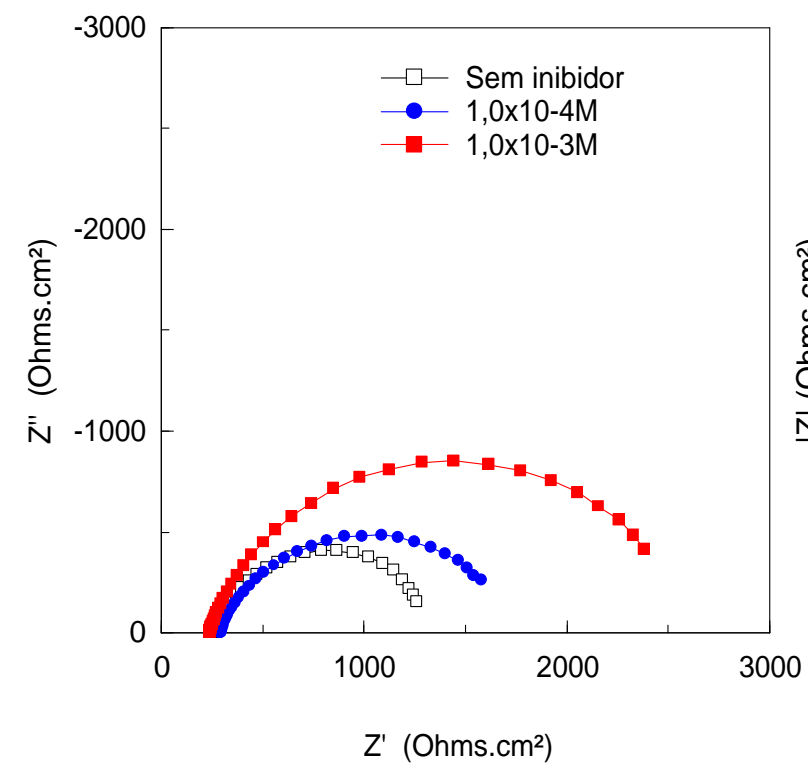

a) Nyquist

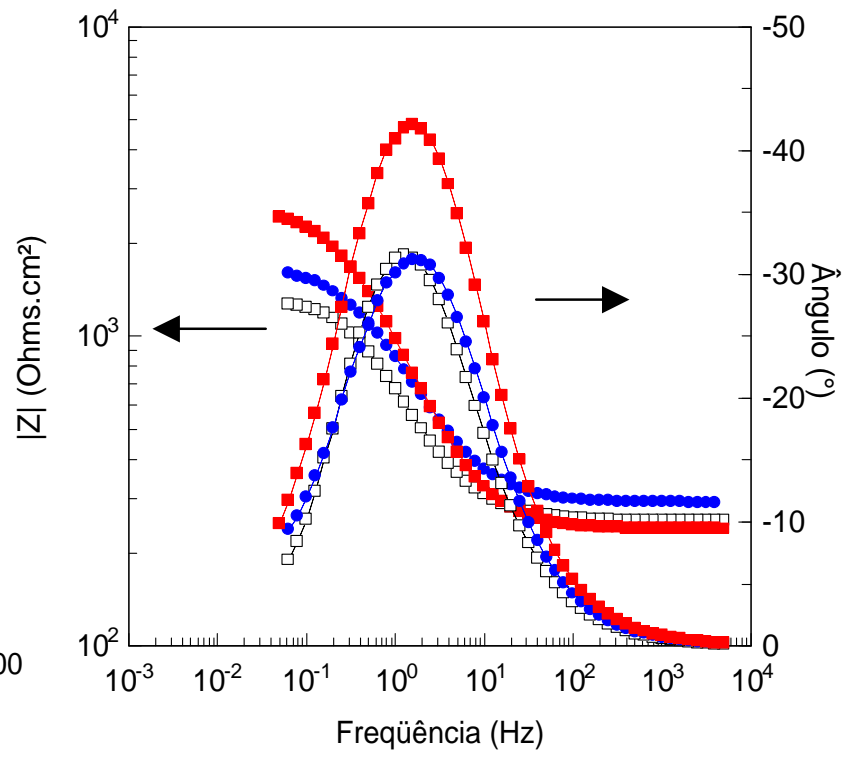

b) Bode

Figura 11- Diagrama de impedância que foram obtidos para o aço carbono ABNT 1005 em meio de água de resfriamento industrial na ausência e na presença de CPPM.

\subsubsection{Ftalocianina de Cobre, Ft-Cu.}

Os espectros de impedância eletroquímica do aço carbono ABNT 1005 em presença e ausência do $\mathrm{Ft}-\mathrm{Cu}$ em meio das águas de resfriamento industrial são apresentadas na Figura 12. Nos diagramas de Nyquist Figura 12a, observa-se que os diâmetros dos arcos capacitivos são crescentes com o aumento da concentração de Ft-Cu. Nos diagramas de Bode, Figura 12b, se observa que os módulos de impedância, |Z|, em freqüências mínimas (dado experimental) também são crescentes com a concentração. Observa-se ainda aumento do ângulo de fase com a concentração de $\mathrm{Ft}-\mathrm{Cu}$, principalmente em relação aquele obtido na ausência da Ft$\mathrm{Cu}$. Isto evidencia que a presença do $\mathrm{Ft}-\mathrm{Cu}$ modifica a superfície do aço carbono 
ABNT 1005, provavelmente através da formação de um filme que age como barreira minimizando os efeitos do eletrólito sobre o metal.

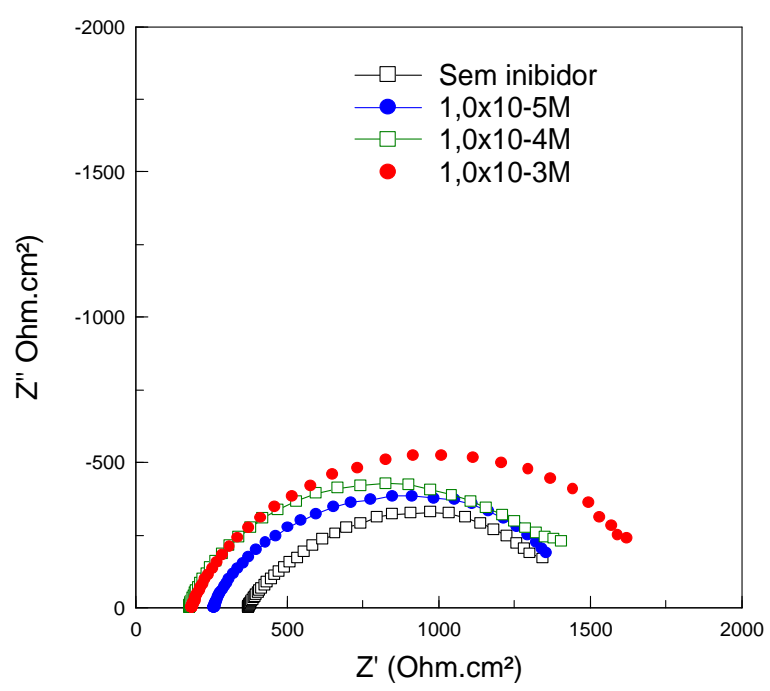

(a) Nyquist

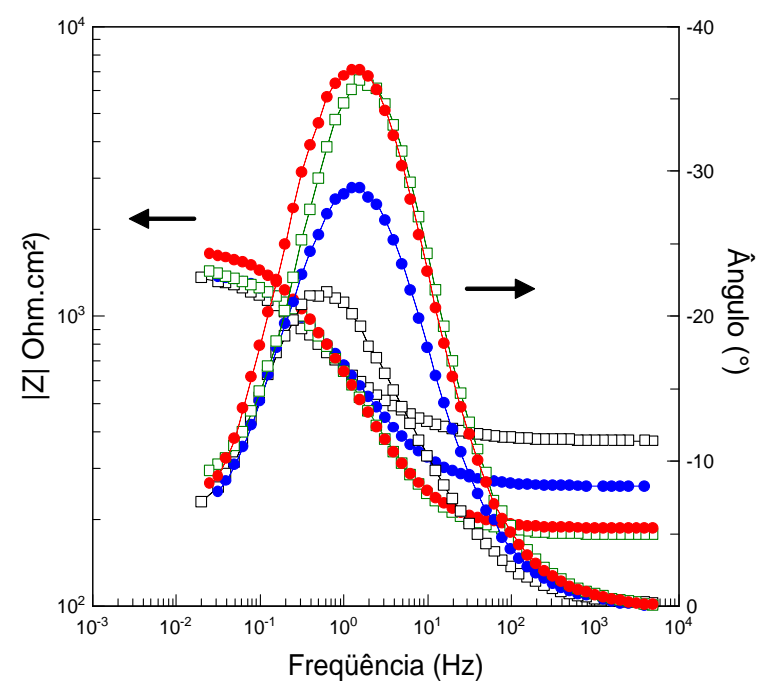

(b) Bode

Figura 12 - Diagramas de impedância que foram obtidos para o aço carbono ABNT 1005 em meio de água de resfriamento industrial na ausência e na presença de Ft-Cu.

\subsubsection{Parâmetros de Impedância eletroquímica.}

Para quantificar os parâmetros de impedância eletroquímica que permitem comparar quantitativamente as substâncias estudadas foram usados circuitos elétricos equivalentes. A seguir são apresentados os circuitos elétricos equivalentes que foram usados para a modelagem dos dados experimentais dos diagramas de impedância eletroquímica obtidos neste trabalho. 
As Figuras 13 e 14 são os modelos de circuitos elétricos equivalentes clássicos mais simples usados para simular sistemas metal/meio e que foram associados aos diagramas de impedância obtidos nesta investigação. O circuito equivalente da Figura 13 representa os diagramas de impedância com uma constante de tempo. Onde $R_{s}$ corresponde à resistência do eletrólito, $R_{\mathrm{tc}}$ a resistência à transferência de carga $\mathrm{e}$ CPE-2, elemento de fase constante que corresponde à capacitância de dupla camada da elétrica $\left(C_{d l}\right)$.

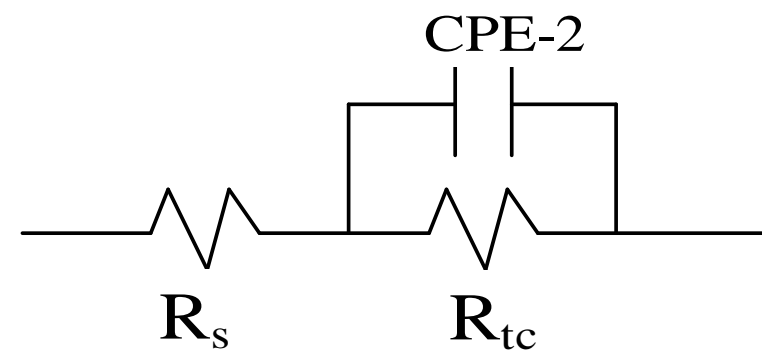

Figura 13 - Circuito elétrico equivalente proposto para ajuste dos resultados de impedância, obtidos para o aço carbono ABNT 1005 em água de resfriamento industrial, cujos diagramas apresentam uma constante de tempo.

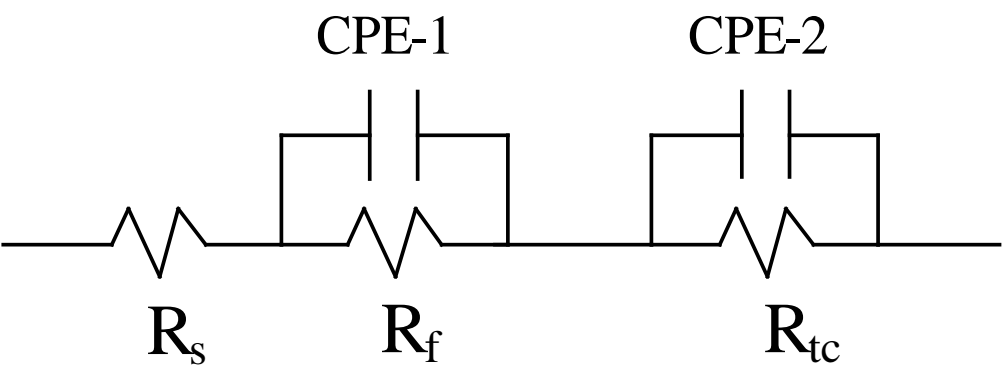

Figura 14 - Circuito elétrico equivalente proposto para ajuste dos resultados de impedância, obtidos para o aço carbono ABNT 1005 em água de resfriamento industrial, cujos diagramas apresentam duas constantes de tempo.

O circuito elétrico equivalente apresentado na Figura 14 corresponde ao mesmo sistema metal/meio quando os diagramas de impedância apresentam duas constantes 
de tempo. Neste circuito, além dos elementos anteriormente descritos para o circuito elétrico da Figura 13, estão representadas: a capacitância do filme $\left(C_{f}\right)$, como sendo um elemento de fase constante CPE-1 e a resistência do filme $\left(\mathrm{R}_{\mathrm{f}}\right)$. Os elementos de fase constante são usados em substituição da capacitância, por considerar a não homogeneidade do sistema, devida a porosidade do filme, diferentes espessuras, etc.

A expressão matemática dos elementos de fase constante é do tipo $(C P E-T)^{\text {CPE-P }}$. É importante ressaltar na hora das análises e discussão dos resultados da modelagem em que foram usados circuitos elétricos equivalentes, que para valores de CPE-P próximos de 1 tem-se a situação de um capacitor ideal.

Os valores de capacitância, tanto do filme, $\left(\mathrm{C}_{\mathrm{f}}\right)$, quanto da dupla camada elétrica, $\left(\mathrm{C}_{\mathrm{dl}}\right)$, foram calculados com o auxilio da equação

$$
C=y_{O}\left(\omega_{m a ́ x}\right)^{\alpha-1}
$$

Onde: $y_{0}=$ CPE-T; e a =CPE-P. Os valores de CPE-T e CPE-P, correspondem aos elementos de fase constante (identificados assim pelo software Zview); $\omega_{\text {máx }}$ corresponde à freqüência no ponto de máximo valor do eixo imaginário (HSU e MANSFELD apud MARIN-CRUZ et al.,2006).

A eficiência do molibdato de sódio como inibidor de corrosão foi calculada através da equação:

$$
\eta=\frac{R_{T c i n i b}-R_{T c o}}{R_{T c i n i b}} \times 100
$$

Onde $R_{T \text { Tinib }}$ e $R_{T c_{0}}$ são as resistências a transferência de carga com e sem inibidor, respectivamente (KARMAN et al.1997). 


\subsubsection{Molibdato de sódio, $\mathrm{Na}_{2} \mathrm{MoO}_{4}$}

$\mathrm{Na}$ Tabela 8 são apresentados os resultados de resistência da solução $\left(R_{S}\right)$, resistência do filme, $\left(R_{f}\right)$ capacitância do filme, $\left(C_{f}\right)$, resistência à transferência de carga $\left(R_{t c}\right)$, capacitância da dupla camada elétrica, $\left(C_{d l}\right)$ e eficiência do inibidor, $(\eta)$. Para obter esses valores os resultados de impedância obtidos na ausência do inibidor e com as concentrações de $1,0 \times 10^{-5} \mathrm{M}$ e $1,0 \times 10^{-4} \mathrm{M}$ de $\mathrm{Na}_{2} \mathrm{MoO}_{4}$ foram ajustados ao circuito elétrico equivalente cujo modelo é representado na Figura 13.

Tendo em vista que o diagrama obtido com a concentração de $1,0 \times 10^{-3} \mathrm{M}$ de $\mathrm{Na}_{2} \mathrm{MoO}_{4}$ apresentou duas constantes de tempo, optou-se por ajustar os resultados ao circuito elétrico equivalente cujo modelo foi o apresentado na Figura 14.

Os parâmetros obtidos a partir do ajuste dos resultados aos circuitos elétricos equivalentes são apresentados na Tabela 8. Observando os parâmetros verifica-se que a resistência à transferência de carga, $\left(R_{t c}\right)$ e a eficiência do inibidor, $(\eta)$ aumentam para concentrações crescentes de $\mathrm{Na}_{2} \mathrm{MoO}_{4}$.

Tabela 8 - Parâmetros obtidos a partir do ajuste dos resultados de impedância do sistema aço carbono ABNT 1005/água de resfriamento industrial com e sem a presença de $\mathrm{Na}_{2} \mathrm{MoO}_{4}$.

\begin{tabular}{|c|c|c|c|c|}
\hline $\mathrm{Na}_{2} \mathrm{MoO}_{4} / \mathrm{M}$ & 0,0 & $1,0 \times 10^{-5}$ & $1,0 \times 10^{-4}$ & $1,0 \times 10^{-3}$ \\
\hline $\mathrm{R}_{\mathrm{s}} / \Omega \cdot \mathrm{cm}^{2}$ & 369 & 200 & 228 & 118 \\
\hline $\mathbf{R}_{\mathrm{f}} / \Omega \cdot \mathrm{cm}^{2}$ & - & - & - & 209 \\
\hline$C_{f / \mu F} \cdot \mathbf{c m}^{-2}$ & - & - & - & 821 \\
\hline $\mathbf{R}_{\mathrm{tc}} / \Omega \cdot \mathbf{c m}^{2}$ & 1132 & 1228 & 1351 & 4216 \\
\hline$C_{d l} / \mu F . c m^{-2}$ & 1232 & 619 & 431 & 414 \\
\hline$\eta(\%)$ & - & 7,8 & 16 & 74 \\
\hline$\alpha \mathbf{C}_{\mathbf{f}}$ & - & - & - & 0,7 \\
\hline$\alpha \mathbf{C}_{\mathrm{dl}}$ & 0,7 & 0,8 & 0,8 & 0,9 \\
\hline
\end{tabular}

Observa-se também que os valores de capacitância da dupla camada elétrica, $\left(C_{d l}\right)$, e da resistência da solução, $\left(R_{s}\right)$, diminuem com o aumento da concentração de 
$\mathrm{Na}_{2} \mathrm{MoO}_{4}$. Os resultados de capacitância da dupla camada elétrica $\left(\mathrm{C}_{\text {dll }}\right)$ e resistência á transferência de carga $\left(R_{t c}\right)$ indicam que o molibdato de sódio em meio de água de resfriamento industrial forma um filme protetor sob a superfície do aço carbono ABNT 1005, dificultando os processos de transferência de carga na interface metal/meio.

$\mathrm{O}$ diagrama obtido com a concentração de $1,0 \times 10^{-3} \mathrm{M}$ de $\mathrm{Na}_{2} \mathrm{MoO}_{4}$ mostra a formação de duas constantes de tempo. A constante de tempo observada em freqüência intermediária deve estar relacionada com a formação de um filme na superfície do aço carbono. O valor de capacitância de filme seja de $821 \mu \mathrm{F} . \mathrm{cm}^{2}$, sabese que este valor é muito elevado para um filme protetor; logo deve estar relacionado com um filme de elevada porosidade, além de haver a possibilidade dos íons de molibdato estarem interagindo na camada óxido presente do filme, o que deve explicar o elevado valor da capacitância. Estes resultados são concordantes os encontrados com Bentley et. al., (1986) e Saremi, Dehghanian e Sabet (2006).

Para baixas concentrações foi usado o circuito da Figura 13, tendo em vista que o filme formado deve ser além de muito fino ser também muito poroso, não permitindo a distinção entre os processos de formação de filme e os processos de transferência de carga nos diagramas de impedância. Estes resultados concordam com àqueles apresentados por Saremi, Dehghanian e Sabet (2006). Os valores tanto de $\mathrm{aC}_{\mathrm{f}}$ quanto de $\mathrm{aC}_{\mathrm{dl}}$, que foram em torno de 0,8 são condizentes com a associação do capacitor do circuito elétrico equivalente ao elemento de fase constante para considerar a não homogeneidade da superfície onde acontecem os processos interfaciais.

\subsubsection{Tungstato de sódio, $\mathrm{Na}_{2} \mathrm{WO}_{4}$}

Na Tabela 9 são apresentados os parâmetros obtidos através da simulação dos resultados aos circuitos elétricos equivalentes. A modelagem para as concentrações de $1,0 \times 10^{-5} \mathrm{M}$ e $1,0 \times 10^{-4} \mathrm{M}$, foi realizada com o circuito elétrico equivalente da Figura 13 , e 
para a concentração de $1,0 \times 10^{-3} \mathrm{M}$, que apresentou duas constantes de tempo foi usado circuito elétrico da Figura 14.

Tabela 9 - Parâmetros obtidos do ajuste dos resultados de impedância do sistema aço carbono ABNT 1005/água de resfriamento industrial com e sem a presença de $\mathrm{Na}_{2} \mathrm{WO}_{4}$.

\begin{tabular}{|c|c|c|c|c|}
\hline $\mathrm{Na}_{2} \mathrm{WO}_{4} / \mathrm{M}$ & 0,0 & $1,0 \times 10^{-5}$ & $1,0 \times 10^{-4}$ & $1,0 \times 10^{-3}$ \\
\hline $\mathbf{R}_{\mathrm{s}} / \Omega \cdot \mathrm{cm}^{2}$ & 369 & 195 & 334 & 134 \\
\hline $\mathbf{R}_{\mathrm{f}} / \Omega \cdot \mathrm{cm}^{2}$ & - & - & - & 280 \\
\hline$C_{f / \mu} F \cdot \mathrm{cm}^{-2}$ & - & - & - & 185 \\
\hline $\mathbf{R}_{\mathrm{tc}} / \Omega . \mathrm{cm}^{2}$ & 1132 & 1229 & 2014 & 11353 \\
\hline$C_{d I} / \mu F \cdot c^{-2}$ & 1047 & 370 & 391 & 306 \\
\hline$\eta(\%)$ & - & 7,8 & 44 & 90 \\
\hline $\mathbf{a C}_{\mathrm{f}}$ & - & - & - & 0,8 \\
\hline $\mathbf{a C} C_{d l}$ & 0,7 & 0,8 & 0,8 & 0,7 \\
\hline
\end{tabular}

Os valores da resistência do eletrólito, $R_{s}$ diminuem na presença de concentrações maiores de tungstato de sódio, devido ao aumento da condutividade elétrica do eletrólito.

$\mathrm{O}$ valor da resistência do filme $\mathrm{R}_{\mathrm{f}}$, indica uma modificação das propriedades elétricas da superfície, na presença de concentrações mais elevadas do tungstato. Este valor é comparável com aquele obtido para a resistência do filme formado na presença do molibdato de sódio, também na concentração de $1,0 \times 10^{-3} \mathrm{M}$. A capacitância do filme resultou em valores inferiores àqueles obtidos para o molibdato de sódio, embora ainda elevados quando comparados com os valores de capacitância do filme formado por inibidores de corrosão em águas de resfriamento obtidos por Marín-Cruz et. al. (2006).

Os valores da resistência à transferência de carga aumentam progresivamente com a concentração de tungstato de sódio; sendo que para a concentração de $1,0 \times 10^{-3} \mathrm{M}$ é 10 vezes maior que aquela obtida na ausência de tungstato de sódio. Os valores obtidos para a capacitância da dupla camada elétrica, embora sejam muito altos, ainda assim refletem um comportamento mais protetor para concentrações crescentes de tungstato de sódio, mas indicam que provavelmente o filme deve ser 
muito fino e poroso; semelhante como no caso de molibdato, com valores de $\mathrm{ac}_{\mathrm{f}} \mathrm{e} \mathrm{aC}_{\mathrm{dl}}$ entre 0,7 e 0,8. A literatura mostra que filmes protetores apresentam valores de

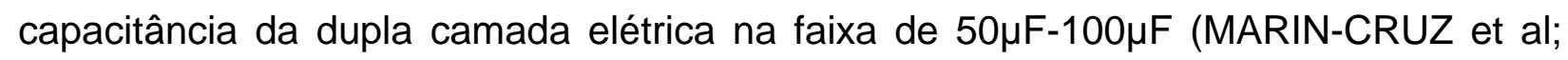
2006).

Finalmente, a eficiência baseada na resistência á transferência de carga estimada pela equação 13 , atingiram valores de $90 \%$ para a máxima concentração de tungstato de sódio usada.

\subsubsection{Copolímero de polioxialquileno e polidimetilsiloxano, CPPM}

Os parâmetros estimados através da modelagem dos resultados de impedância eletroquímica, usando o circuito equivalente apresentado na Figura 13, da sessão 4.1.3 são apresentados na Tabela 10.

Tabela 10 - Parâmetros obtidos a partir do ajuste dos resultados de impedância do sistema aço carbono ABNT 1005 / água de resfriamento industrial na ausência e presença de CPPM.

\begin{tabular}{l|ccc}
\hline $\mathbf{C C P M} / \mathbf{M}$ & $\mathbf{0 , 0}$ & $\mathbf{1 , 0 \times 1 0 ^ { - 4 }}$ & $\mathbf{1 , 0 \times 1 0 ^ { - 3 }}$ \\
\hline $\mathbf{R}_{\mathbf{s}} /$ Ohm. $\mathbf{~ m}^{2}$ & 369 & 289 & 238 \\
$\mathbf{R}_{\mathrm{tc}} /$ Ohm. $\mathbf{c m}^{2}$ & 1132 & 1458 & 2368 \\
$\mathbf{C}_{\mathrm{dl}} / \boldsymbol{\mu F} \cdot \mathbf{c m}^{-2}$ & 1047 & 392 & 298 \\
$\boldsymbol{\eta} / \%$ & - & 22 & 52 \\
$\mathbf{a C}_{\mathrm{dl}}$ & 0,7 & 0,8 & 0,8 \\
\hline
\end{tabular}

Assim como para as demais substâncias estudadas, os valores da resistência da solução diminuem com a presença do CPPM em relação à condição do ensaio sem inibidor. A resistência à transferência de carga $\left(R_{t c}\right)$ aumenta com o aumento da concentração de CPPM, isto é, duplica seu valor para a máxima concentração usada. 
No entanto, os resultados são muito inferiores àqueles obtidos com o molibdato de sódio e o tungstato de sódio, porém maiores do que os obtidos com a $\mathrm{Ft}$-Cu. Os valores de capacitância da dupla camada elétrica diminuem com o aumento da concentração de CPPM, mas continuam sendo elevados em relação aos valores correspondentes a filmes com características protetoras.

\subsubsection{Ftalocianina de Cobre, Ft-Cu}

Os resultados da análise quantitativos dos diagramas de impedância são apresentados na Tabela 11. Os resultados foram estimados usando o circuito equivalente apresentado na Figura 13 da sessão 4.1.3, tendo em vista que os diagramas de Bode não evidenciam a separação dos processos de formação do filme e de transferência de carga, isto é, apresentaram apenas uma constante de tempo.

Tabela 11- Parâmetros obtidos a partir do ajuste dos resultados de impedância do sistema aço carbono ABNT 1005 / água de resfriamento industrial na ausência e na presença de Ft-Cu.

\begin{tabular}{l|cccc}
\hline $\mathbf{F t}-\mathbf{C u} / \mathbf{M}$ & $\mathbf{0 , 0}$ & $\mathbf{1 , 0 \times 1 0 ^ { - 5 }}$ & $\mathbf{1 , 0 \times 1 0 ^ { - 4 }}$ & $\mathbf{1 , 0 \times 1 0 ^ { - 3 }}$ \\
\hline $\mathbf{R}_{\mathbf{s}} /$ Ohm. $\mathbf{~ m}^{2}$ & 369 & 255 & 174 & 183 \\
$\mathbf{R}_{\mathbf{t c}} /$ Ohm. $\mathbf{c m}^{2}$ & 1132 & 1233 & 1366 & 1586 \\
$\mathbf{C}_{\mathrm{dl}} / \boldsymbol{\mu F} \cdot \mathbf{c m}^{-2}$ & 1047 & 580 & 471 & 559 \\
$\boldsymbol{\eta} / \%$ & - & 8 & 17 & 29 \\
$\mathbf{a C}_{\mathrm{dl}}$ & 0,7 & 0,7 & 0,7 & 0,8 \\
\hline
\end{tabular}

A resistência do eletrólito diminui com a concentração da $\mathrm{Ft}-\mathrm{Cu}$, logo a presença da ftalocianina no meio deve aumentar a condutividade elétrica e, portanto a resistência do eletrólito tenda a ser menor. Os valores de $R_{\mathrm{tc}}$ são crescentes com a concentração do inibidor; o que pressupõe que a Ft-Cu deve formar um filme na superfície do aço carbono. 
Os valores da capacitância da dupla camada elétrica, $\left(\mathrm{C}_{\mathrm{dl}}\right)$ diminuem na presença de $\mathrm{Ft}-\mathrm{Cu}$. A eficiência, ( $\eta$ ) estimada a partir de resistência á transferência de carga, $\left(\mathrm{R}_{\mathrm{tc}}\right)$ aumenta com a concentração de $\mathrm{Ft}-\mathrm{Cu}$. No entanto, o valor máximo foi de $29 \%$. Este valor não permite afirmar que a $\mathrm{Ft}-\mathrm{Cu}$ atua como inibidor de corrosão para o aço carbono ABNT 1005 em meio de água resfriamento industrial nas condições em que foi estudada.

\subsubsection{Curvas de Polarização}

\subsubsection{Molibdato de Sódio, $\mathrm{Na}_{2} \mathrm{MoO}_{4}$}

$\mathrm{Na}$ Figura 15 a seguir são apresentadas as curvas de polarização potenciodinâmicas anódicas e catódicas que foram obtidas para o aço carbono ABNT 1005 em meio de água de resfriamento industrial com e sem a presença de $\mathrm{Na}_{2} \mathrm{MoO}_{4}$.

Os resultados mostram claramente que $\circ \mathrm{Na}_{2} \mathrm{MoO}_{4}$ comporta-se como inibidor anódico, ou seja, todas as curvas anódicas apresentam-se polarizadas em relação àquela obtida sem a presença do inibidor. Isto significa que o molibdato inibe as reações de dissolução do aço carbono ABNT 1005. Esses resultados indicam que o $\mathrm{Na}_{2} \mathrm{MoO}_{4}$ deve formar um filme nos sítios anódicos, que age como barreira entre o meio e a superfície do metal. Para maiores concentrações de molibdato o efeito inibidor sob o aço carbono ABNT 1005 é crescente, com um efeito marcante na polarização anódica. Para qualquer valor de potencial fixo e acima de $-500 \mathrm{mV}$ verifica-se que a densidade de corrente de corrosão é menor em relação àquela obtida na ausência do $\mathrm{Na}_{2} \mathrm{MoO}_{4}$ além desses valores de densidade corrente serem decrescentes com o aumento da concentração de $\mathrm{Na}_{2} \mathrm{MoO}_{4}$ 


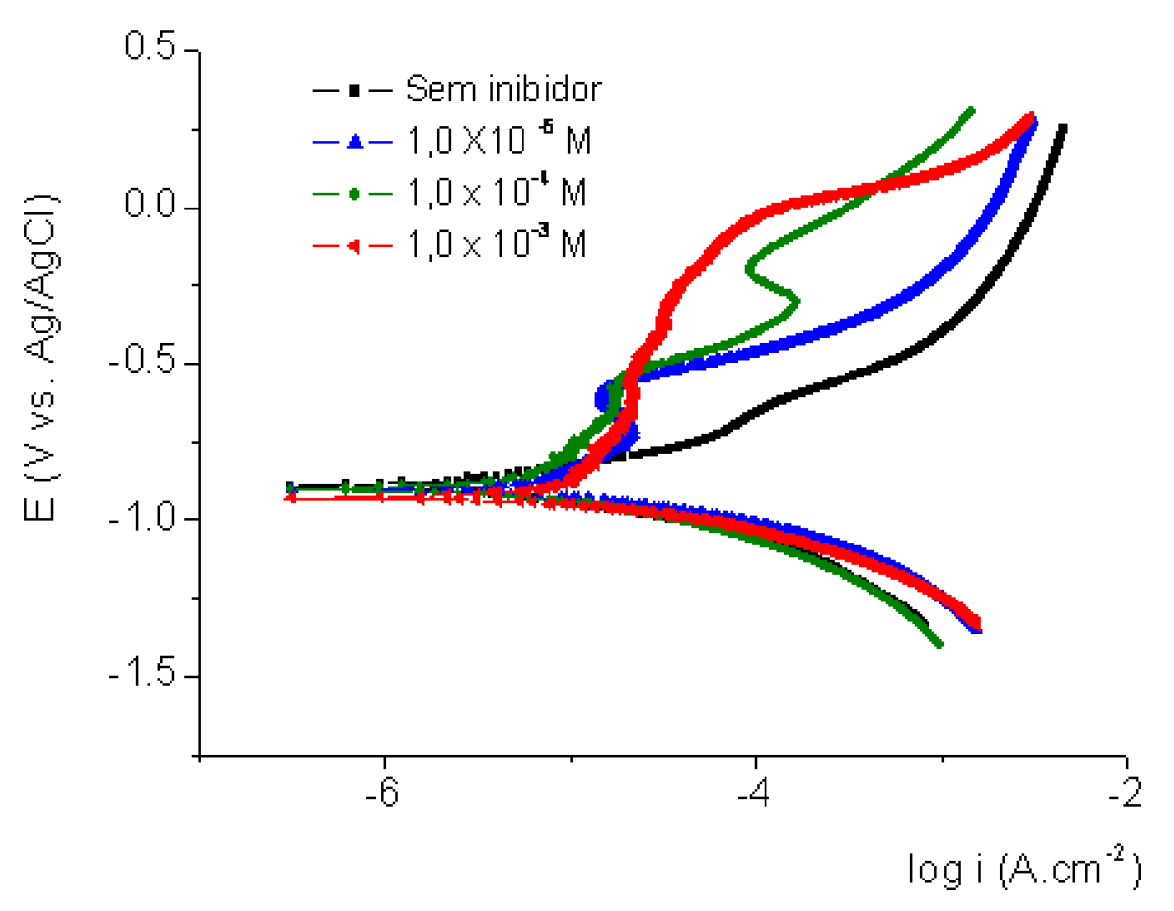

Figura 15 - Curvas de Polarização potenciodinâmicas do aço carbono ABNT 1005 em água de resfriamento industrial com e sem $\mathrm{Na}_{2} \mathrm{MoO}_{4}$.

Estes resultados concordam com os apresentados por Saremi, Dehghanian e Sabet (2006). Observa-se também, que as curvas de polarização catódicas são levemente despolarizadas em relação à curva obtida na ausência de $\mathrm{Na}_{2} \mathrm{MoO}_{4}$. Portanto, esses resultados mostram que o $\mathrm{Na}_{2} \mathrm{MoO}_{4}$ age apenas como inibidor anódico para o aço ABNT 1005 no meio em que foi estudado. A faixa de potencial em que se tem o comportamento passivo é aumentada para concentrações crescentes de molibdato. Os resultados obtidos com o uso do molibdato de sódio para aço carbono nas condições em que foram estudados são concordantes com aqueles apresentados por Farr e Saremi (1983).

$\mathrm{Na}$ Tabela 12 são apresentados os valores das densidades de corrente de corrosão que foram obtidos através da extrapolação da reta catódica de Tafel até o 
potencial de corrosão. Os valores de eficiência do inibidor $(\eta)$ foram calculados segundo a equação:

$$
\eta=\left[1-\frac{i_{\text {corr }(i)}}{i_{\text {corr }(0)}}\right] \times 100
$$

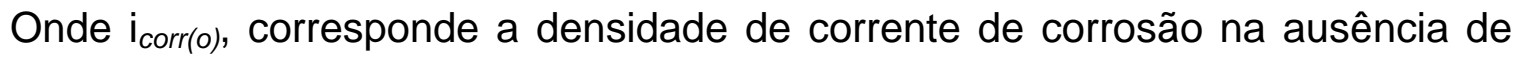
inibidor, e $\mathrm{i}_{\text {corr(i) }}$ a densidade corrente de corrosão na presença de inibidor (GUEDES; 1996).

Os valores de $\mathrm{i}_{\text {corr }}$ diminuem com o amento da concentração, ou seja, com $1,0 \times 10^{-3} \mathrm{M}$ de molibdato de sódio a velocidade de corrosão é 4 vezes menor que na condição sem inibidor, atingindo uma eficiência de $77 \%$.

Tabela 12 - Valores de densidades de correntes de corrosão, (i $\mathrm{i}_{\text {corr }}$ ) para aço carbono ABNT 1005 em meio de água de resfriamento industrial na ausência presença de $\mathrm{Na}_{2} \mathrm{MoO}_{4}$.

\begin{tabular}{ccc}
\hline $\mathrm{Na}_{2} \mathrm{MoO}_{4} / \mathbf{M}$. & $\mathbf{i}_{\text {corr }} / \mathbf{A} . \mathrm{cm}^{-2}$ & $\boldsymbol{\eta} / \%$ \\
\hline Sem inibidor & $7,6 \times 10^{-6}$ & - \\
$1,0 \times 10^{-5}$ & $5,3 \times 10^{-6}$ & 31 \\
$1,0 \times 10^{-4}$ & $4,9 \times 10^{-6}$ & 36 \\
$1,0 \times 10^{-3}$ & $1,7 \times 10^{-6}$ & 77 \\
\hline
\end{tabular}

\subsubsection{Tungstato de sódio, $\mathrm{Na}_{2} \mathrm{WO}_{4}$}

As curvas de polarização do aço carbono ABNT 1005 em presença e na ausência do $\mathrm{Na}_{2} \mathrm{WO}_{4}$ em meio das águas de resfriamento industrial são apresentadas na Figura 16. 


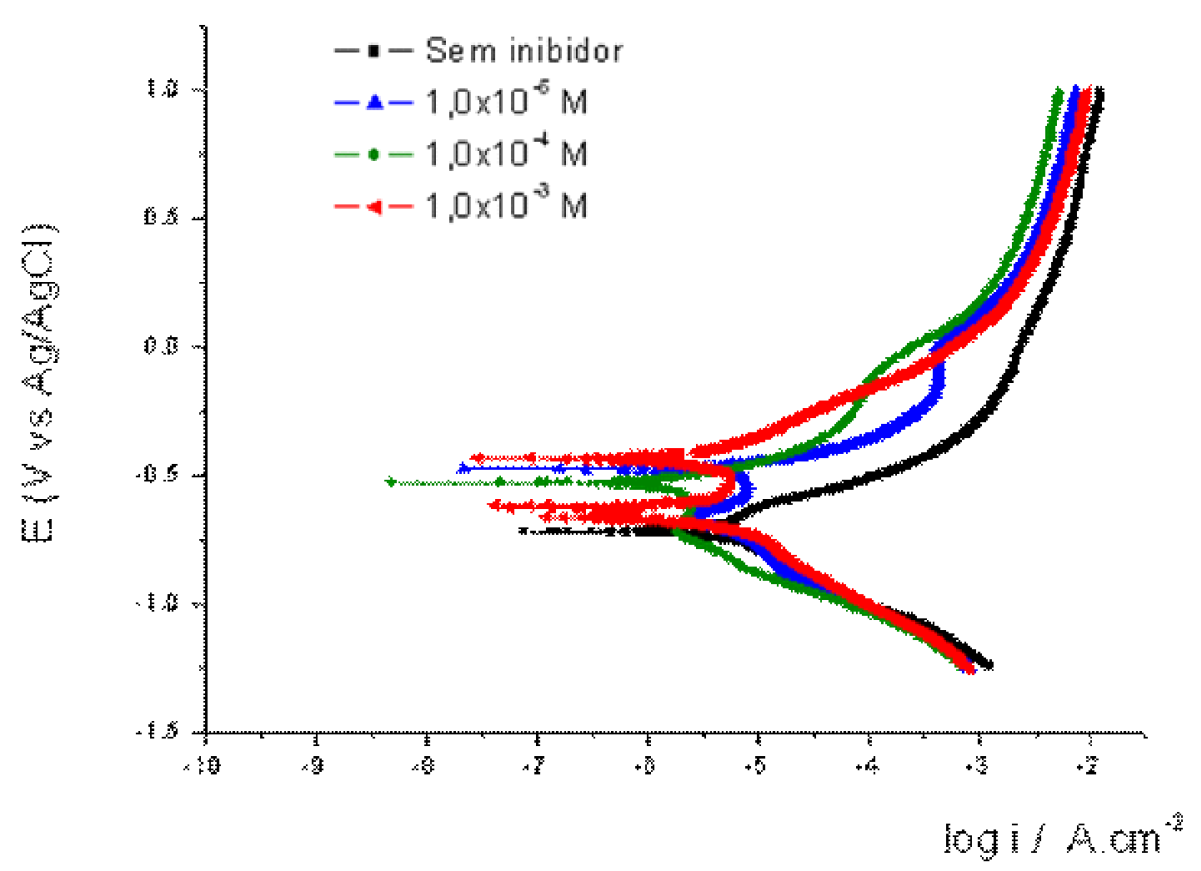

Figura 16 - Curvas de Polarização potenciodinâmicas do aço carbono ABNT 1005 em água de resfriamento industrial com e sem $\mathrm{Na}_{2} \mathrm{WO}_{4}$.

As curvas de polarização comprovam o caráter anódico do tungstato do sódio, ou seja, foram todas polarizadas anodicamente. Este comportamento é similar ao do molibdato de sódio, onde somente as reações de dissolução do metal foram inibidas.

$\mathrm{Na}$ Tabela 13 são apresentados os valores de densidade de corrente de corrosão ( $\mathrm{i}_{\text {corr }}$ ) e da eficiência para aço carbono na ausência e na presença de tungstato de sódio, calculado com a equação (13). Pode-se observar que a presença do $\mathrm{Na}_{2} \mathrm{WO}_{4}$ provoca uma diminuição dos valores da densidade de corrente de corrosão em relação ao valor de $\mathrm{i}_{\text {corr }}$ obtido na ausência deste. A máxima eficiência calculada a partir da densidade de corrente de corrosão atingiu 69 \% para uma concentração de $1,0 \times 10^{-3} \mathrm{M}$. As densidades de corrente de corrosão estimadas resultaram em valores inferiores àqueles obtidos por Saji e Shibli (2002), e Shibli e Saji (2005) para aço carbono em meio de água destilada e na presença de tungstato de sódio. A 
comparação foi feita interpolando linearmente os valores de concentração usados neste trabalho na faixa de concentração usada pelos autores.

O maior valor de eficiência foi de $69 \%$, obtido para a concentração de $1,0 \times 10^{-3} \mathrm{M}$ de tungstato de sódio.

Tabela 13 - Densidades de correntes de corrosão e valores de eficiência para aço carbono ABNT 1005 em meio de água de resfriamento industrial na ausência e na presença de $\mathrm{Na}_{2} \mathrm{WO}_{4}$.

\begin{tabular}{ccc}
\hline $\mathrm{Na}_{2} \mathbf{W O}_{4} / \mathbf{M}$ & $\mathbf{i}_{\text {corr }} / \mathbf{A} . \mathbf{c m}^{-2}$ & $\boldsymbol{\eta} / \%$ \\
\hline Sem inibidor & $7,6 \times 10^{-6}$ & \\
$1,0 \times 10^{-5}$ & $5,9 \times 10^{-6}$ & 22 \\
$1,0 \times 10^{-4}$ & $2,7 \times 10^{-6}$ & 65 \\
$1,0 \times 10^{-3}$ & $2,3 \times 10^{-6}$ & 69 \\
\hline
\end{tabular}

\subsubsection{Copolímero de polioxialquileno e polidimetilsiloxano, CPPM}

A Figura 17 mostra as curvas de polarização do aço carbono ABNT 1005 am água de resfriamento industrial na presença e ausência de CPPM.

Observar-se na Figura 17, que as curvas de polarização apresentam-se polarizadas anodicamente, com respeito a curva na ausência de CPPM. 


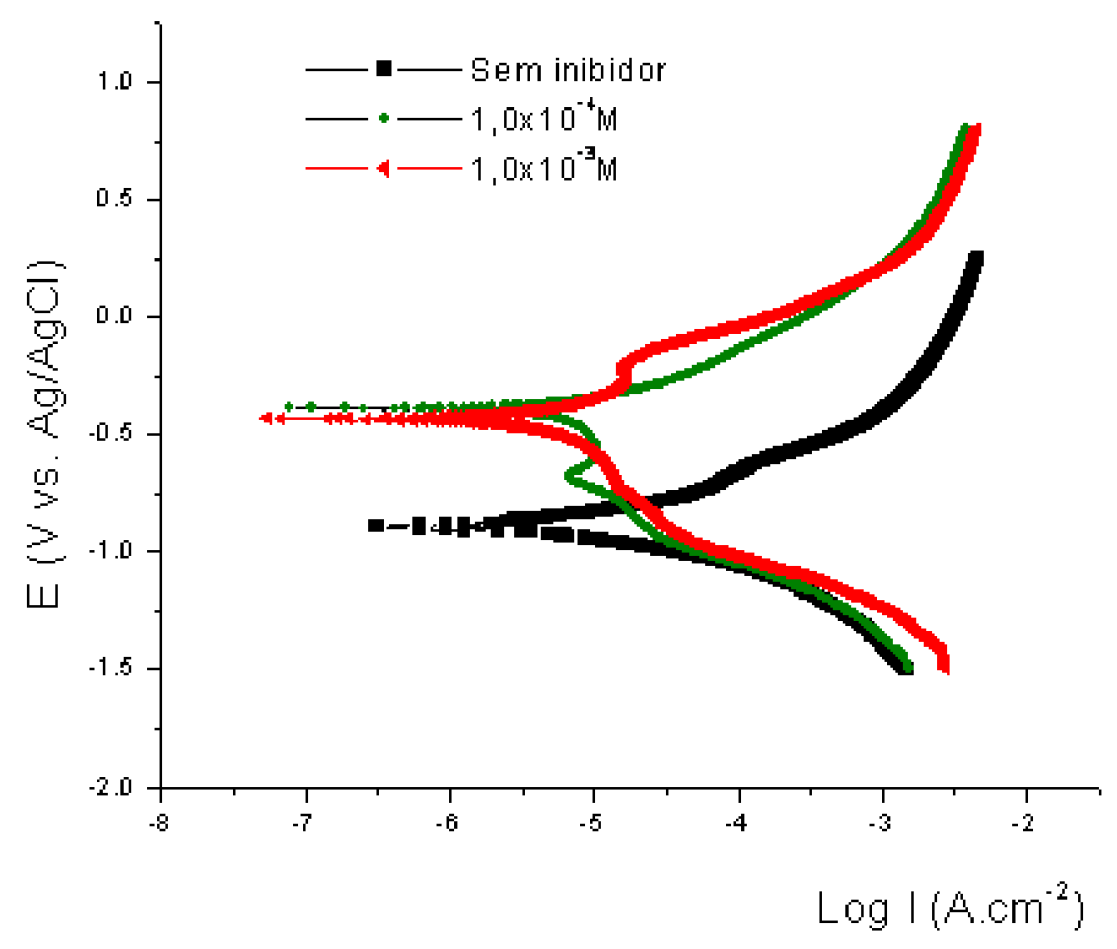

Figura 17 - Curvas de Polarização potenciodinâmicas do aço carbono ABNT 1005 em água de resfriamento industrial com e sem CPPM.

Por outro lado é também possível observar que as curvas catódicas praticamente não apresentam variação em relação à curva sem CPPM, logo a CPPM se comporta como inibidor anódico no meio estudado. Souza (2005) obteve resultados que mostraram que a CPPM para aço carbono ABNT 1005, comporta-se como inibidor misto em meio de $\mathrm{HCl} 2 \mathrm{M}$.

$\mathrm{Na}$ Tabela 14 são apresentados os valores de densidade de corrente de corrosão e os valores da eficiência do CPPM. Estes resultados evidenciam a redução da velocidade de dissolução do metal na presença do CPPM no meio. Os valores de eficiência estimados a partir da densidade de corrente de corrosão são menores do que aqueles obtidos com o $\mathrm{Na}_{2} \mathrm{MoO}_{4}$ e $\mathrm{Na}_{2} \mathrm{WO}_{4}$ e maior do que a presença do Ft-Cu. Esses resultados são concordantes com os valores de eficiência obtidos a partir da resistência à transferência de carga. 
Tabela 14 - Densidades de correntes de corrosão e valores de eficiência para aço carbono ABNT 1005 em meio e água de resfriamento industrial na presença e na ausência de CPPM.

\begin{tabular}{lcc}
\hline CPPM / M & $\mathbf{i}_{\text {corr }} / \mathbf{A . c m}^{-2}$ & $\boldsymbol{\eta} / \%$ \\
\hline Sem inibidor & $7,6 \times 10^{-6}$ & - \\
$1,0 \times 10^{-4}$ & $3,8 \times 10^{-6}$ & 50 \\
$1,0 \times 10^{-3}$ & $2,9 \times 10^{-6}$ & 62 \\
\hline
\end{tabular}

\subsubsection{Ftalocianina de Cobre, Ft-Cu}

A Figura 18 apresenta as curvas de polarização anódicas e catódicas que foram obtidas para o aço carbono ABNT 1005 no sistema em estudo. Pode-se observar que baixas concentrações de $\mathrm{Ft}-\mathrm{Cu}$ não inibem a dissolução do aço ABNT 1005. No entanto, para a concentração de $1,0 \times 10^{-3} \mathrm{M}$ de $\mathrm{Ft}-\mathrm{Cu}$, a curva anódica torna-se mais polarizada em relação a aquela obtida sem a presença do inibidor, evidenciando o mecanismo de atuação como inibidor anódico. Por outro lado, as curvas de polarização catódicas não exibem mudanças em relação à curva sem inibidor, mesmo para alta concentração. Portanto, a Ft-Cu nas condições em que foi estudada inibe a reação de dissolução do metal formando um filme que age como barreira entre o meio e a superfície do metal quando é usado apenas na concentração de $1,0 \times 10^{-3} \mathrm{M}$ de Ft-Cu. 


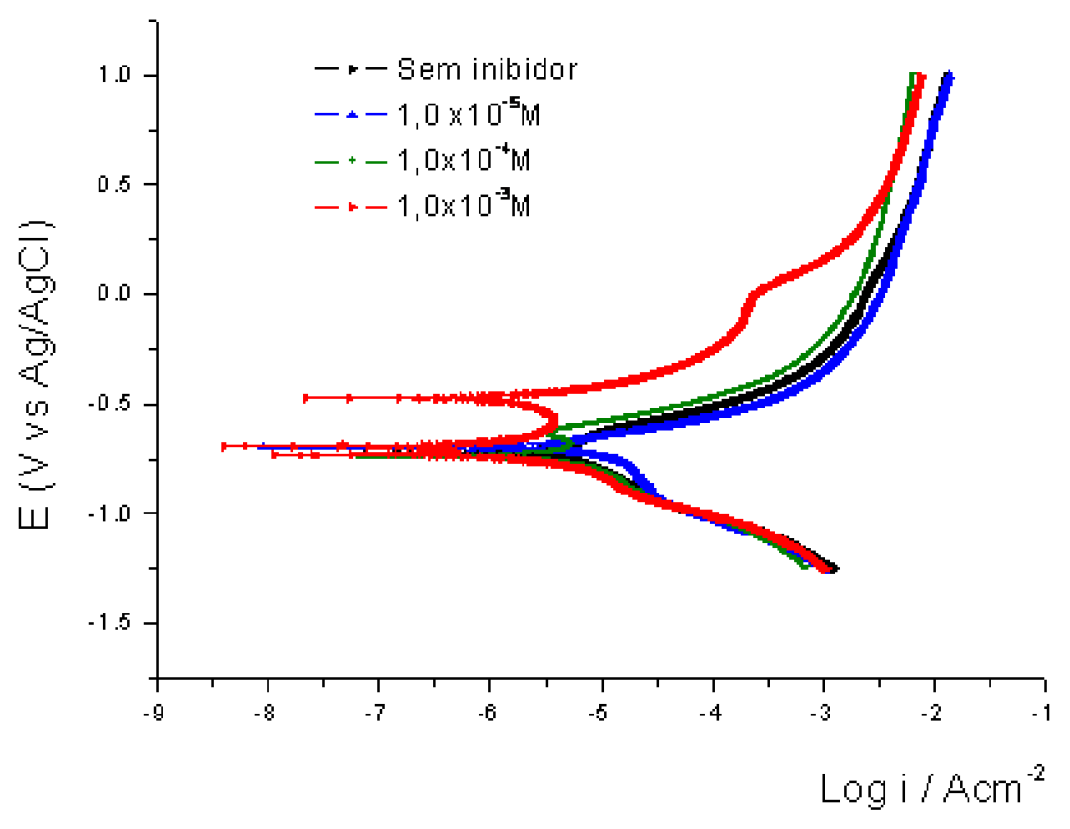

Figura 18 - Curvas de Polarização potenciodinâmicas do aço carbono ABNT 1005 em água de resfriamento industrial com e sem Ft-Cu.

Entretanto, em meio de acido clorídrico 16\%, Guedes, Maranhão e Aoki (2002) verificaram que a $\mathrm{Ft}-\mathrm{Cu}$ age como inibidor misto, para um aço de alta resistência e baixa liga. Estudos desenvolvidos por Zhao, Liang e Li (2005), para aço carbono em meio de ácido clorídrico $1 \mathrm{M}$, também mostram que a $\mathrm{Ft}-\mathrm{Cu}$ age como inibidor misto. Provavelmente a diferença no desempenho da $\mathrm{Ft}-\mathrm{Cu}$ como inibidor misto e como inibidor anódico obtido neste trabalho, pode ser atribuída a variação no pH do meio. É sabido que em meio ácido a reação catódica de evolução de hidrogênio é favorecida pela alta concentração dos íons $\mathrm{H}^{+}$em solução (GENTIL, 2007). Portanto, é possível concluir que a Ft-Cu é também capaz de agir de modo a diminuir a velocidade da reação catódica de evolução de hidrogênio, somente em meio ácido.

$\mathrm{Na}$ Tabela 15 são apresentados os valores de densidade de corrente de corrosão e os valores de eficiência que foram estimados por meio da equação (13) apresentada na sessão 4.1.4.1. 
Tabela 15 - Densidades de correntes de corrosão e valores de eficiência para aço carbono ABNT 1005 em meio de água de resfriamento industrial na presença e na ausência de $\mathrm{Ft}-\mathrm{Cu}$

\begin{tabular}{lcc}
\hline .Ft-Cu / M & $\mathrm{I}_{\text {corr }} / \mathbf{A} . \mathbf{c m}^{-2}$ & $\boldsymbol{\eta} / \%$ \\
\hline Sem inibidor & $7,610^{-6}$ & \\
$1,0 \times 10^{-5}$ & $6,6 \times 10^{-6}$ & 13 \\
$1,0 \times 10^{-4}$ & $5,0 \times 10^{-6}$ & 34 \\
$1,0 \times 10^{-3}$ & $4,9 \times 10^{-6}$ & 36 \\
\hline
\end{tabular}

Os valores de densidade de corrente de corrosão diminuem com a concentração de $\mathrm{Ft}-\mathrm{Cu}$, logo os valores de eficiência da $\mathrm{Ft}$-Cu são consistentes em ordem de magnitude com aqueles estimados usando os valores da resistência à transferência de carga. Os valores de eficiência da Ft-Cu são bem inferiores que aqueles com molibdato e tungstato.

\subsection{Comparação dos resultados obtidos com as substâncias estudadas individualmente.}

Os valores de eficiência de inibição da corrosão das substâncias estudadas na concentração de $1,0 \times 10^{-3} \mathrm{M}$ estimados pela resistência à transferência de carga, $R_{\mathrm{tc}}$ obtidas dos diagramas de impedância e pela densidade de corrente de corrosão, $\mathrm{i}_{\text {corr }}$ obtidas das curvas de polarização, são apresentados na Tabela 16. 
Tabela 16 - Valores de eficiência das substâncias estudadas como inibidores de corrosão estimada pela $R_{\text {tc }}$ e pela $i_{\text {corr. }}$.

\begin{tabular}{l|cr}
\hline \multirow{2}{*}{ Inibidor } & \multicolumn{2}{|c}{ Eficiência / $\boldsymbol{\eta}(\%)$} \\
\cline { 2 - 3 } $\mathrm{Na}_{2} \mathrm{MoO}_{4}$ & $\mathbf{R}_{\mathbf{t c}}$ & $\mathbf{i}_{\text {corr }}$ \\
$\mathrm{Na}_{2} \mathrm{WO}_{4}$ & 74 & 77 \\
$\mathrm{CCPM}$ & 90 & 69 \\
$\mathrm{Ft}-\mathrm{Cu}$ & 52 & 62 \\
\hline
\end{tabular}

Ao comparar os valores de eficiência obtidos para cada substância verifica-se que a diferença entre as técnicas não é tão alta, logo, os resultados aparecem concordantes para ambas as técnicas; só no caso do tungstato de sódio obteve-se uma diferença relativamente alta entre os dois valores. Também se verifica que os resultados obtidos com molibdato e tungstato de sódio são concordantes com aqueles encontrados na literatura, onde a eficiência dos inibidores anódicos inorgânicos em meio neutro, é maior do que a eficiência de compostos poliméricos orgânicos (KUZNETSOV, 2004). Na literatura, não estão bem estabelecidas as vantagens de molibdato sobre o tungstato quanto à inibição da corrosão, embora o custo relativamente alto do tungstato tenha influenciado a preferência pelo molibdato de sódio (SAJI; SHIBLI, 2005).

Em relação à diferença entre os valores de eficiência por ambas as técnicas, estimadas para o tungstato de sódio; Lorenz e Mansfelf (1981) concluíram que nem sempre existe correlação entre os métodos, devido à complexidade da natureza dos processos corrosiva metal/meio na presença de inibidores.

Os valores de eficiência contra a corrosão baseada na resistência à transferência de carga apresentam-se na seguinte ordem das substâncias envolvidas: $\mathrm{Na}_{2} \mathrm{WO}_{4}>\mathrm{Na}_{2} \mathrm{MoO}_{4}>\mathrm{CCPM}>\mathrm{Ft}-\mathrm{Cu}$.

Se forem comparados os valores de eficiência obtida partir de densidade de corrente de corrosão, a ordem crescente de eficiência é $\mathrm{Na}_{2} \mathrm{MoO}_{4}>$ 
$\mathrm{Na}_{2} \mathrm{WO}_{4}>\mathrm{CCPM}>\mathrm{Ft}-\mathrm{Cu}$, mostrando uma pequena vantagem a favor do molibdato em relação ao tungstato.

\subsection{Caracterização da superfície}

Os ensaios de caracterização da superfície usando a microscopia eletrônica de varredura, permitiram comprovar a presença do filme na superfície do aço, para cada uma das substâncias estudadas. Outras características do filme tais como porosidade, espessura ou a presença de complexos entre o ferro e os inibidores não foram possíveis detectar com os ensaios realizados. Os ensaios de EDS não permitiram identificar quantitativamente a presença, por exemplo, de molibdato, tungstato, ou cobre na superfície. Isto pode ser explicado devido o filme formado pelos inibidores de corrosão, estudados neste trabalho, ser extremamente fino e pouco homogêneo.

\subsubsection{Molibdato de sódio e Tungstato de sódio.}

Nas Figuras 19a, 19b e 19c, observam-se imagens que foram obtidas por MEV após três horas de imersão em meio de água de resfriamento industrial, na ausência e presença de molibdato e tungstato de sódio respectivamente, ambos na concentração de $1,0 \times 10^{-3} \mathrm{M}$.

Na Figura 19a não se observa produto de corrosão, isto porque o meio é neutro e o tempo de imersão é apenas de três horas. Observam-se os riscos da lixa

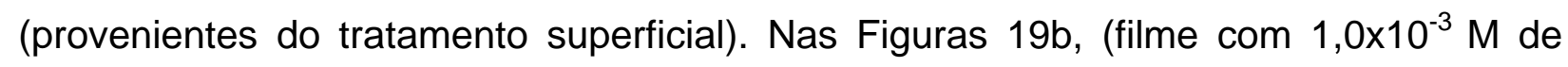
$\mathrm{Na}_{2} \mathrm{MoO}_{4}$ ) e $19 \mathrm{c}$ (filme com $1,0 \times 10^{-3} \mathrm{M}$ de $\mathrm{Na}_{2} \mathrm{WO}_{4}$ ) resulta evidente a presença do filme na superfície do aço carbono ABNT 1005. Este resultado é concordante com 
aqueles obtidos pelas técnicas eletroquímicas, nas quais foi observado que tanto a presença de $\mathrm{Na}_{2} \mathrm{MoO}_{4}$ como a de $\mathrm{Na}_{2} \mathrm{WO}_{4}$ inibem a dissolução do aço.

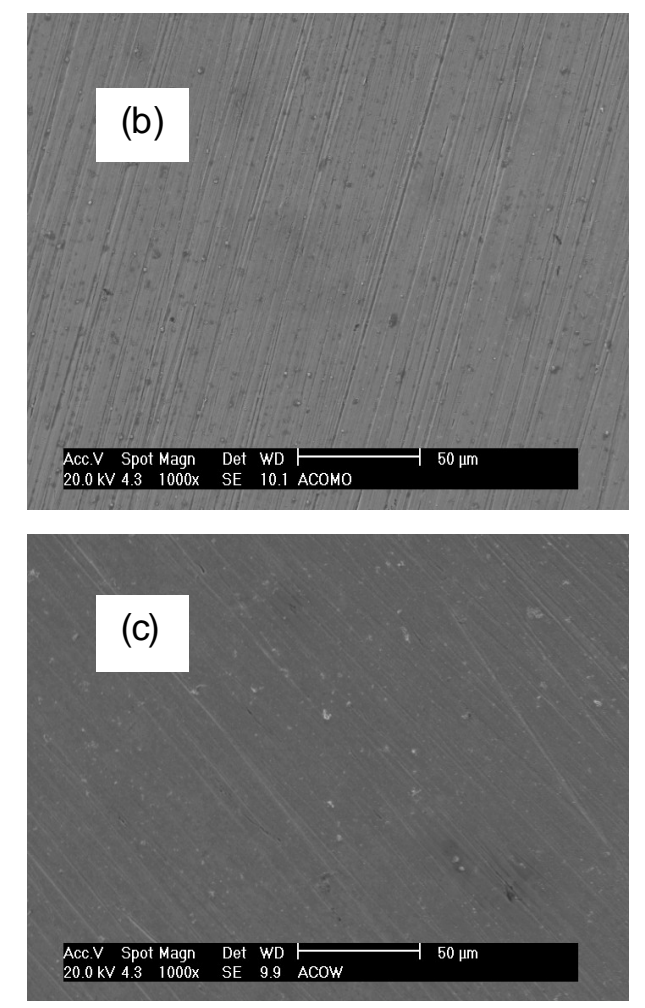

Figura 19 - Imagens obtidas em MEV por elétrons secundários com aumento de 1000X.

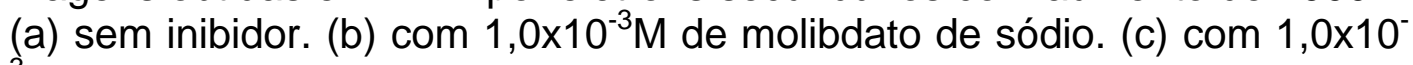
${ }^{3} \mathrm{M}$ de tungstato de sódio.

\subsubsection{Copolímero de polioxialquileno e polidimetilsiloxano, CPPM}

Na Figura 20a e 20b são apresentadas às imagens obtidas em MEV por elétrons secundários e 500X de aumentos para aço carbono após três horas de imersão em

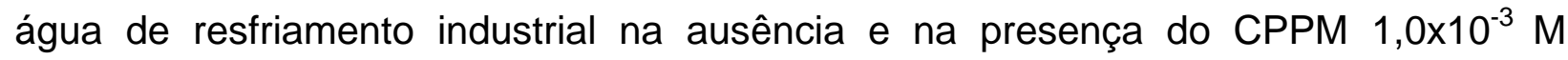
respectivamente. Na figura $20 \mathrm{~b}$, a superfície de aço carbono na presença da CPPM apresenta um aspecto homogêneo em relação à superfície do aço sem a presença de 
CPPM. As regiões manchadas provavelmente são devido a problemas na secagem da amostra após a imersão.
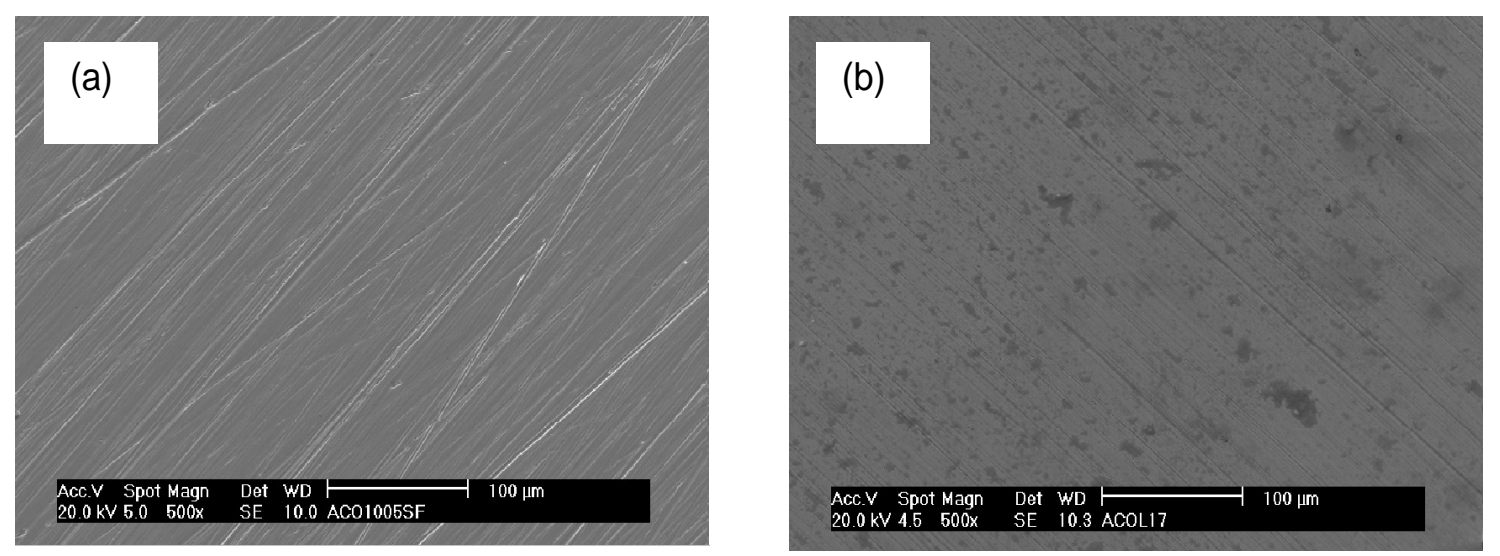

Figura 20 - Imagens obtidas em MEV por elétrons secundários do aço ABNT 1005 após 3 horas de imersão em água de resfriamento industrial com aumento de 1000X. (a) sem inibidor. (b) $1,0 \times 10^{-3} \mathrm{M}$ CPPM.

\subsubsection{Ftalocianina de cobre, Ft-Cu}

Na Figura 21a, e 21b são apresentadas às imagens da amostra do aço carbono obtidas em MEV por elétrons secundários com 1000X de aumentos; imersa por três horas em água de resfriamento industrial na ausência e na presença de ftalocianina de cobre $1,0 \times 10^{-3} \mathrm{M}$ respectivamente. A figura $21 \mathrm{c}$ apresenta um detalhe da mesma amostra com 3000X de aumento.

A superfície de aço carbono na presença da Ft-Cu, Figura 21b, apresenta um aspecto não homogêneo com áreas de acúmulo de possíveis cristais compostos de Ft$\mathrm{Cu}$ e que provavelmente não foram dissolvidos no eletrólito, segundo pode ser observado no detalhe da Figura 21c. 

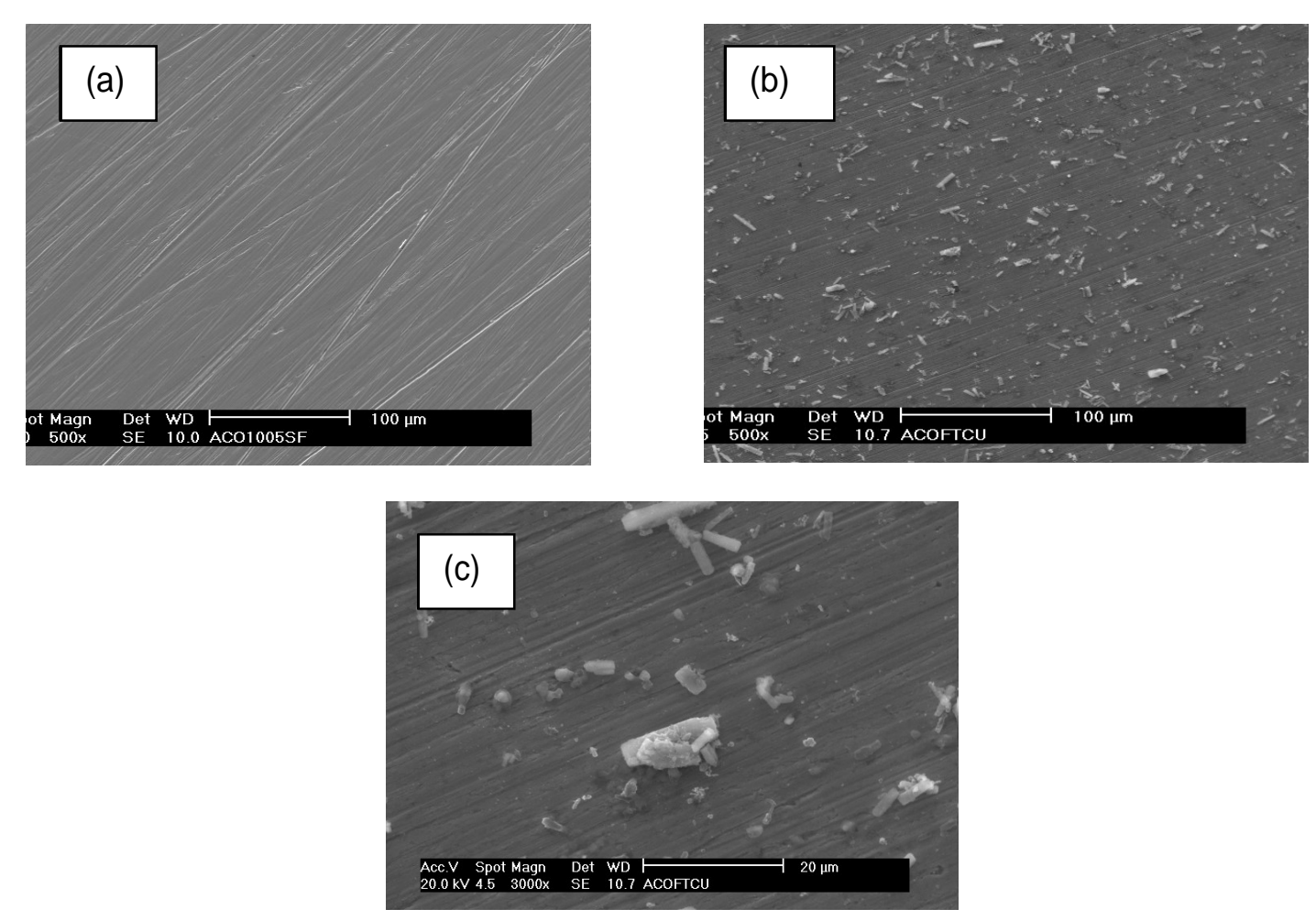

Figura 21 - Imagens obtidas em MEV por elétrons secundários do aço ABNT 1005 após 3 horas de imersão em água de resfriamento industrial com aumento de 1000X. (a) sem inibidor. (b) $1,0 \times 10^{-3} \mathrm{M} \mathrm{Ft}-\mathrm{Cu}$. (c) detalhe com aumento de $3000 \mathrm{X}$.

\subsection{Planejamento fatorial completo}

O planejamento fatorial completo permitiu estudar o comportamento da mistura das substâncias como inibidores de corrosão para aço carbono ABNT 1005 em meio da água de resfriamento industrial.

$\mathrm{Na}$ Tabela 16 são apresentados os resultados da variável de resposta, (resistência à transferência de carga), de cada ensaio da matriz do planejamento fatorial completo. Para facilitar a análise matemática e a interpretação dos resultados, os dois níveis das variáveis de entrada são codificados com os números -1 e+1 que representam os níveis mínimo e máximo de concentração. 
Realizando-se a análise estatística por meio do software Minitab foi possível identificar os efeitos e as interações das variáveis de entrada na variável de resposta estudada. Assim, foi também possível estabelecer um modelo matemático/estatístico que representa a variação da resistência à transferência de carga com a concentração molar de cada uma das substâncias estudadas como inibidor de corrosão que foram: $\mathrm{Na}_{2} \mathrm{MoO}_{4}\left(\mathrm{x}_{1}\right)$; CPPM $\left(\mathrm{x}_{2}\right) ; \mathrm{Na}_{2} \mathrm{WO}_{4}\left(\mathrm{x}_{3}\right)$ e Ft-Cu $\left(\mathrm{x}_{4}\right)$.

Tabela 16 - Matriz de ensaios experimentais para as variáveis de entrada codificadas, (concentração molar das substâncias) tendo como resposta os valores de resistência à transferência de carga $\left(\mathrm{R}_{\mathrm{tc}}\right)$.

\begin{tabular}{ccccc|c}
\hline \multicolumn{5}{c}{ Variáveis de entrada codificadas } & $\begin{array}{c}\text { Variável de } \\
\text { resposta }\end{array}$ \\
\hline Padrão & $\mathbf{N a}_{2} \mathbf{M o O}_{4}$ & $\mathbf{C P P M}$ & $\mathbf{N a}_{2} \mathbf{W O}_{4}$ & $\mathbf{F t}-\mathbf{C u}$ & $\mathbf{R}_{\mathbf{t c}} /$ Ohm.cm $^{2}$ \\
\hline 1 & -1 & -1 & -1 & -1 & 1132 \\
2 & 1 & -1 & -1 & -1 & 7564 \\
3 & -1 & 1 & -1 & -1 & 2339 \\
4 & 1 & 1 & -1 & -1 & 6107 \\
5 & -1 & -1 & 1 & -1 & 11259 \\
6 & 1 & -1 & 1 & -1 & 65673 \\
7 & -1 & 1 & 1 & -1 & 13366 \\
8 & 1 & 1 & 1 & -1 & 84176 \\
9 & -1 & -1 & -1 & 1 & 1580 \\
10 & 1 & -1 & -1 & 1 & 11011 \\
11 & -1 & 1 & -1 & 1 & 2300 \\
12 & 1 & 1 & -1 & 1 & 3393 \\
13 & -1 & -1 & 1 & 1 & 22331 \\
14 & 1 & -1 & 1 & 1 & 33576 \\
15 & -1 & 1 & 1 & 1 & 10439 \\
16 & 1 & 1 & 1 & 1 & 26422 \\
\hline
\end{tabular}

$\mathrm{Na}$ Tabela 17 são apresentados os resultados da análise estatística realizada com software Minitab. Observam-se os efeitos das variáveis de entrada na variável de 
reposta, resistência à transferência de carga. A probabilidade de cada variável de entrada ser significativa al modelo é representada pela letra "p", sendo importante ressaltar que para a variável ser significativa, o valor de "p" deve ser o menor possível; também podem observar-se coeficientes da regressão do modelo e o desvio padrão. Para este estudo o grau de confiança foi fixado em $90 \%$.

Tabela 17- Resultados da análise estatística usando o software Minitab, mostrando os valores dos efeitos individuais e as interações na variável de resposta resistência à transferência de carga.

\begin{tabular}{l|ccc}
\hline \multicolumn{1}{c|}{ Variável Entrada } & Efeitos & $\begin{array}{c}\text { Probabilidade } \\
(\mathbf{p})\end{array}$ & $\begin{array}{c}\text { Coeficientes do } \\
\text { modelo }\end{array}$ \\
\hline Termo constante & $\mathbf{1 8 8 9 8}$ & $\mathbf{0 , 0 0 2}$ & $\mathbf{1 8 8 9 8}$ \\
$\mathrm{Na}_{2} \mathrm{MoO}_{4}\left(\mathrm{x}_{1}\right)$ & $\mathbf{2 1 6 1 0}$ & $\mathbf{0 , 0 1 7}$ & $\mathbf{1 0 8 0 5}$ \\
$\mathrm{CPPM}\left(\mathrm{x}_{2}\right)$ & -660 & 0,919 & -330 \\
$\mathrm{Na}_{2} \mathrm{WO}_{4}\left(\mathrm{x}_{3}\right)$ & $\mathbf{2 8 9 3 9}$ & $\mathbf{0 , 0 0 5}$ & $\mathbf{1 4 4 7 0}$ \\
$\mathrm{Ft}_{-\mathrm{Cu}}\left(\mathrm{x}_{4}\right)$ & -10033 & 0,164 & -5016 \\
$\mathrm{Na}_{2} \mathrm{MoO}_{4}{ }^{*} \mathrm{CPPM}\left(\mathrm{x}_{1}{ }^{*} \mathrm{x}_{2}\right)$ & 1304 & 0,841 & 652 \\
$\mathrm{Na}_{2} \mathrm{MoO}_{4}{ }^{*} \mathrm{Na}{ }_{2} \mathrm{WO}_{4}\left(\mathrm{x}_{1}{ }^{*} \mathrm{x}_{3}\right)$ & $\mathbf{1 6 4 2 9}$ & $\mathbf{0 , 0 0 4 4}$ & $\mathbf{8 2 1 4}$ \\
$\mathrm{Na}_{2} \mathrm{MoO}_{4}{ }^{*} \mathrm{Ft}-\mathrm{Cu}\left(\mathrm{x}_{1}{ }^{*} \mathrm{x}_{4}\right)$ & -12171 & 0,105 & -6086 \\
$\mathrm{CPPM}^{*} \mathrm{Na}_{2} \mathrm{WO}_{4}\left(\mathrm{x}_{2}{ }^{*} \mathrm{x}_{3}\right)$ & 1126 & 0,862 & 563 \\
$\mathrm{CPPM}^{*} \mathrm{Ft}-\mathrm{Cu}\left(\mathrm{x}_{2}{ }^{*} \mathrm{x}_{4}\right)$ & -5825 & 0,387 & -2913 \\
$\mathrm{Na}_{2} \mathrm{WO}_{4}{ }^{*} \mathrm{Ft}-\mathrm{Cu}\left(\mathrm{x}_{3}{ }^{*} \mathrm{x}_{4}\right)$ & -10319 & 0,154 & -5159 \\
\hline $\mathrm{COflilem}$ & & &
\end{tabular}

Coeficiente de determinação $\mathrm{R}^{2}=0,73$

Levando em conta que o objetivo principal da aplicação da técnica estatística nesta investigação foi à identificação dos possíveis efeitos sinérgicos pela mistura das substâncias na variável de resposta selecionada, $\left(R_{\mathrm{tc}}\right)$; todo efeito com sinal positivo pode ser interpretado como aumento na resistência à transferência de carga. Adicionalmente, analisando os valores de probabilidade, $p$, conclui-se que $x_{1}, x_{3}$ e a relação linear entre $x_{1}$ e $x_{3}$ são as variáveis significativas para o grau de confiança utilizado (90\%).

$\mathrm{Na}$ Figura 22 é apresentado o gráfico de probabilidade normal dos efeitos e as interações significativas na variável de resposta; onde se mostra que os efeitos e interações positivas e significativas correspondem às variáveis $x_{1}$, molibdato de sódio, 
$x_{3}$ tungstato de sódio e sua interação, $x_{1}{ }^{*} x_{3}$, tendo em vista que, estes são os pontos mais distantes do efeito zero.

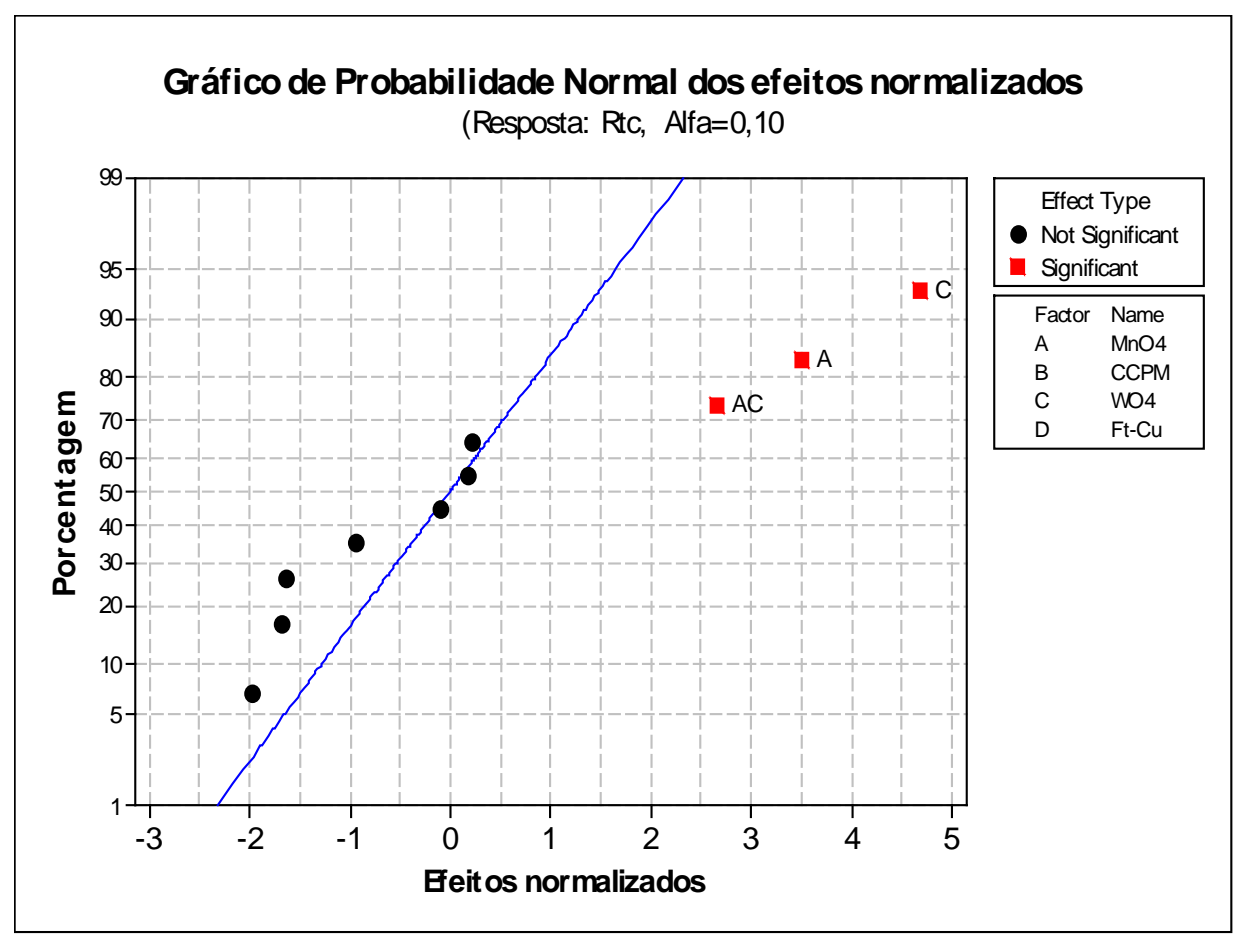

Figura 22 - Gráfico de probabilidade normal para os efeitos das variáveis de entrada para cada substância estudada como inibidor de corrosão, destacando as variáveis de entrada com maior efeito na variável de resposta, $\left(R_{t c}\right)$.

Finalmente o modelo matemático/estatístico obtido para estimar a resistência à transferência de carga como função das variáveis: concentração do molibdato de sódio $\left(x_{1}\right)$ e tungstato de sódio $\left(x_{3}\right)$ é representado pela equação 14:

$$
R_{t c}=18898+21610 x_{1}+28939 x_{3}+16425 x_{1} x_{3}
$$

Na Figura 23 é apresentado o valor residual (erros) vs. os valores estimados da variável de resposta $\left(R_{t c}\right)$. Pode observar-se uma distribuição aleatória, sugerindo que 0 modelo é razoavelmente apropriado, o qual é condizente com o valor do coeficiente de determinação que foi de 0,74 . 


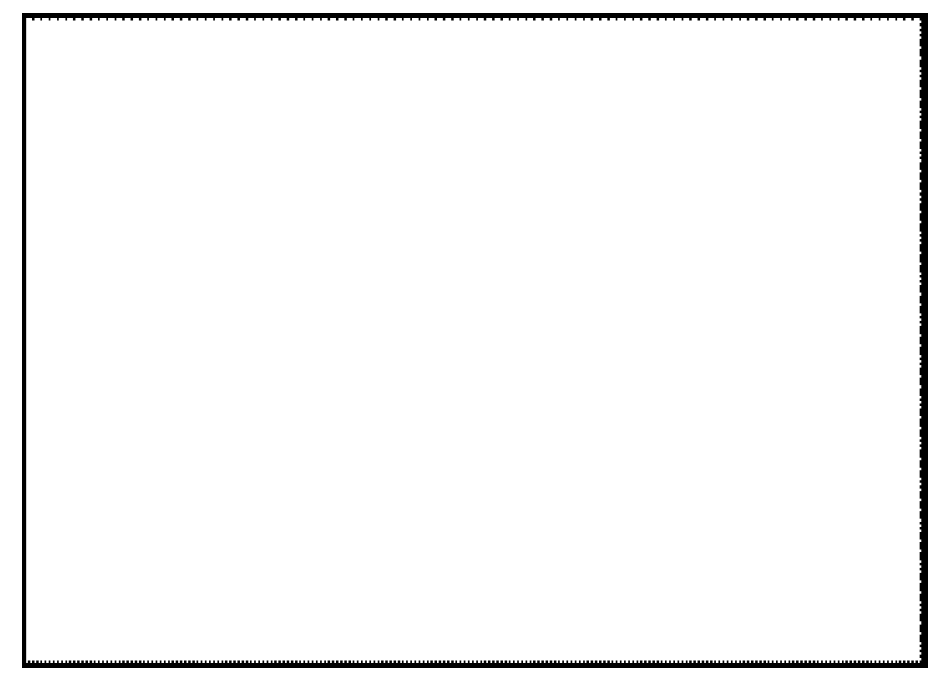

Figura 23 - Gráfico de probabilidade normal dos resíduos.

Os resultados obtidos nesta etapa de trabalho permitem propor um estudo mais aprofundado da mistura de das substâncias molibdato e tungstato de sódio na próxima etapa.

\subsection{Planejamento fatorial composto}

Nesta oportunidade foram estudadas mediante a análise estatística duas variáveis de resposta. Foi selecionada como variável de reposta, além da resistência a transferência de carga, $R_{\mathrm{tc}}$, o módulo de impedância, IZI na freqüência de $100 \mathrm{mHz}$, com a finalidade de validar o modelo matemático obtido e a consistência dos resultados experimentais. O módulo de impedância, $I Z I_{\text {a } 100 \mathrm{mHz}}$ é um valor obtido diretamente do diagrama de impedância a uma freqüência considerada intermediaria, mas no limite com baixas freqüências, onde é possível detectar os processos de transferência de carga, difusão etc, portanto, associados com os fenômenos corrosivos estudados neste trabalho. A resistência à transferência de carga, $R_{t c}$, como já discutido anteriormente, foi estimada através da modelagem usando circuitos elétricos equivalentes. 
A Tabela 18 apresenta a matriz de ensaios na ordem padrão e de execução e os resultados das variáveis de resposta, $R_{t c}$ e do IZI a $100 \mathrm{mHz}$ obtidos para o planejamento fatorial composto.

Tabela 18- Matriz de ensaios experimentais para as variáveis de entrada codificadas, tendo como variáveis de resposta os valores de resistência à transferência de carga $\left(R_{\mathrm{tc}}\right)$ e o módulo de impedância, $\mid \mathrm{ZI}$ a $100 \mathrm{mHz}$.

\begin{tabular}{|c|c|c|c|c|c|}
\hline Padrão & Execução & $\mathrm{Na}_{2} \mathrm{MoO}_{4}$ & $\mathrm{Na}_{2} \mathrm{WO}_{4}$ & $\begin{array}{c}\mathbf{R}_{\mathrm{tc}} \\
\text { Ohm.cm }{ }^{2}\end{array}$ & $\begin{array}{l}\text { IZI a } 100 \mathrm{mHz} \\
\text { Ohm.cm² }\end{array}$ \\
\hline 1 & 10 & -1 & -1 & 25940 & 4702 \\
\hline 2 & 13 & 1 & -1 & 15504 & 4887 \\
\hline 3 & 12 & -1 & 1 & 9506 & 1956 \\
\hline 4 & 14 & 1 & 1 & 49915 & 6264 \\
\hline 5 & 9 & -1.41 & 0 & 11808 & 2450 \\
\hline 6 & 8 & 1.41 & 0 & 55792 & 7139 \\
\hline 7 & 11 & 0 & -1.41 & 14516 & 2764 \\
\hline 8 & 5 & 0 & 1.41 & 68094 & 10841 \\
\hline 9 & 3 & 0 & 0 & 74267 & 9998 \\
\hline 10 & 7 & 0 & 0 & 96054 & 10172 \\
\hline 11 & 2 & 0 & 0 & 65404 & 7062 \\
\hline 12 & 4 & 0 & 0 & 55423 & 9295 \\
\hline 13 & 6 & 0 & 0 & 54427 & 5644 \\
\hline 14 & 1 & 0 & 0 & 94636 & 7689 \\
\hline
\end{tabular}

Com os resultados de $R_{\mathrm{tc}}$ e $I \mathrm{ZI} \mathrm{a}_{\mathrm{a} 100 \mathrm{mHz}}$ foi feita uma análise estatística por meio de software Statistica, visando obter o modelo matemático/estatístico que relaciona as variáveis de entrada e as variáveis de saída.. Para realizar a análise foram consideradas as interações lineares e as quadráticas das variáveis de entrada e a interação linear entre elas. Nas Tabelas 19 e 20 são apresentados os resultados da análise estatística, podem observar-se: os efeitos em cada variável de resposta; o valor de " $p$ " e os coeficientes de modelo matemático. Para ambas as variáveis de resposta foram considerados significativos todos os efeitos; pois os valores máximos de "p" atingiram um valor muito próximo de 0,2 considerado por Box e Hunter (1978) como o valor limite para a seleção dos efeitos significativos. 
Tabela 19 - Análise estatística do planejamento fatorial composto usando como variável de reposta a resistência à transferência de carga $\left(R_{t c}\right)$.

\begin{tabular}{lccc}
\hline & Efeitos & $\mathbf{p}$ & Coeficientes \\
\hline Meia/interações & 73393 & 0,000196 & 73393 \\
$\mathrm{Na}_{2} \mathrm{MoO}_{4}$ linear $(X)$ & 23066 & 0,138676 & 11533 \\
$\mathrm{Na}_{2} \mathrm{MoO}_{4}$ quadrático $\left(X^{2}\right)$ & -45927 & 0,020159 & -22963 \\
$\mathrm{Na}_{2} \mathrm{WO}_{4}$ linear $(Y)$ & 23450 & 0,133535 & 11725 \\
$\mathrm{Na}_{2} \mathrm{WO}_{4}$ quadrático $\left(\mathrm{Y}^{2}\right)$ & -39377 & 0,037739 & -19188 \\
$\mathrm{Na}_{2} \mathrm{MoO}_{4}{ }^{*} \mathrm{Na}_{2} \mathrm{WO}_{4}$ linear $\left(X^{\star} \mathrm{Y}\right)$ & 25423 & 0,227871 & 12711 \\
\hline
\end{tabular}

Coeficiente de determinação $\left(R^{2}\right): 0,78$

Tabela 20 - Análise estatística do planejamento fatorial composto usando como variável de resposta o módulo de impedância $\mid Z I_{\text {a }} 100 \mathrm{mHz}$.

\begin{tabular}{lccc}
\hline & Efeitos & $\mathbf{p}$ & Coeficientes \\
\hline Meia / interaçõess & 8844 & 0,000144 & 8846 \\
$\mathrm{Na}_{2} \mathrm{MoO}_{4}$ linear $(X)$ & 2784 & 0,048123 & 1392 \\
$\mathrm{Na}_{2} \mathrm{MoO}_{4}$ quadrático $\left(X^{2}\right)$ & -4744 & 0,011169 & -2372 \\
$\mathrm{Na}_{2} \mathrm{WO}_{4}$ linear $(Y)$ & 2512 & 0,064039 & 2356 \\
$\mathrm{Na}_{2} \mathrm{WO}_{4}$ quadrático $\left(Y^{2}\right)$ & -2724 & 0,062623 & -1362 \\
$\mathrm{Na}_{2} \mathrm{MoO}_{4}{ }^{*} \mathrm{Na}_{2} \mathrm{WO}_{4}$ linear $\left(X^{*} Y\right)$ & 2061 & 0,214149 & 1031 \\
\hline
\end{tabular}

Coeficiente de determinação $\left(R^{2}\right): 0.71$

A seguir são representadas as superfícies de reposta obtida para a resistência á transferência de carga, (Figura 24) e para o módulo de impedância IZI a 100 mHz, (Figura 25). A curvatura das superfícies de resposta (forma parabólica) é característica das funções de segundo ordem e resultado da predominância dos efeitos quadráticos das variáveis de entrada e a interação entre elas. 


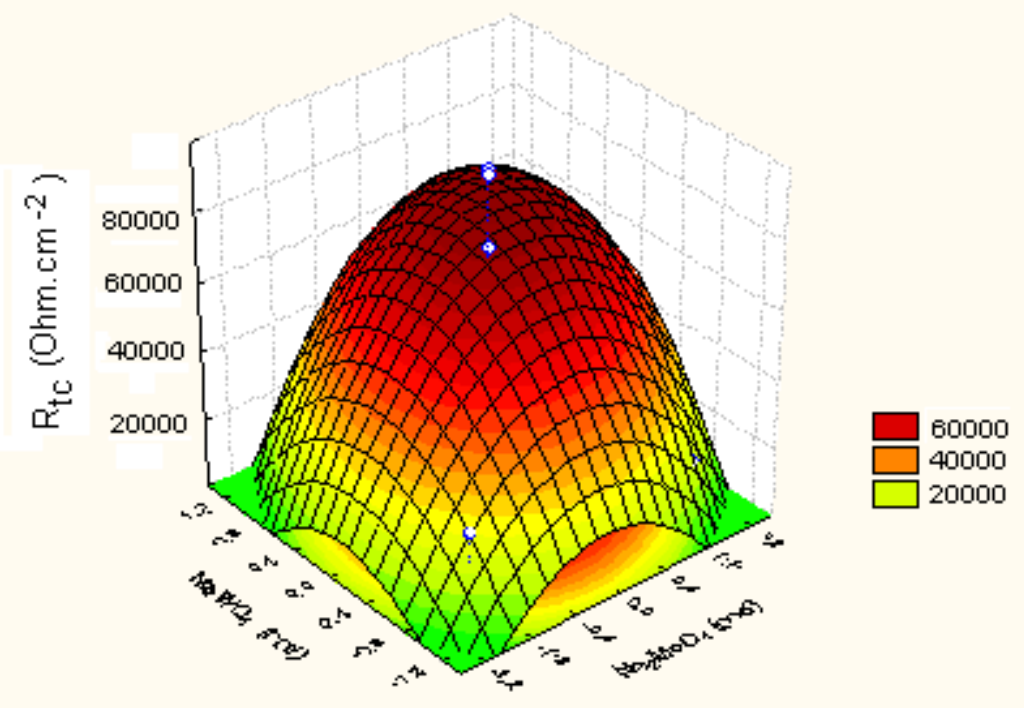

Figura 24 - Superfície de resposta obtida tendo como variáveis de entrada concentração de molibdato e de tungstato de sódio, e variável de saída $R_{t c}$

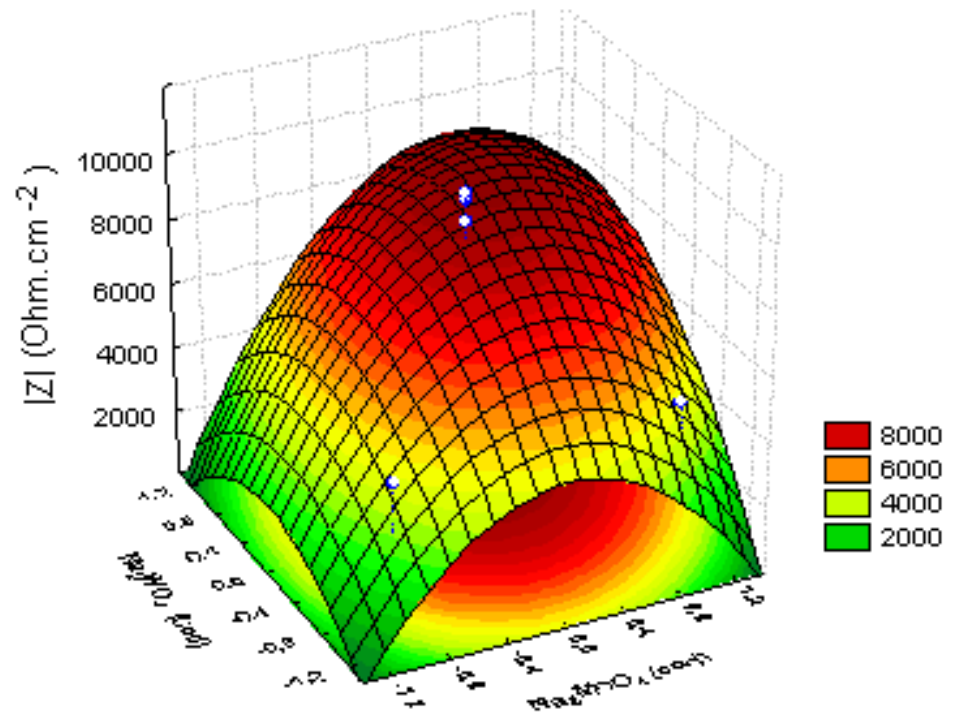

Figura 25 - Superfície de resposta obtida tendo como variáveis de entrada concentração de molibdato e de tungstato de sódio, e variável de saída IZI a $100 \mathrm{mHz}$. 
Ainda se referindo aos resultados da análise estatística do planejamento fatorial composto e em vista do anteriormente discutido, o modelo matemático-estatístico que representa a superfície de resposta com variável de saída $R_{\text {tc }}$ é representado pela equação (15):

$\mathbf{R}_{\mathrm{tc}}=73393+11533 \mathbf{X}-22963 \mathbf{X}^{2}+11725 \mathbf{Y}-19188 \mathbf{Y}^{2}$

Onde:

$\mathbf{X}$ : concentração de molibdato de sódio (variável codificada)

Y: concentração de tungstato de sódio (variável codificada)

Similarmente, quando a varivel de saída é o $\quad I Z \mid$ a $100 \mathrm{mHz}$, o modelo matemático- estatístico que representa a superfície de reposta é representado pela equação (16):

$$
\mathrm{IZI}_{\mathrm{a} 100 \mathrm{mHz}}=8846+1392 \mathrm{X}-2372 \mathbf{X}^{2}+1253 \mathrm{Y}-1362 \mathrm{Y}^{2}
$$

Onde:

$\mathbf{X}=$ concentração de molibdato de sódio (variável codificada)

$\mathbf{Y}=$ concentração de tungstato de sódio (variável codificada)

Para obter as concentrações do "ponto de ótimo" da mistura de $\mathrm{Na}_{2} \mathrm{MoO}_{4} \mathrm{e}$ $\mathrm{Na}_{2} \mathrm{WO}_{4}$ foi feita a derivada da função superfície de reposta para cada um das variáveis de resposta, representadas nas equações 15 e 16 respectivamente, e igualadas à zero; obtendo-se em cada caso um sistema de duas equações, cujas soluções, proporcionaram a combinação ótima de molibdato e tungstato de sódio em valores codificados e que são apresentados na Tabela 21. 
Tabela 21 - Valores ótimos da mistura de molibdato e tungstato de sódio em valores codificados.

\begin{tabular}{lcc}
\hline Valores codificados & $\mathrm{Na}_{2} \mathrm{MoO}_{4}$ & $\mathrm{Na}_{2} \mathrm{WO}_{4}$ \\
\hline $\mathbf{R}_{\mathrm{tc}}$ & 0,25 & 0,29 \\
$\mathbf{I Z I}_{\mathrm{a} 100 \mathrm{mHz}}$ & 0,31 & 0.46 \\
\hline
\end{tabular}

Posteriormente com o auxilio de equação (10) apresentada na seção 3.2.4 que relaciona as variáveis de entrada codificadas com seus valores reais, foram identificadas às concentrações molares ótimas da mistura de molibdato e tungstato de sódio nas condições investigadas. Os resultados obtidos são apresentados na Tabela 22.

$$
\mathrm{C}_{\mathrm{c}}=0,5 \times 10^{3} \mathrm{C}_{\mathrm{r}}-1,5
$$

Tabela 22 - Concentração ótima da mistura de molibdato e tungstato de sódio obtidas para as variáveis de resposta $R_{\mathrm{tc}}$ e $I \mathrm{ZI}$ a $100 \mathrm{mHz}$.

\begin{tabular}{lccc}
\hline Variável de reposta & $\mathrm{Na}_{2} \mathbf{M o O}_{4} / \mathbf{M}$ & $\mathrm{Na}_{2} \mathrm{WO}_{4} / \mathbf{M}$ & $\mathbf{R}^{2}$ \\
\hline $\mathbf{R}_{\mathrm{tc}}$ & $3,6 \times 10^{-3}$ & $3,5 \times 10^{-3}$ & 0,78 \\
$\mathbf{I Z I}$ a $100 \mathrm{mHz}$ & $3,6 \times 10^{-3}$ & $3,9 \times 10^{-3}$ & 0.71 \\
\hline
\end{tabular}

$\mathrm{Na}$ Tabela 22 observa-se que as concentrações obtidas para o ponto de ótimo são praticamente as mesmas, isto é para $R_{t c}$ e IZI a $100 \mathrm{mHz}$. No entanto, o coeficiente de determinação, $R^{2}$ para 0 modelo que relaciona a resistência à transferência de carga é ligeiramente superior ao valor obtido para o módulo de impedância, IZI a 100 $\mathrm{mHz}$. Diante dessa análise, a combinação ótima selecionada foi à correspondente à resistência à transferência de carga, isto é, molibdato de sódio e tungstato de sódio nas concentrações de $3,6 \times 10^{-3} \mathrm{M}$ e $3,5 \times 10^{-3} \mathrm{M}$ respectivamente. 


\subsection{Avaliação da mistura no ponto de ótimo ao longo do tempo}

Uma vez obtida à concentração ótima da mistura de inibidores, foi avaliada seu comportamento com o tempo de imersão. Com este objetivo, foram mantidos os ensaios de impedância eletroquímica para tempos de imersão de 3,6,12, 24,72, é 88 horas.

Na Figura 26 são apresentados os diagramas de impedância, cujos resultados mostram que os diagramas de Nyquist e Bode apresentam arcos capacitivos de diâmetros crescentes e módulos de impedância também crescentes com o tempo de imersão. Observa-se ainda que o tempo de imersão não altera o comportamento dos diagramas; o que pode ser interpretado como a não existência de novos processos na superfície do metal.
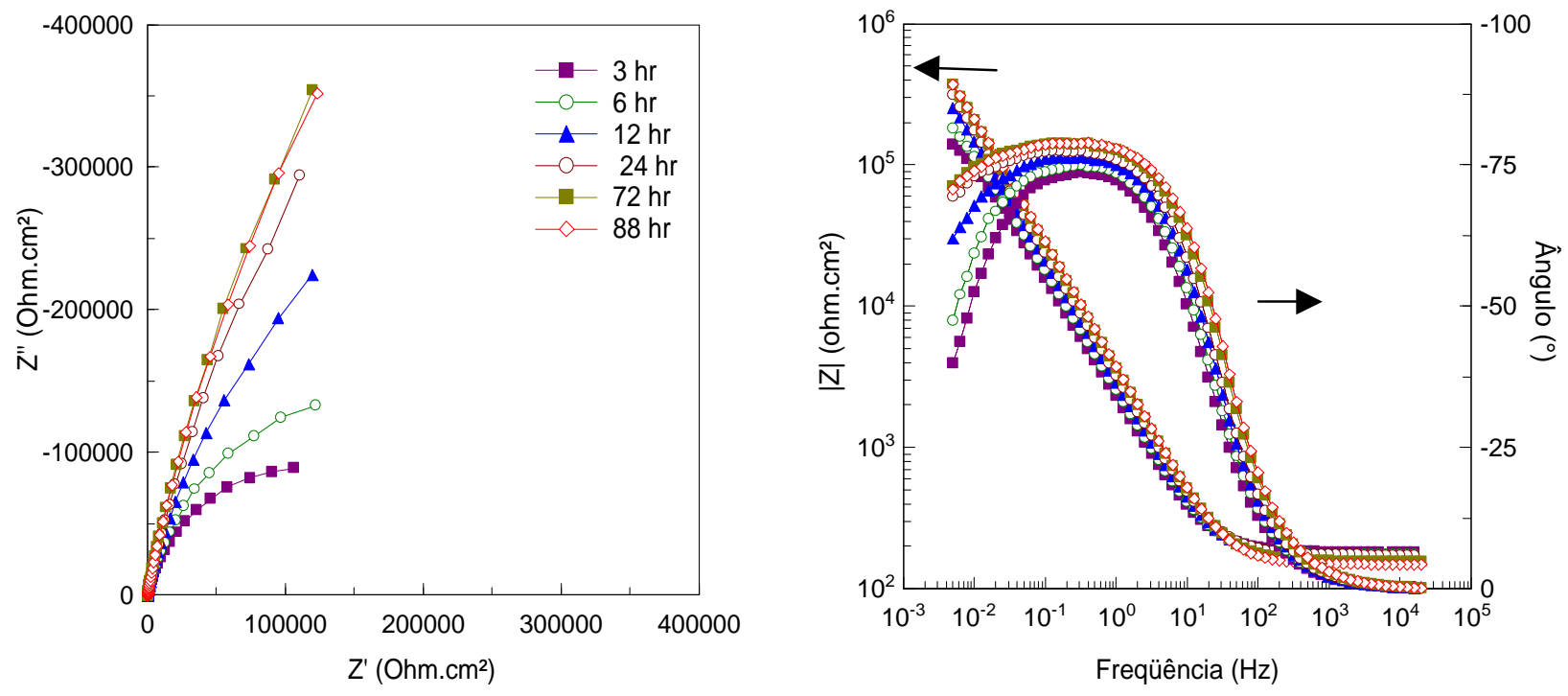

Figura 26 - Diagramas de impedância eletroquímica obtidos para sistema metal/meio estudado, com a concentração ótima da mistura: $3,6 \times 10^{-3} \mathrm{M}$ de $\mathrm{Na}_{2} \mathrm{MoO}_{4}+$ $3,5 \times 10^{-3} \mathrm{M}$ de $\mathrm{Na}_{2} \mathrm{WO}_{4}$ para diferentes tempos de imersão. 
Na Tabela 23 encontram-se os parâmetros estimados a partir da simulação por meio do circuito elétrico equivalente para os diferentes tempos de imersão do sistema metal/meio na concentração do ponto ótimo da mistura de molibdato e de tungstato de sódio.

Observa-se que os valores da resistência do eletrólito permanecem praticamente constantes como esperado, devido a que todos os resultados correspondem a uma mesma concentração da mistura de inibidores.

Tabela 23 - Parâmetros de impedância eletroquímica para diferentes tempos de imersão do aço carbono ABNT 1005 em meio de água de resfriamento industrial na presença da concentração ótima da mistura de molibdato e tungstato e de sódio.

\begin{tabular}{|c|c|c|c|c|c|}
\hline $\begin{array}{l}\text { Tempo de } \\
\text { imersão }\end{array}$ & $\mathbf{R}_{\mathbf{s}}$ & $C_{d l}$ & $\mathbf{R}_{\mathrm{tc}}$ & $|Z|_{100 \mathrm{mHz}}$ & $\begin{array}{c}\text { Ângulo de } \\
\text { fase / } \theta\end{array}$ \\
\hline $\mathrm{Hr}$ & $0 . \mathrm{cm}^{2}$ & $\mu \mathrm{F} . \mathrm{cm}^{-2}$ & KO.cm² & KO.cm² & Grau \\
\hline 3 & 180 & 198 & 223 & 16,9 & -40 \\
\hline 6 & 174 & 173 & 357 & 18,0 & -47 \\
\hline 12 & 171 & 142 & 817 & 21,0 & -62 \\
\hline 24 & 173 & 120 & 1653 & 24,1 & -69 \\
\hline 72 & 156 & 99 & 2252 & 27,8 & -71 \\
\hline 88 & 149 & 96 & 2064 & 28,6 & -71 \\
\hline
\end{tabular}

Os valores estimados pelas equações (15) e (16) dos modelos matemáticos e que correspondem a um tempo de imersão de 3 horas foram de $84,3 \mathrm{KO} . \mathrm{cm}^{2}$ para $R_{\mathrm{tc}}$, e $9,3 \mathrm{KO} \cdot \mathrm{cm}^{2}$ para IZI a $100 \mathrm{mHz}$. Esses valores que são os preditos pelo modelo resultaram inferiores aqueles obtidos da modelagem matemática dos dados experimentais usando circuitos elétricos equivalentes, na composição do ponto de ótimo, que são $223 \mathrm{KO} . \mathrm{cm}^{2}$ para $\mathrm{R}_{\mathrm{tc}}$ e $15,9 \mathrm{KO} . \mathrm{cm}^{2}$ para IZI a $100 \mathrm{mHz}$. 
Comparando esses resultados se verifica que trabalhar com a composição no ponto de ótimo é significativamente importante, pois neste ponto é onde se obtém os melhores resultados, produto das interações sinérgicas.

Na Figura 27 é apresentada a variação da resistência à transferência de carga, $\left(R_{t c}\right)$ e da capacitância da dupla camada elétrica, $\left(C_{d l}\right)$ com o tempo de imersão. Observa-se que a $\mathrm{C}_{\mathrm{dl}}$ diminui ao longo do tempo de imersão, no entanto, a partir de 72 horas tende a ficar constante. $A R_{\mathrm{tc}}$ apresenta uma tendência de crescimento maior nas primeiras 24 horas de imersão. Estes resultados verificam que ao longo do tempo a mistura de inibidores no sistema estudado apresenta uma tendência a estabilizar seu comportamento, indicando que o melhor comportamento está entre 48 e 72 horas de imersão.

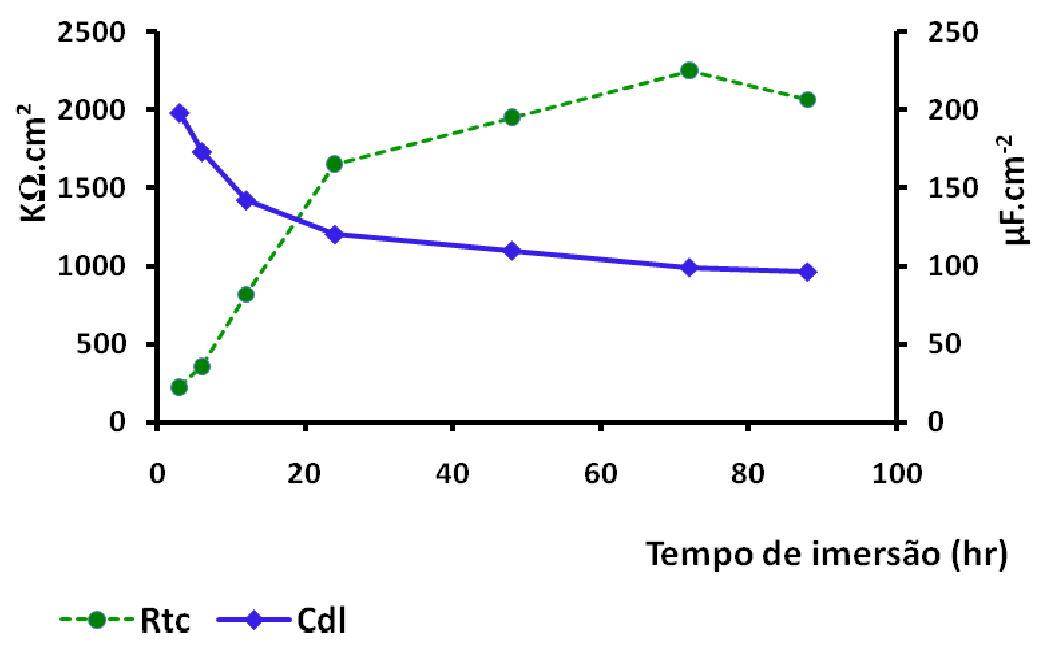

Figura 27 - Variação com o tempo da resistência a transferência de carga $\left(R_{\mathrm{tc}}\right)$, e da capacitância da dupla camada elétrica $\left(\mathrm{C}_{\mathrm{dl}}\right)$ para o sistema metal/meio na presença da concentração ótima de molibdato e tungstato de sódio.

Obs. O valor correspondente a 48 horas de imersão foi estimado por interpolação linear.

Finalmente, pode-se concluir que além da composição no ponto de ótimo, o tempo de imersão é outro fator importante, uma vez que os valores de $R_{\mathrm{tc}}$, e IZI a 100 $\mathrm{mHz}$ são crescentes com o tempo, enquanto que a $\mathrm{C}_{\mathrm{dl}}$ é decrescente, atingindo o valor de $96 \mu \mathrm{F} . \mathrm{cm}^{-2}$ para um tempo de imersão de 88 horas. Essa análise permite afirmar 
que o filme formado na superfície do aço torna-se mais protetor para tempos crescentes de imersão. Portanto, o tempo de imersão deve conduzir ao crescimento do filme, devido a um provável aumento das camadas de produtos de corrosão na superfície do metal. 


\section{CONCLUSÕES}

Através dos resultados obtidos em cada uma das etapas do trabalho se conclui que:

\subsection{Estudo individual das substâncias como inibidores de corrosão.}

\section{Ensaios eletroquímicos}

- Os potenciais de corrosão, $E_{\text {corr }}$ obtidos para todas as substâncias estudadas foram deslocados para valores mais positivos.

- Os parâmetros de impedância, isto é, os valores de resistência à transferência de carga, $R_{t c}$ e módulo de impedância são crescentes com aumento da concentração de todas as substâncias estudadas. Os valores de capacitância da dupla camada elétrica $\left(\mathrm{C}_{\text {dl }}\right)$ tornam-se menores para concentrações crescentes de todas as substâncias estudadas, devido a formação de um filme adsorvido na superfície do metal.

- As curvas de polarização obtidas mostram que as quatro substâncias estudadas agem como inibidores de corrosão anódicos, inibindo as reações anódicas de dissolução do aço carbono ABNT 1005 no meio da água de resfriamento estudada.

- Na concentração de $1,0 \times 10^{-3} \mathrm{M}$, os valores de eficiência para cada uma das substâncias aparecem na seguinte ordem: tungstato de sódio>molibdato de sódio $>$ CPPM $>$ ftalocianina de cobre. 


\subsection{Caracterização da superfície}

- As Imagens obtidas em MEV mostram a presença de um filme na superfície do aço ABNT 1005, após a imersão no meio com a presença de cada uma das substâncias estudadas.

\subsection{Planejamento fatorial completo}

- O planejamento fatorial completo e a análise estatística resultaram em uma ferramenta eficiente na determinação dos efeitos e interações mais importantes entre as quatro substâncias estudadas.

- Da análise estatística do planejamento fatorial completo foram identificadas que os efeitos positivos mais importantes na resistência a transferência de carga, $R_{\mathrm{tc}}$ são devidos a presença do molibdato de sódio e do tungstato de sódio. Os resultados de $R_{\mathrm{tc}}$ atingiram valores superiores àqueles obtidos para cada substância individual, logo, constatando-se efeitos sinérgicos das substâncias estudadas como inibidores de corrosão.

\subsection{Planejamento fatorial composto}

O tratamento dos resultados do planejamento fatorial composto permitiu mostrar que a concentração ótima da mistura de molibdato de sódio e de tungstato de sódio na faixa de concentração estudada foi de $3,6 \times 10^{3} \mathrm{M}$ e $3,5 \times 10^{3} \mathrm{M}$ respectivamente. 


\subsection{Avaliação da mistura no ponto de ótimo ao longo do tempo.}

Finalmente, com a avaliação do tempo de imersão da mistura de molibdato de sódio e tungstato de sódio, na composição ótima e em água de resfriamento industrial, conclui-se que o filme formado na superfície do aço torna-se mais protetor para tempos crescentes de imersão e apresentou o melhor desempenho entre 48 e 72 horas de imersão. 


\section{REFERÊNCIAS BIBLIOGRÁFICAS}

ALVES, V. A. M.; BRET, C. M.; MOMTEMOR, M. F. Caracterização por XPS de filmes passivos formados sobre aços de baixa liga em meio de bicarbonato. Química nova, vol. 20, No. 2, pp. 204-210, 2005.

ALENTEJANO, C.R.; AOKI, I. V. Localized corrosion inhibition of 304 stainless steel in pure water by oxyanions tungstate and molybdate, Eletrochimica acta, vol. 49, pp. 2779-2785, 2004.

AOKI, I.V.; GUEDES, I.C.; MARANHÃO, S.L.A. Copper Phthalocyanine as corrosion inhibitor for ASTM A606-4 steel in 16\% hydrochloric acid. Journal of Applied Electrochemistry, vol. 32, pp. 915-919, 2002.

AOKI, I.V; GUEDES, I.C.; TAQUEDA, M.E.S. Polarization Curves and Experiment Design as Tools in The Search of Optimized inhibitors Mixture Formulation for HSLA Steel in Hydrochloric Acid. Materials Science Forum, vol. 289-292, pp. 12371244.1998.

AQUINO, I.P. Caracterização da superfície do aço carbono ABNT 1008 revestida com organo-silanos por meio de técnicas eletroquímicas. 2006129 p. Dissertação (Mestrado)- Escola Politécnica, Universidade de São Paulo, São Paulo, 2006.

BENTLEY, A. J.; EARWAKER, L. G.; FARR, J.P.G.; SAREMI, M.; SEENEY, A. M. Molibdates in aqueous corrosion inhibition - III. Effects of molybdate in the anodic filming of steel. Polyhedron, vol. 5, no. 1 / 2 pp. 547-550, 1986.

BELTRAN, H.I.; ESQUIVEL, R.; LOZADA-CASSOU, M.; DOMINGUES-AGUILAR, M.; SOSA-SÁNCHEZ, J.L.; HÖPFL, H.; BARBA, V.; LUNA-GARCIA, R.; FARFÁN, N.; ZAMUDIO-RIVERA, L.S. Nano-cap-Shaped Tin Phthalocyanines: Synthesis, Characterization, and Corrosion Inhibition Activity; Chemical European Journal, vol. 11, pp. 2705-2715, 2005.

BLIN, F.; LEARY, S.G.; WILSON, K.; DEACON, G. B.; KUMK, P.C.; FORSYTH, M. Corrosion Mitigation of mild steel by new rare earth cinnamate compounds, Journal of Applied Electrochemistry, No. 34, pp. 591-594, 2004 
BOCKRIS, J.; AMULYA, K.N.; Eletroquímica moderna, Volume 1, Editorial Reverté, S.A, 658p. 1978.

BONORA, P.L.; DEFLORIAN, F.; FEDRIZZI, L. Electrochemical impedance spectroscopy as a tool for investigating under paint corrosion. Electrochimica Acta, vol. 41, n.7/8, p. 1073-1082, 1996.

BOX, G. E. P.; HUNTER, W. G.; HUNTER, J. S. Statistics for experimenters. New York: John Willey, 653p. 1978.

BRASIL, J. L. C.; VAGHETTI, J. C. P.; ROYER, B.; DOS SANTOS, JR. A.; SIMON, N. M; PAVAN, F. A.; DIAS, S. L. P.; LIMA, E. C; Planejamento estatístico de experimentos como uma ferramenta para otimização das condições de biossorção de $\mathrm{Cu}$ (II) em batelada utilizando-se casca de nozes pecã como biossorvente ; Química. Nova, vol. 30 no. 32007.

CASTANHEIRO, S. L., Estudo dos oxiânions molibdato e tungstato como inibidores de corrosão localizada para aços inoxidáveis austeníticos 347 e 304L água de elevado grau de pureza contendo íons cloreto e em condições hidrodinâmicas controladas. 156p. Tese (Mestrado). Escola Politécnica Universidade de São Paulo. São Paulo 2008.

CHEN, J.; CHAO, H.; LIN, Y.; YANG, I.; OUNG, J.; PAN, F. Studies on carbon steel corrosion in molybdates and silicates solutions as corrosion inhibitors, Surface Science no. 247 , pp-352-359,1991.

CHIAVERINI, V. Aços-carbono e Aços-liga: Características Gerais, Tratamentos Térmicos, Principais Tipos. São Paulo: Associação Brasileira de Metais. 1971.

DIAMATINO, T.V.; GUILHERMINO L.; ALMEIDA, E.; SOARES M.V.M.; Toxicity of Sodium Molybdate and Sodium Dichromate to Daphnia magna Straus Evaluated in Acute, Chronic, and Acetyl-cholinesterase Inhibition Tests. Eco-toxicology and Environmental Safety. Vol. 45, pp. 253-259, 2000.

DONG-JIN, C.; SEUNG-JAE, Y.; JUNG-GU K.; Development of an environmentally safe corrosion, scale, and microorganism inhibitor for open recirculating cooling systems, Materials Science and Engineering: A, vol. 335, pp 228-236, 2002. 
DOEDY, J.; HOAGLAND, J.; HIPPS, K.W. Infrared and Raman Spectroscopic Study of Ultra thin Cooper Phthalocyanine Films Vapor Deposited on Oxidized Alumina, Journal of Physical-Chemistry, vol. 95, pp. 3751-3755, 1991.

EL KADER, J.M. ABD.; EL WARRAKY, A.; EL AZIZ, A.M. Corrosion inhibition of mild steel by sodium tungstate in neutral solution. Part I: Behavior in distilled water, British Corrosion Journal, vol. 33, No.2 pp.139-144, 1998a.

EL KADER, J.M. ABD.; EL WARRAKY, A.; EL AZIZ, A.M. Corrosion inhibition of mild steel by sodium tungstate in neutral solution. Part III: Co inhibitors and synergism, British Corrosion Journal, vol.33, No.2 pp.152-157, 1998b.

EMEREGÜL, K.C.; AKSÜT, A. A. The effect of sodium molybdate on the pitting corrosion of aluminium. Corrosion science, vol. 45 pp. 2425-2463, 2003.

FARR, J.P.G.; SAREMI, M. Molybdate in aqueous corrosion Inhibition. Effects of Molybdate on the potentiodynamic behavior of steel and some other metal. Surface technology, vol.19, pp.37-144, 1983.

FIGUEIREDO, C; ABREU, M. Técnica para seleção de variáveis aplicada a separação de gases; Química Nova; vol. 25; n.2; 2002.

FUCHS-GUDEC, R. Inhibitory effect of non-ionic surfactants of the TRITON-X series on the corrosion of carbon steel in sulfuric acid. Eletrochimica acta, vol. 52, pp. 49744981, 2007.

GALDAMEZ, E. C.; CARPINETTI, L. R. Aplicação de técnicas de planejamento e análise de experimentos no processo de injeção plástica, Gestão e produção, vol.11, no.1, 2004.

GENTIL, V. Corrosão. Rio de Janeiro: Editora LTC - Livros Técnicos e Científicos SA. $5^{\text {a }}$ ed. 2007. $p 11$.

GUEDES, I. C. Eficiência dos inibidores de corrosão benzotraizol, $\mathrm{N}$-feniltiouréia e cloreto de hexadeciltrimetil amônio quaternário para ferro puro, aço carbono e 
aço ARBL em meio de acido sulfúrico. 178p. Tese (Doutorado) - Escola Politécnica, Universidade de São Paulo. São Paulo. 1996.

HETTIARACHCHI, S.; CHAN, Y.W.; WILSON, JR. R.B.; AGARWALA, V.S. Macrocyclic Corrosion Inhibitors for Steel in Acid Chloride Environments, Corrosion Science, vol. 45, no.1 pp.30-34, 1989.

HJERESEN, D.L. Green Chemistry and the global water crisis. Pure Applied Chemistry, vol.73, No.8 pp.1237-1241, 2001.

KNAG, M. Fundamental behavior of model corrosion inhibitors. Journal of dispersion and technology, vol. 27, pp. 587-597, 2006.

KOUTSISPYROS, A.; BRAIDA, W.; CHRISTODULATOS, C.; DERMATAS, D, STRIGUL, N. A. Review of Tungsten: From environmental obscurity to scrutiny, Journal of Hazardous Materials vol. 135 pp.1-10, 2006.

KREITH F. Princípios da Transmissão de Calor, Editora. Edgard Blücher Ltda. 672p. 1977.

KUZNETSOV, YURII I. Organic Inhibitors of Corrosion of Metals, Plenum Press, New York and London: Cap 5, 1996.

KUZNETSOV, YURII I. Physicochemical aspects of metal corrosion inhibition in aqueous solutions, Russian Chemical Reviews, vol. 73, pp 75-78, 2004.

LAHODNY-SARC, E; KAPOR F. Corrosion inhibition of carbon steel in the near neutral media by blends of tannin and calcium gluconate, Materials and Corrosion, vol. 53, p. 264-268, 2002.

LORENTZ, W. J.; MANSFELD, F. Determination of corrosion rates by electrochemical DC and AC methods. Corrosion Science, vol. 21, no. 9, pp.647-672, 1981.

MANSFELD, F, KENDEIG M.W., TSAI, S. Corrosion kinetics in low conductivity media. Iron in naturals waters. Corrosion science, vol. 22 no.5 pp. 455-471, 1982. 
MARIN-CRUZ, L.; CABRERA-SIERRA, R.; PECH-CANUL, M.A.; GONZALES, I. EIS study on corrosion and scales processes and their inhibition in cooling system media, Electrochimica Acta, vol. 51 No. 8-9, pp-1847-1854, 2004.

MANCUSO, S.P.C. Reúso de água para torres de resfriamento. São Paulo 2001.

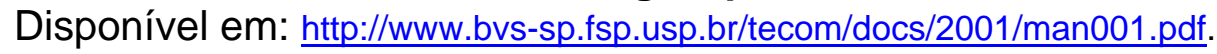

Acesso em 22/06/08.

OCHOA, N.; BARRIL, M. G.; MORAN, F.; PÉBÈRE, N. Study of the properties of a multi-component inhibitor used for water treatment in cooling circuits. Journal of Applied Electrochemistry, vol. 32, p 497-504, 2002.

OLIVEIRA, F. M; Estudo da influência de organo-silanos na resistência a corrosão de aço carbono por meio de técnicas eletroquímicas. 2006, 218p. Tese (Doutorado)- Escola Politécnica, Universidade de São Paulo. São Paulo. 2006.

PALOMINO, L.E.M. Caracterização micro-estrutural e eletroquímica de revestimentos ambientalmente amigáveis aplicados sobre a liga de Al 2024-T3. 240p. Tese (Doutorado)- Escola Politécnica, Universidade de São Paulo. São Paulo. 2007.

PALOMINO, L.E.M., SUEGAMA, H. P.; AOKI, I.V.; MONTEMOR, M.F.; DE MELO, H.G. Electrochemical study of modified non-functional bis-silane layers on alloy 2023-T3, Corrosion science, vol.50 pp.1258-1266, 2008.

ROBERTSON, W. D. Molybdate and Tungstate as Corrosion Inhibitors and the mechanism of inhibition. Journal of the Electrochemical Society, vol. 98, No 3, pp. 94-100, 1950.

REIS, J.; SILVEIRA J., DOMENI, P. Economia de energia elétrica em torres de resfriamento. Disponível em:

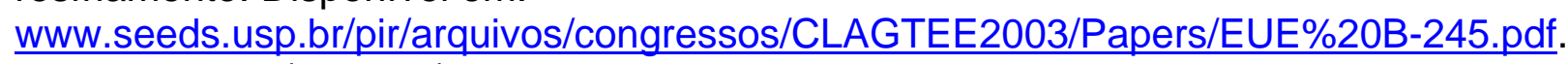

Acesso em: 15/outubro/2007.

ROSE CORROSION SERVICES LIMITED. TECHINCAL NOTE 5; TREATMENT AND CORROSION CONTROL OF COOLING WATER. Disponível em: 
hittp://www.rosecorrosionservices.co.uk/technical notes.htm. Acesso em:

$15 /$ outubro/2007.

ROZENFELD, I.L. Corrosion Inhibitors; Mac Graw Hill, cap.2 pp 27-68, cap. 5 pp.155$157,1981$.

SAREMI, M.; DEHGHANIAM, C.; SABET, M. The effect of Molybdate concentration and hydrodynamic effect on mild steel corrosion inhibition in simulates cooling water. Corrosion Science, vol. 48, pp. 1404-1412. 2006.

SAJI, V.S.; SHIBLI, S.M.A. Synergistic inhibition of carbon steel corrosion by sodium tungstate and sodium silicate in neutral aqueous media, Anti-Corrosion Methods and Materials, vol. 49 No. 6 pp. 4323-446, 2002.

SASTRI, V. S, Corrosion Inhibitors, Principles and Applications, John Wiley and Songs Ltd, cap. 3, 6 e 8. 2001.

SCHAFTINGHEN, T.; LE PEN, C.; TERRYN, H.; HORZENBERGER, F. Investigation of the barrier properties of silanos on cold rolled Steel. Electrochimica Act, vol. 49, pp. 2997-3004, 2004.

SHAMS EL, DIM; WANG L., Mechanism of corrosion inhibition by sodium molybdate. Desalination, vol.107, pp. 29-43, 1996.

SHIBLI, S.M.A. KUMARY, V. ANITA, Inhibitive effect of calcium gluconate and sodium molybdate on carbon steels, Anti-corrosion Methods and Materials, vol. 51, n.4 pp. 277-281, 2004

SHIBLI, S.M.A., SAJI, V.S. Co-inhibition characteristics of sodium tungstate with potassium iodate on mild steel corrosion. Corrosion Science, vol. 47, pp.2213-2224, 2005.

SOUZA, P. Estudo do comportamento de tensoativos a base de organo-silanos como inibidores de corrosão para o aço ABNT 1005 em meio de $\mathbf{H C l} 2 \mathrm{M}$. 2005 103p. Dissertação (Mestrado) - Escola Politécnica, Universidade de São Paulo. São Paulo, 2005. 
SUBRAMANIAN, V.; OOJI, W.J. VAN. Effect of the amine functional group on corrosion rate of iron coated with filmed of organo functional silanes. Corrosion science, vol. 54,n.3, 1998.

SUEGAMA, P.H.; AOKI, I.V. Electrochemical behavior of carbon steel pre-treated with an organo functional bis-silane filled with copper phthalocyanine, Journal Brazilian chemical society, vol.19. no.4 pp.744-754, 2008.

TRABANELLI, G. Corrosion Inhibitors in: Mansfeld, F. Corrosion mechanism, New York, Marcel Dekker, 1987 p.119-142.

ULLMANNS'S ENYCLOPEDIA OF INDUSTRIAL CHEMESTRY, Vol. A20, VCH Publishers Inc, pp. 213-236, 1992.

VUKASOVICH, M.S.; FARR, J.P.G; Molybdate in corrosion inhibition. A review. Polyhedron; vol. 5, No.12, pp.551-559, 1985.

VUKASOVICH, M.S.; ROBITAILLE, D.R. Corrosion Inhibition by Sodium Molybdate. Journal of less common Metals. vol. 54 p. 437-448, 1977.

WANG, D.; TANG XIAO, QIU. Y, GAN F, ZHENG C.G, A study of the film formation kinetics on zinc in different acidic corrosion inhibitor solutions by quartz crystal microbalance. Corrosion science; vol. 47 pp. 2157-2172, 2005

WOLYNEC, S. Técnicas eletroquímicas em corrosão. São Paulo: Editora da Universidade de São Paulo - EDUSP, 2003

ZHANG, R.; SOMASUDARAM, $\mathrm{P}$, Advances in adsorption of surfactants and their mixtures at solid solution interfaces, Advances in colloid and Interface Science, vol. 123-126, pp 213-216, 2006

ZHAO P.; QIANG, L. LI, Y. Electrochemical, SEM/EDS and quantum chemical study of Phthalocyanines as corrosion inhibitors for mild steel in $1 \mathrm{~mol} / \mathrm{l} \mathrm{HCL}$; Applied Surface Science; vol. 252, pp.1596-1607, 2005. 
This document was created with Win2PDF available at http://www.win2pdf.com.

The unregistered version of Win2PDF is for evaluation or non-commercial use only.

This page will not be added after purchasing Win2PDF. 